\title{
The well-being of patients having coronary artery bypass surgery : a test of Orem's self-care nursing theory
}

Citation for published version (APA):

Senten, M. C. M. (1991). The well-being of patients having coronary artery bypass surgery : a test of Orem's self-care nursing theory. [Doctoral Thesis, Maastricht University]. Rijksuniversiteit Limburg. https://doi.org/10.26481/dis.19911129ms

Document status and date:

Published: 01/01/1991

DOI:

10.26481/dis.19911129ms

Document Version:

Publisher's PDF, also known as Version of record

Please check the document version of this publication:

- A submitted manuscript is the version of the article upon submission and before peer-review. There can be important differences between the submitted version and the official published version of record.

People interested in the research are advised to contact the author for the final version of the publication, or visit the DOI to the publisher's website.

- The final author version and the galley proof are versions of the publication after peer review.

- The final published version features the final layout of the paper including the volume, issue and page numbers.

Link to publication

\footnotetext{
General rights rights.

- You may freely distribute the URL identifying the publication in the public portal. please follow below link for the End User Agreement:

www.umlib.nl/taverne-license

Take down policy

If you believe that this document breaches copyright please contact us at:

repository@maastrichtuniversity.nl

providing details and we will investigate your claim.
}

Copyright and moral rights for the publications made accessible in the public portal are retained by the authors and/or other copyright owners and it is a condition of accessing publications that users recognise and abide by the legal requirements associated with these

- Users may download and print one copy of any publication from the public portal for the purpose of private study or research.

- You may not further distribute the material or use it for any profit-making activity or commercial gain

If the publication is distributed under the terms of Article $25 \mathrm{fa}$ of the Dutch Copyright Act, indicated by the "Taverne" license above, 
THE WELL-BEING OF PATIENTS

HAVING CORONARY ARTERY BYPASS SURGERY

- A Test of Orem's Self-CARE NuRsing Theory - 

THE WELL-BEING OF PATIENTS

HAVING CORONARY ARTERY BYPASS SURGERY

A TEST OF OREM's SElF-CARE NURSING THEORY -

\section{Proefschrift}

ter verkrijging van de graad van doctor aan de Rijksuniversiteit Limburg te Maastricht, op gezag van de Rector Magnificus, Prof. mr. M.J. Cohen, volgens het besluit van het College van Dekanen, in het openbaar te verdedigen

op vrijdag, 29 november 1991 om 14.00 uur

door

\section{Margaretha Christina Maria Senten}

geboren te Hilversum in 1962 
Promotores:

Prot. dr. H. Philipsen

Prof. dr. M.A. Isenberg, Wayne State University, Detroit, U.S.A.

Beoordelingscommissie:

Prof. dr. L. Boon, voorzitter

Prof. dr. H. Huijer Abu-Saad

Dr. S. Käppeli, Universitåtspital Zürich, Switzerland

Prof. dr. G.J. Kok

Prof. dr. P. Meriläinen, University of Kuopio, Finland

CIP-GEGEVENS KONINKLIJKE BIBLIOTHEEK, DEN HAAG

Senten, Margaretha Christina Mana

The well-being of patients hawing coronary artery bypass

surgery: a test of Orem"s self-care nursing theory/

Margareh ha Chrislina Mania Senten.- Maastricht :

Datawyse. - III.

Thesis Maastricht. - With ret. - With summary in Dutch.

ISBN 90-5291-066-9

NUGI 750

Subject heading: self-care; CAB-patients.

produktie: Datawyse Maastricht

druk: Krips Repro Meppel

Financial support by the Netherlands Heart Foundation for the publication of this thesis is gratefully acknowledged. 


\section{TABLE OF CONTENTS}

$\begin{array}{ll}\text { ACKNOWLEDGEMENTS } & 5\end{array}$

INTRODUCTION $\quad 7$

$1 \quad$ RESEARCH PROBLEM 9

1.1. The Testing of Nursing Theories 9

1.1.1. The role of theory in the nursing discipline 9

1.1.2. The need for theory testing 11

1.1.3. Purpose of the study 13

1.2. Testing Orem's General Theory of Nursing 14

1.2.1. Orem's view on the development of nursing science 14

$\begin{array}{ll}\text { 1.2.2. Testability of the theory } & 16\end{array}$

1.2.3. The research model 16

$\begin{array}{ll}\text { 1.3. Summary } & 20\end{array}$

2 THEORETICAL FRAMEWORK 21

2.1. Orem's Perspective 21

2.1.1. Orem's general theory of nursing 21

2.1.2. The concept of self-care 22

2.1.3. The concept of state of well-being 25

2.1.4. The relationship between self-care and well-being 28

2.2. Review of the Literature 29

2.2.1. The concept of well-being 29

2.2.2. Predictors of well-being 31

2.2.3. The well-being of CABS-patients 33

2.2.4. Testing of Orem's theory 36

2.3. Hypotheses 41

2.4. Summary 47

3 METHOD $\quad 48$

3.1. Design 48

3.2. Sampling-Method 49

3.3. Operationalization of the Concepts 50

3.3.1. State of well-being $\quad 51$

3.3.2. Self-care $\quad 52$

3.3.3. Self-care agency $\quad 55$

3.3.4. Basic conditioning factors $\quad 56$

3.4. Procedure in Data Collection and Data Analysis 58

3.5. Descriptive Statistics of the Major Variables 60

3.5.1. State of well-being 61 
3.5.2. Self-care 61

3.5.3. Self-care agency 65

3.5.4. Basic conditioning factors 66

4 RESULTS

71

4.1. The Relationship between Selt-care and State of Well-being 71

4.2. The Relationship between Self-care Agency, Self-care and State of Well-being

4.3. The Relationships between the Basic Conditioning Factors, Self-care and State of Well-being

4.3.1. To what extent do basic conditioning factors influence self-care?

4.3.2. To what extent do basic conditioning factors influence state of well-being ?

4.3.3. To what extent do basic conditioning factors affect the relationship between self-care and state of well-being?

5.1. The Relationship between Self-care and State of Well-being 98

5.2. The Effect of Self-care Agency and Basic Conditioning Factors on the Achievement of Self-care Requisites

5.3. The Effect of Basic Conditioning Factors and Self-care on State of Well-being

5.4. The Effect of Self-care Agency and Basic Conditioning Factors on the Relationship Self-care - State of Well-being

5.5. A Summary of the Findings

5.6. Methodological Issues

5.7. Conclusion 114

5.7.1. Orem's general theory of nursing

5.7.2. The self-care and well-being of coronary artery bypass patients - implications for nursing practice $\quad 116$

5.7.3. Need for further study

\section{SUMMARY}

SAMENVATTING

\section{APPENDICES}

I Analysis of non-response and dropout 135

II $\quad$ Factor analysis Self-Care Inventory 136

III Verbal explanation of study and informed consent form 137

IV Multiple regression analysis tables 139 


\section{ACKNOWLEDGEMENTS}

The study reported here is part of the research-project "Changes in Self-Care in relation to Coronary Artery Bypass Surgery: A Longitudinal Study" (projectleaders prof. di. M.A Isenberg and prof. di. H. Philipsen). This project has been made possible by grant 86.021 of the Netherlands Heart Foundation. This financial support is gratefully acknowledged.

Here, I would also like to acknowledge and express my thanks to all those persons who have supported me in one way or another in completing this study. There have been quite a few. First of all my promotors Marjorie Isenberg and Hans Philipsen. Since the summer of 1984 both have acted as my mentors. In their combined roles of teachers, projectleaders, and promotors they provided me with all sorts of interesting learning opportunities. Marjorie always knew which questions to ask to challenge me in my own theoretical thinking, whereas with his creativity and insights Hans broadened my perspective on research. to both of them.

I also want to thank George Evers. His contagious enthusiasm played a major role in my decision to take up dissertation work. Especially in the early phases of my writing he was always willing to listen and respond to my ideas. I enjoyed the many group discussions on Orem's Theory with Marjorie Isenberg. Hans Philipsen, George Evers, Theo van Achterberg and Ger Brouns. They proved to be helpful to me and stimulated my interest in theory-based research.

Then, there have of course been the hundred and seven patients who showed interest in participating in our study, despite their anxieties and worries over their surgery and hospital admission. The great majority of them continued their participation for a period of more than three years. They made me feel welcome in their homes, and made the data collection a pleasant experience for me. Data collection in the hospital was a two-person job. I really enjoyed working with Dominique Jaspers in his role of nurse data collector. He was a pleasant and reliable person to work with. I also want to acknowledge the nurses, the cardiologists, the surgeons, and the assistants who worked in the period January-May 1987 on the CCC and/or cardiac follow-up unit of the Academic Hospital in Maastricht. Their cooperation and hospitality greatly facilitated our daily visits to the nursing units. Prof. dr. O. Penn, drs. G. van Ommen and drs. H. de Swart were especially helpful in the process of accessing the patients and the units.

As for the technical aspects of processing all the data, Truus Custers took the responsibility for coding, entering and matching the different data sets. I admire 
and thank her for her precision and perseverance in this so often tedious job. She also assisted in the data-analysis. I want to thank Pia Schurgers for her contribution in the coding and entering of the data of the last phase.

Somewhat more from a distance, there were my parents who continued to show interest and support, and my friends who accepted my being anti-social during the last months of producing chapters.

Finally, Patrick's computer skills have been indispensable in both the data analysis, as well as in the preparation of the final product. Moreover, his caring, everyday support and sense of humor have been vital to my well-being during the last years. 


\section{INTRODUCTION}

Nursing is often described as both an art and a science, and these two components are perceived as being interrelated. On the one hand, nursing is an helping or enabling art, in that its aim is to produce favorable changes within clients through nursing actions (Peplau 1988). The professional nurse uses his/her skills for the purpose of improving his/her client's state of existence. As these purposeful actions are preferably based on scientific knowledge which is for a great part unique for the discipline, nursing is considered to have a scientific component as well. Nursing science consists of systematized knowledge, which is organized and classified. It includes theories and facts that explore, describe, predict, and prescribe nursing practice in relationship to human responses to actual or potential health problems (Menke 1990). However", nursing science is still in an early stage of development. As a consequence, most of the theories that are designed to guide both practice and knowledge development are still in need of empirical validation. Theories can only be useful in directing nursing practice, after their speculative notions have been found to be congruent with reality.

It is the purpose of the current study to investigate the underlying validity of certain propositions from Orem's General Theory of Nursing. The focus is on the assumption in the theory which deals with the quality of life of human beings. As nurses actions are considered to aim at improving the quality of life or state of wellbeing of their clients, this is recognized as a worthwhile area for study. According to Orem, to reach a certain level of well-being, it is necessary to fulfill so-called selfcare needs. This leads to the formulation in chapter 1 of the research problem as: "How does self-care contribute to state of well-being ?"

The need for validation of nursing theories through theory testing research is further explained in the first chapter. Next, the examination of Orem's proposition on the relationship between self-care and state of well-being is introduced as the purpose of this study. Three sets of research questions are formulated to serve as guides in the derivation of hypotheses and the subsequent analyses.

In chapter two the theoretical framework is discussed. It is explained how Orem defines the major concepts of the study, and how they are interrelated. A review of the literature on predictors of well-being, on the well-being of persons undergoing coronary artery bypass surgery, as well as on the state of the art of testing Orem's conceptual framework is included. The chapter ends with the derivation of twentyfive hypotheses, aiming at testing the specific relationships as proposed by Orem. Next, in the third chapter the research method is described. Besides, the descriptive data on the major variables of study are presented. 
Chapter four then reports the results in relation to the formulated hypotheses. The results of the analyses are discussed in the last chapter. This chapter also includes a discussion on the internal and external validity of the study. Next, conclusions are drawn with respect to the extent in which Orem's General Theory of Nursing is supported by the results of this study, as well as to how this study contributes to the further refinement of the conceptual model. Finally, some implications for nursing practice as well as some openings for further study are suggested. 


\section{CHAPTER 1 RESEARCH PROBLEM}

\subsection{THE TESTING OF NURSING THEORIES}

\subsubsection{The Role of Theory in the Nursing Discipline}

Ever since Nightingale's "Notes on Nursing", there has been a growing awareness among nurses that their practice should be based on reliable knowledge. Gradually, this has led to the currently general belief that the nursing discipline does not only have a practical component, but a scholarly, scientific component as well. Nursing has its own body of knowledge, which forms the scientific foundation of nursing practice. However, the exact content and structure of the scientific knowledge component of the nursing discipline has not yet been unambiguously defined, even though several authors have made suggestions in this area (Johnson 1959; Abdellah 1969; Andreoli and Thompson 1977; Donaldson and Crowley 1978; Conway 1985).

Since about two decades there is a fairly general agreement that nursing theories could aid in giving structure to the body of nursing knowledge. A nursing theory provides the discipline with a specific perspective on its phenomena of interest (Ellis 1982). Within the specific perspective those phenomena that are of interest to the field are defined and interrelated in a way relevant for nursing. Consequently. the theory becomes a meaningful organizing structure for nursing knowledge. Walker and Avant (Walker and Avant 1988) contend that theory provides a more complete picture for practice than unrelated bits of factual knowledge, as it includes more aspects of practice and integrates them more fully. Moreover, welldeveloped theories not only organize existing knowledge they also guide in making new relevant discoveries for the advancement of nursing kinowledge.

Theories have not always been present in the nursing discipline. Although Nightingale's work is often referred to as representing the first nursing theory or model, theory development did not get the serious attention of nurses until the fifties. And at that time the interest came predominantly from nurses in the United States of America. The onset of this interest was for a great part due to changes in the American nursing education system. With the introduction in the fifties of nursing programs into the university, in addition to the diploma schools, new curricula had to be developed. Setting up educational programs in nursing at this level required more thorough insight into what nurses do in everyday practice and what nurses need to know to function effectively. The formulation of ideas on these matters, that 
is, the theoretical insights into what nursing is, which were then formulated by nurse scholars, represent the furst nursing theories (Peplau 1952. Henderson 1955, Abdellah 1960, Johnson 1959). The major purpose for which these first models were developed was to serve as guides for curriculum development in nursing. Though it was also acknowledged that theories could help to guide practice and serve as a base for nursing research, there were no real efforts made in these directions at the time. After the publication of the position paper of the ANA in 1965 which stated that the development of theories was one of the most significant goals of nursing, more nursing theories emerged (Levine 1967, King 1968, Ragers 1970 , Roy 1970, Orem 1971). Again these were mainlly applied for educational purposes. This educational orientation was reintorced by the requirement for American schools of nursing to offer a theory-based curriculum, which was initiated in 1972.

With the publication of new nursing theories and the further development of the older ones, issues of a metatheoretical nature appeared in the nursing literature. In the late sixties and throughout the seventies articles were published that dealt with questions such as "what types of theories are needed in nursing"; "what ought to be their structure and purpose"; "how should they be developed"; etc. A major issue has been the single versus the pluralistic approach: In the beginning it was thought that the nursing discipline needed a singie, all encompassing theory. Such a grand theory was supposed to guide practice, education and the development of all nursing knowledge. However, during the last 10 to 15 years most nurse scholars have come to the conclusion that (at least for the moment) it is more fruitful for the development of the discipline to have several theories instead of one. "The complexities of human behaviors and interactions, and the dynamic nature of development and change make it imperative that we accept a pluralistic approach to theory development and utilization (Meleis 1987, p.47). The reality of nursing is found to be too complex to fit completely into one conceptual framework.

Thus, in the first twenty to thirty years of theory development the energy of nurse scholars was mostly spent on relating theory to education and on metatheoretical discussions. Although it had been acknowledged from the beginning that uitimately theory had to guide nursing research and nursing practice, it was not until the second part of the seventies that these aspects received more structural attention. For example, the slow progress in nursing research was attributed to the lack of theory-based research (Notter 1975). The lack of coherence in nursing research led to isolated, unrelated findings. The use of theoretical models in research on the other hand, would lead to cumulative, interrelated nursing knowledge. Fawcett described the relationship between nursing theory and research as a double helix (Fawcett 1978). Since nursing theory gets to the core of what nursing is, it will help generate research questions that are relevant for nursing. Mareover, findings stemming from this type of theory-guided research can be fed back into the structure of the theory, which will lead to organized bodies of cumulated nursing knowledge and refinement of the theory. The last ten to fifteen years more and more research studies are published that are more or less conceptualized within one of the nursing models. 
As far as the relationship between nursing theory and nursing practice is concer. ned, little progress has been made so far. The idea is that the nursing theories define goals for practice, and as such, guide nursing practice. Theory provides the nurse with goals for assessment, diagnosis and intervention. Theory helps to identify the focus, the means, and the goals of practice. Besides, common use of the same theory helps nursing communication and promotes autonomy. Although since the seventies, university educated nurses followed a theory-based curriculum. there is little evidence of actual use of theory in their everyday practice. Most publications giving examples of how nursing models are used with specific groups of patients, stem from the last 10 years. According to Meleis, one of the main reasons for not using theories in nursing practice, is the fact that they have not yet been empirically validated. Nevertheless, she is of the opinion that "Until empirical validation or modification is completed, theory could be given practical validation and could therefore be allowed to give direction to practice." (Meleis $1985 ;$ p.30).

In summary, theoretical frameworks or conceptual models or theories in nursing are perceived as providing the discipline with a relevant and specific perspective on its phenomena of interest. They are considered as guides in identifying what nurses need to know, guides in deriving relevant research questions, and guides for setting goals in nursing practice. Moreover, they promote professional identity and give structure to the body of nursing knowledge. Nursing theories have been developed over the last three to four decades and have mainly been used for educational purposes. There is a trend showing that they are applied more often in the generation of research questions, and - in relation to that - in giving structure to the accumulation of research findings. Recently efforts are being made to use the nursing theories in nursing practice, but lack of empiricall validation has inhibited this process.

\subsubsection{The Need for Theory Testing}

Nowadays, nursing is perceived as a professional discipline. One of the characteristics of a profession is that the practice is based on a body of scientific knowledge. As described in the former section, in nursing, theories are seen as playing a crucial role in the generation and structuring of this nursing knowledge base, and thus in guiding practice. However, when such an important role is ascribed to the nursing theories, it is a requirement that the underlying assumptions and propositions of the different theories are vallidated.

While encouraging nurse practitioners to work with theory, Meleis urges nurse researchers to work on the refinement and extension of the theories (Meleis 1985). Testing of a theory's propositions is necessary, as in the end only theories with sufficient empirical support have meaning for nursing practice and nursing's body of knowledge. If a theory remains untested, its usefulness remains in question. Evaluating the empirical validity of a theory can lift the theory from the level of common sense to the level of scientific knowledge (Jacobs \& Huether 1978). 
Walker and Avant consider theory testing in nursing of equal or greater importance than in the basic sciences, as nursing is a practice discipline: "The public trust in a profession warrants using the very best procedures in making scientific judgments which have social import" (Walker \& Avant 1988, p.201).

It seems remarkable that despite the continuously recognized and expressed need (Ellis 1968; Duffey and Muhlenkamp 1974; Hardy 1974; Jacobs \& Huether 1978; Fawcett 1984; Schlotfeldt 1988), so few nurse researchers have actually undertaken theory testing studies. In an attempt to determine the current state of the art on research testing nursing theory. Silva examined the nursing literature from 1952 till 1985 (Silva 1986). This search revealed 62 studies involving 5 major nursing models (Johnson's, Roy's, Orem's, Rogers' and Newman's). Only nine of these studies explicitly tested nursing theory. In 24 studies the theory was only mentioned, and not actually used, while 29 studies used theory as organizing framework, implicitly assuming that the theory's underlying assumptions were valid. Silva identified 4 factors that have impeded progress in theory testing, despite the recognized need for it: lack of investigator commitment, intolerance of methodological imperfections, unsystematic retrieval strategies, and lack of clarity about what constitutes theory testing in nursing.

Silva proposes the following evaluation criteria for theory testing research (Silva 1986, p.4):

1. The purpose of the study is to determine the underlying validity of a designated nursing model's assumptions or propositions.

2. The nursing model explicitly is stated as the theoretical framework for the research.

3. The nursing model is discussed in sufficient breadth and depth, so that the relationship between the model and the study hypotheses or purposes is clear.

4. The study hypotheses or purposes are deduced clearly from the nursing model's assumptions or propositions.

5. The study hypotheses or purposes are empirically tested in an appropriate manner.

6. As a result of this empirical testing, indirect evidence exists of the validity (or lack thereof) of the designated assumptions or propositions of the model.

7. This evidence is discussed in terms of how it supports, refutes or explains relevant aspects of the nursing model.

In addition, Silva is of the opinion that to promote progress, studies testing a theory preferably build on one another. If that is not possible, study findings should be discussed in relation to results of other studies testing the same model, so that a state of the art on the model's validity is addressed. 
Theories are tested through research. In theory testing studies the research hypotheses are deduced from the theory, and the operational definitions reflect the meaning of the theoretical terms. Before a theory can be tested, its testability must be determined. A testable theory permits researchers to derive hypotheses. Preferably hypotheses which are capable of falsification. To be falsifiable, a theory must be able to predict with enough specificity that empirical results that are incompatible with the theory can be readily identified. The more specific the predictions that can be made from a theory, the more rigorously it can be tested. It is harder to falsify a theoretical proposition which predicts an association between two concepts, than when for example time-order or particular values of the concepts are predicted.

This aspect of testability (falsifiability) can be related to the categorizing of nursing theories in (1) grand theories, (2) middle range theories, and (3) practice theories (Walker \& Avant 1988). Grand nursing theories are of a general and abstract nature, and provide global perspectives for nursing practice, education and research. Because of their lack of specificity they are usually untestable. Middle range theories contain limited numbers of variables and are limited in scope, and because of this they are testable. The essence of practice theory is a desired goal and prescriptions for action to achieve the goal. Therefore, these theories need to be very specific in predicting relations. Walker \& Avant present a model in which these three categories or levels of theories are linked with one another. The broad perspective of a grand theory can guide the development of a middle range theory on a specific phenomenon. Next, when the middle-range theory is subsequently tested, it contributes to the refinement of the grand theory. The relationship between middle-range and practice theory can be described in a similar way. The development of a practice theory is directed by one or a combination of middlem range theories; and the prescriptions for nursing practice that follow from the practice theory are empirical tests of the middle-range theory (Walker \& Avant 1988).

\subsubsection{Purpose of the Study}

The focus of this thesis is on the testing of one of the major nursing modells. Specific propositions from Orem's General Theory of Nursing are examined for their empirical validity in a population of cardiac patients. The choice for Orem's model of nursing is related to the fact that it is considered one of the more promising nursing frameworks. Firstly, being developed for nursing practice, it has many adherents among nurse practitioners. In the United States, it is used more widely in nursing practice than any of the other nursing theories (Meleis 1985; Grypdonck 1990). As far as research is concerned. Fawcett (Fawcett 1984) reports that despite the lack of publications numerous ongoing and completed studies are presented at conferences. In addition, the model is used in a growing number of master's theses and dissertations. In Europe as well, especially in the Scandinavian countries and the Netherlands, nurses in practice, research and education (Van der Peet 1990) are applying Orem's theory of nursing. 
Orem's General Theory of Nursing is based on a description of the condition in which nursing care is required more than other forms of health care. Orem describes this condition as the inability of a person to provide on a continuous basis the required amount and quality of self-care because of the personall health situation. The General Theory of Nursing consists of three interrelated theories: the theory of self-care, the theory of self-care deficit, and the theory of nursing system. As the theory has such great and international appeal to nurse practitioners and educators, the testing and the further development of this theory becomes an important task for nurse researchers.

The purpose of the study is twofold. Firstly, it aims to determine the validity of Orem's proposition on the relationship between the concepts self-care and wellbeing. Secondly; it is the intention to go one step further and offer insight into the nature of this relationship. This second purpose should be interpreted as an attempt to refine Orem's General Theory of Nursing and therefore contribute to its further development.

\subsection{TESTING OREM'S GeNERAL THEORY OF NURSING}

It was stated in the first part of this chapter that a theory needs to be examined for its testability before it can be tested. For the judgment of Orem's model it is important to have some notion of the theorist's own perspective on nursing science as a field of knowledge. Therefore, in the following section Orem's view on the structure of nursing knowledge is briefly described. Then, the testability of the model is examined in the context of its development.

\subsubsection{Orem's View on the Development of Nursing Science}

Nursing is defined by Orem (Orem 1988; 1991) and the National Development Conference Group (N.D.C.G.) as a practical science and a set of applied sciences. "Practical science is one of action, behavior, conduct. It says how we ought to behave and includes development of a method" (N.D.C.G. 1979, p.105). Its referent is to modes of inquiry and fields of knowledge associated with the practical order of things, things that are 'do-able'. Practical science is contrasted with theoretical science, which is concerned with 'knowable' things (Orem 1991, p.87). Applied science is defined as an existing science that is put to use or is pursued to achieve some end outside the domain of that science (Orem 1991, p.88). 
In a further refinement of what practical science is, Orem follows Maritain in distinguishing speculatively practical science from practically practical science (Orem 1988). Speculatively practical science has a theoretical character. In nursing it is concerned with the goals of nursing, the reasons for nursing's existence, and its intelligible structures (person, conditions, factors and events). Practically practical science is practical in that it is concerned with "the details of cases, the assignment of 'proximate rules' for [nursing] action" (Orem 1988, p.77). in relation to these two types of practical science, Orem developed 5 so-called stages of understanding nursing, expressing the 5 types of inquiry needed for the development of the practical science of nursing. Each stage relates to the kinds of data and the images involved in the development of insights, not in terms of times of their occurrence. This means that various stages of development may be in process at the same time. Specific insights resulting from the first two stages would, according to Orem, contribute to speculatively practical science, whereas practically practical science would result from the data and images from the other three identified stages. The end products of the first three stages identified by Orem are comparable with the three levels of theory Walker and Avant propose (Walker \& Avant, 1988).

The first stage identified consists of identifying, conceptualizing, and expressing the regularly recurring features of the human and action elements of nursing practice situations, naming them, and expressing the relationships among them. Early products of this stage are general conceptualizations about nursing and models in the form of circles of terms and relationships. A later product has the form of a general theory of nursing that is descriptively explanatory of nursing as a form of care with exposition of the product and process of nursing (Walker and Avant: a Grand Nursing Theory). In stage 2 the ranges of values of the nurse and patient variables of nursing practice situations are identified and arranged, including the vaiues of the components of their substantive conceptual structure. This stage includes investigation of the nature and effects of relationships between variables when specific values prevail, and establishing the meaning of these values for action on the part of nurse ar patient (Orem 1988). During this stage less comprehensive theories emerge as research progresses (Walker and Avant: middle-range theories). In stage 3 models and rules for nursing practice are developed and validated (analogue: practice theory). Stage 4 consists of describing nursing cases. Whereas in stage 5 models and rules for the provision of nursing for populations are formulated and developed. This last stage contributes to nursing economics and nursing administration.

Orem's own contribution to the development of nursing science, which is presented in the four editions of her book "Nursing - Concepts of Practice -" (Orem 1971, $1980,1985,1991)$, can be seen as speculatively practically science. 


\section{1:2.2. Testability of the Theory}

Orem's General Theory of Nursing can be considered a Grand Nursing Theory: The theory provides a global perspective for nursing practice, education and research, and as such it is not testable. Orem perceives it as being of a descriptive-explanatory nature, serving "to organize the outlook of nurses" (Orem 1985, p.34); in other words an end product of stage 1. The Grand Theory becomes testable in its division into three interrelated theories. The three theories define the relationships between the main concepts. The theory of self-care deficit describes when and why nursing is required; the theory of self-care explains why self-care is necessary for the continuance of life; and the theory of nursing systems explains how persons can be helped through nursing. These three can be considered on the edge between stage 1 and stage 2 .

Each of these three theories consists of sets of propositions and so-called presuppositions; in which the latter serve as linkages between the theories. The relational statements as put forth in the three theories are not very specific. No precise predictions can be derived from them. The majority are statements that a relationship exists, without determination of the nature or direction of the relationship. Moreover, several of them are not relational statements about two or more concepts, but are descriptive or existence statements on one concept. The lack of specificity on the relationships between the concepts in the statements is acknowledged by Orem. In both her own work (Orem 1985) as well as in the cooperative work of the N.D.C.G. (N.D.C.G. 1979), the need for further explication of relationships between concepts is pointed out.

This lack of specificity in the statements does not allow for rigid testing. However, it has the advantage that it invites the researcher to explore the relationships. Exploration then leads to more precise knowledge on the nature of the relations between concepts and so contributes to the theory. Such a combination of testing and exploring falls under Orem's second stage of development of nursing as a speculatively practical science. In this stage research is identified as the tool to develop more precise theories. The area of validation and exploration of this study is the proposed relationship between self-care and well-being.

\subsubsection{The Research Model}

The relationship between self-care and well-being as put forth by Orem has been chosen as the focus of theory testing in this thesis. Both concepts are essential in her theory and represent phenomena that are central themes in the current health care literature. The western cultural values of self-reliance and self-help are often translated in the realm of professional health care in terms of self-care. However, it should be noted that the definition of self-care differs greatly within and between disciplines. Since a few decades, well-being on individual as well as on group level has become more of an issue in modern professicnal health care. Now that most 
diseases are more or less under control, and in most instances do not signify immediate life-threats anymore, the focus of professional health care systems has come to include the promotion of the quality of life of its clients, including their wellbeing.

Nurses also render services related to the quality of life (Donaldson \& Crowley 1978). Congruently, in writings about nursing, well-being is often referred to as a goal for nursing care:

* "The goals of nursing are humanistic nursing itself, and to help patients to develop their human potential and to come toward, through choice and intersubjectivity, well-being or more well-being" (Paterson \& Zderad 1976);

* "The goal of nursing service is to foster self-caring behavior that leads to individual health and well-being" (Donaldson \& Crowley 1978; p.117);

* "...the consistent orientation of nurses to the provision of care that promotes well-being in the people served" (ANA 1980; p.9);

* "...help our clients... to achieve the highest sense of well-being" (Meleis $1987)$;

* "...nursing caring functions.... are relevant to the health, function, comfort, well-being. productivity, self-fulfilment, and happiness of human beings" (Schlotfeldt 1988; p.35).

This selection of statements from nursing scholars reflects the general belief in nursing that firstly, the well-being of clients is an essential aim to strive for in nursing, and secondly that 'caring' (either self- or nursing care) enhances clients' well-being. This second point makes the purpose of the underlying study, a closer' examination into the nature of the relationship between (self-)care and well-being. even more worthwhile.

In most writings and theories the concept of well-being is not at all or only very globally defined. Besides, it is often used interchangeably with such concepts as maximal personal development, health, life satisfaction, harmony, adaptation, or stress reduction. Orem on the other hand does define and elaborate on the concept. She ascribes meaning to it and explicitly differentiates it from the concept of health. Moreover, a formal statement in her model describes the relationship between the concept self-care and the concept well-being. In the second presuppasition of the self-care deficit theory. Orem assumes self-care to be necessary for the well-being of individuals.

"Self-care as a form of self-regulation is necessary for life itself, for health, for"

human development, and for general well-being." (Orem 1985, p.35).

As the intention is to test and explore the nature of this relationship, it follows that the research problem of this study is formulated as:

\section{How does self-care contribute to general well-being?}

Since Orem proposes the relationship on a rather abstract level, it was concluded that a contribution to the theory can be made by further exploration of the relationships. This involves looking at the relationship between self-care and well-being in the context of other relevant concepts identified in the theory. 
Orem associates both self-care agency and the so-called 'basic conditioning factors" with the concept of self-care. Figure 1.1 presents those two concepts and their theoretical relationships with self-care. In the propositions of the theory of selfcare deficit Orem states that self-care results from self-care agency. The propositions of both the theory of self-care deficit and of self-care introduce the basic conditioning factors as influencing both self-care agency and self-care. The concepts and their proposed relationships are described in detail in the following chapter.

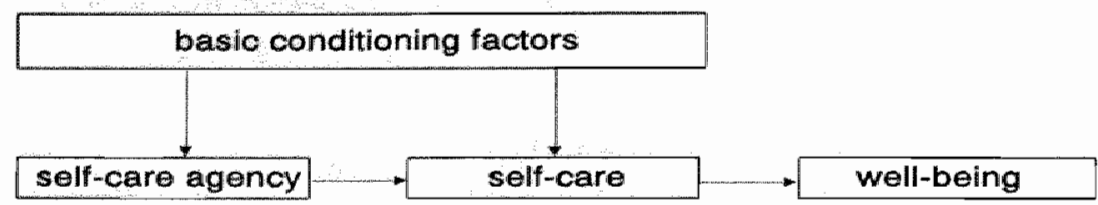

figure 1.1 The relationship between basic conditioning factors, self-care agency, self-care and state of well-being acconding to Orem.

The research model then is pictured in figure 1.2, with the arrows representing the relationships under study. The double-lined box outlines the relationship of central focus in this study (arrow A). The basic conditioning factors will be examined for their influence on self-care, on state of well-being as well as on the interrelationship (arrow $\mathrm{C}$ ). In the literature these factors are often directly associated with wellbeing. Arrow B stands for the relationship between self-care agency and self-care. The theoretically proposed relationship (see figure 1.1) between basic conditioning factors and self-care agency is not investigated in this thesis.

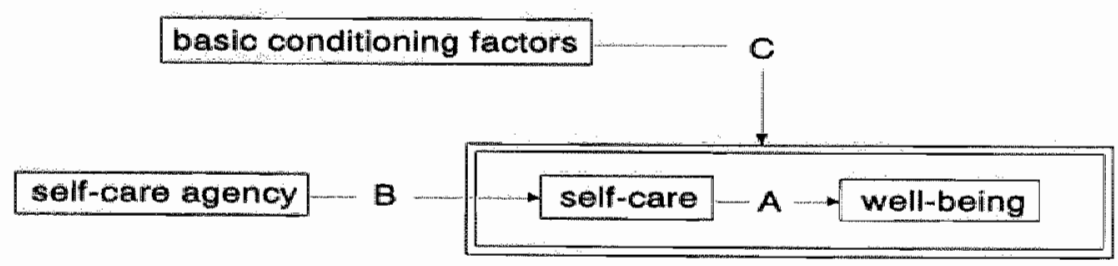

figure 1.2 Research model of this study.

Three sets of research questions, which are represented by the three arrows are formulated to organize the data analysis.

The first one is of a theory testing nature:

A 1. Does achievement of self-care requisites contribute to state of wellbeing ?

Next, to gain insight in the relationship of central focus, two research questions of an explorative nature are formulated: 
A 2. Is the relationship between self-care and state of well-being consistent over time?

A 3. Do different aspects of self-care contribute differently to state of wellbeing?

The stability of the relationships can be studied as the study includes a longitudinal design.

The second set (arrow B) consists of two theory testing research questions.

B 1. Does self-care agency relate to achievement of self-care requisites ?

B 2. Does self-care agency relate to state of well-being after controling for achievement of self-care requisites ?

From the detailed theoretical discussion in the next chapter it will be deduced that Orem uses the concept of self-care in the relationship with well-being in terms of needifulfilment and not in terms of abilities.

The last set of research questions deals with the testing and exploration of the influence of the basic conditioning factors. Question C1 addresses the testing of specific propositions from Orem's theory of self-care. The last two are of an explorative nature.

C 1. To what extent do basic conditioning factors influence self-care ?

C 2. To what extent do basic conditioning factors influence state of wellbeing?

In addition ${ }_{*}$ the possibility of an influence of the basic conditioning factors on the relationship between self-care and well-being is explored.

C 3. Do basic conditioning factors affect the relationship between self-care and state of well-being ?

These 3 sets of questions serve to set the boundaries of this research study. The formulated research questions are studied through analysis of data collected in a longitudinal study among Coronary Artery Bypass Surgery (CABS) patients. This type of cardiac patients represents a group of special interest in relation to the research problem formulated for this study. Firstly, the well-being or quality of life is always an important issue in elective coronary artery bypass surgery. Improvement of quality of life is often stated as the main reason for having people undergo $C A B$ surgery. Secondly, their specific health problem puts them under nursing care for a certain period of time. Thus, insight in the process through which the well-being of CABS-patients can be promoted, becomes relevant knowledge for nurses. Most importantly, as they undergo a change in their state of health, the effect of one of the critical basic conditioning factors on self-care can be examined.

The longitudinal study under CABS-patients has as main research question: "What are the changes in self-care needs and abilities of people undergoing coronary artery bypass surgery ?" The correlational design includes one pre- and several postoperative measurements. The results in relation to the changes over time in self-care needs and abilities are reported elsewhere (Senten, Evers, Philipsen Isenberg 1990; Isenberg \& Senten 1991). These analyses also report on the 
findings regarding the relationship between basic conditioning factors and self-care agency.

\subsection{SUMMARY}

In this chapter the need for testing nursing theories has been explained. Certain relationships as proposed in the General Theory of Nursing of D.E. Orem are chosen as the focus of theory testing in this study. The theory of Orem leaves foom for further development and refinement, as the nature of some of the proposed relationships is not defined very specifically. Central to this study is the assumed relationship between self-care and well-being. This relationship is studied in the context of the related concepts of self-care agency and basic conditioning factors. The inclusion of these two concepts in the research model, will contribute to the further exploration of the theory. In the following chapter Orem's idleas on the concepts of the model and their interrelationships will be discussed. Based on this discussion and on the review of the literature, hypotheses are derived which test the proposed relationships in a population of persons undergoing coronary artery bypass surgery. 


\section{CHAPTER 2 THEORETICAL FRAMEWORK}

This chapter starts with a short description of the central idea of Orem's General Theory of Nursing. Then Orem's theoretical work in relation to the concepts of selfcare and well-being and their relationships with self-care agency and basic conditioning factors will be discussed in more detail. Subsequently, the literature is reviewed with reference to the research model and to studies testing Orem's theory. In combining the literature findings with Orem's theoretical work, the last section deals with the derivation of hypotheses that test specific propositions from Orem's theory.

\subsection{OREM'S PERSPECTIVE}

\subsubsection{Orem's General Theory of Nursing}

Orem"s General Theory of Nursing was developed for the purpose of structuring the field of nursing knowledge. Orem perceived a need for conceptualization of elements in the domain of nursing and of the relationships between them (Orem $1985, p .18$ ). Six related concepts were formulated that were recognized as affording structure and meaning to nursing practice situations. They are self-care, therapeutic self-care demand, self-care agency, self-care deficit, nursing agency, and nursing system.

The interrelation of the six main concepts is rooted in the underlying idea of Orem's model, namely her perception of what it is that distinguishes nursing from other health care disciplines. Her insight into the condition in which nursing care is required more than other types of health care is formulated as follows:

the human condition associated with requirements for nursing is the inability of a person to provide continuously for self the amount and quality of required self-care because of the situation of personal health." (Orem 1985, p.19).

In this formulation the described human condition is synonymous with the concept of self-care deficit; whereas the ability to perform self-care stands for the self-care agency concept; and the required self-care refers to the concept of therapeutic self-care demand. Thus in Orem's perspective, it is the existence of a self-care deficit that legitimates nursing intervention. 
The model rests on two interrelated views: Firstly, the view of human beings as needing continuous self-maintenance and self-regulation through a type of action named self-care. Secondly, the related view of the nursing focus being this need of individuals for self-care action and the provision and management of it on a continuous basis.

\subsubsection{The Concept of Self-Care}

Self-care is the central concept in Orem's modell. It is described as 'the practice of activities that individuals initiate and perform on their own behalf in maintaining life, health and well-being" (Orem 1985, p.84). It is a practical response to an experienced demand to attend to oneself. Self-care is learned behavior, learned within the context of social groups by human interaction and communication. Selfcare is deliberate action. Performing a self-care measure involves a decision; this is so even with routine practices. Unless self-care activities have become habitual processes, there is a need for reflection about what should be done and how it will be done (Orem 1985, p.88). It follows that self-care has purpose. It is action that has pattern and sequence. The purposes to be attained through the kinds of actions termed self-care are named self-care requisites. Three sets of requisites are distinguished:

1. Universal self-care requisites are common to all human beings during all stages of the life cycle, adjusted to age, developmental state, and environmental and other factors. They are associated with life processes, with the maintenance of human structure and functioning, and with general well-being.

Universal self-care requisites are always present and relevant. Meeting them becomes usually an integrated part of the daily living of individuals, until certain unfavorable conditions (for example bad health, scarcity of food/water, etc.) predominate. Orem suggests eight categories of universal self-care requisites:

1. The maintenance of a sufficient intake of air.

2. The maintenance of a sufficient intake of water.

3. The maintenance of a sufficient intake of food (nutrients).

4. The provision of care associated with elimination processes and excrements.

5. The maintenance of a balance between activity and rest.

6. The maintenance of a balance between solitude and social interaction.

7. The prevention of hazards to human life, human functioning, and human well-being.

8. The promotion of human functioning and development within social groups in accord with human potential, known human limitations, and the human desire to be normal. 
2. Developmental self-care requisites are associated with human developmental processes and with conditions and events occurring during various stages of the life cycle and events that can affect development. Developmental self-care requisites are specialized expressions of universal self-care requisites or they are new requisites derived from a condition (for example pregnancy) or associated with an event (for example loss of spouse).

3. Health deviation self-care requisites are associated with genetic and constitutional defects and human structural and functional deviations and with their effects, and with medical diagnostic and treatment measures. Health deviation self-care requisites arise from both the disease state and the measures used in its diagnosis or treatment.

Health-deviated self-care includes

1. seeking and securing appropriate medical assistance;

2. being aware of and attending to effects and results of pathological conditions and states;

3. effectively carrying out medically prescribed measures directed to the prevention of specific types of pathology and to the pathology itself;

4. being aware of and attending to or regulating the discomforting effects of medical care measures;

5. modifying the self-concept;

6. learning to live with the effects in a life-style that promotes continued personal development (Orem 1985, p.99).

Fulfilment of health-deviated self-care requisites leads to secondary and tertiary prevention.

Each set of self-care requisites represents a category of deliberate actions to be taken by or for individuals because of their needs as human beings. Individuals need to recognize a self-care requisite before it can serve as purpose of self-care behavior. Universal self-care requisites should become known by all educable adults. Ideally, this also holds true for developmental self-care requisites. Health deviation self-care requisites usually become known by those who have genetic or constitutional defects or health-deviations or whose familly members or associates have such defects or health deviations. (Orem 1985, p.86)

Orem considers self-care necessary for the continuance of life (Orem 1985, p.3435). She states (Orem 1985, p.90) that when the three types of requisites are effectively met, they are productive of human and environmental conditions that

1. support life processes,

2. maintain human structure and human functioning within a normal range,

3. support development in accord with the human potential

4. prevent injury and pathological states,

5. contribute to the regulation or control of the effects of injury and pathology,

6. contribute to the cure or regulation of pathological processes, and

7. promote general well-being. 
Self-care is described as purposeful behavior that is learned and deliberate. According to Orem, individuals develop over time, specific abilities for self-care. This (complex) acquired capability to recognize, reflect and decide on self-care needs and actions, and subsequently take action, is what Orem calls self-care agency. The following propositions reflect the notion that the activation of self-care agency results in self-care:

From the theory of self-care deficit proposition 1:

Persons who take action to provide their own self-care or care for dependents have specialized capabilities for action.

From the theory of self-care proposition 7:

Self-care (or dependent care) as a process or system results from the individual's deliberate use of conceptualized processes or technologies to meet known self-care requisites.

The theoretical concept self-care agency is constituted from two interrelated components (N.D.C.G. 1979, p.188-193): self-care agency is the POWER to engage in three specific types of SELF-CARE OPERATIONS. These operations are firstly estimative operations, in which the way of acting is that of investigation, inquiry: what is to be done with respect to self-care. Secondly, there are productive operations, in which the way of acting is regulation, bringing about change in or maintaining some condition. Estimative operations precede productive operations. The movement from investigation (estimative) to regulation (productive) has been conceptualized as a third set of operations. These are named transitional operations, they deal with decision-making; what should and what will be done. Self-care agency as the individual's ability to engage in self-care action, can be described in terms of development, operability and adequacy. Development is identified in terms of the kinds of self-care operations individuals have learned to consistently and effectively perform; operability expresses how much self-care agency is in operation at a certain moment; whereas adequacy refers to the quality of self-care agency in relation to the therapeutic self-care demand.

As becomes clear from the descriptions of both concepts, neither self-care abilities, nor self-care requisites are constant entities. The value of each can vary with individuals, groups, situations and time. Orem and her colleagues of the N.D.C.G. identified eight so-called Basic Conditioning Factors. These factors are

- age;

- sex;

- health state"

- health care system elements:

- family system elements;

- patterns of living:

- developmental state;

- sociocultural orientation (N.D.C.G. 1979).

They are judged to have an active influence at points in time on the concrete values of the patient variables. A basic conditioning factor is defined as "something which precipitates a chain of intrahuman events which may change existent 
requirements or bring about added requirements for deliberate regulatory inputs to the person or the person's environment or affect the value of self-care agency' (N.D.C.G. 1979, p.171).

The relationship between these basic conditioning factors and the concepts of selfcare and self-care agency are formally stated in the propositions of the theory of self-care and the theory of self-care deficit:

Proposition 5 of theory of self-care :

Universal self-care requisites and ways of meeting them may be modified by the age, sex, or developmental or health state of individuals.

Presupposition 2 of theory of self-care :

Ways of meeting self-care needs are cultural elements and vary with individuals and larger social groups. Proposition 2 of the theory of self-care deficit :

The individual's abilities to engage in self-care are conditioned by age, developmental state, life experience, sociocultural orientation, health, and available resources.

It is not clear why Orem does not explicitly mention each of the 8 basic conditioning factors in these propositions. Nevertheless, in other parts of her work (Orem 1985, p.95 and p.220-222) all eight factors are discussed as influencing the values of an individual's self-care needs and abilities.

The N.D.C.G. is of the opinion that the formulation of laws (conditional propositions) that express the interdependence of values of each of the basic conditioning factors and values of the patient variables would contribute substantially to the structuring of nursing knowledge (N.D.C.G. 1979, p.172). This study explores the relation between several basic conditioning factors and selfcare, as well as a possible effect of the factors on the relationship between selfcare and well-being.

\subsubsection{The Concept of State of Well-being}

Contrary to some other nursing theorists, Orem distinguishes the concept of wellbeing from the concept of health. Health and well-being are referred to as two different but related states.

Well-being (Orem 1985, p.179) is used in the sense of individuals" perceived condition of existence. "Well-being is a state characterized by experiences of contentment, pleasure, and kinds of happiness; by spiritual experiences; by movement toward fulfilment of one"s self-ideal; and by continuing personalization. Well-being is associated with health, with success in personal endeavors, and with sufficiency of resources". Thus, experiencing well-being refers to how a person perceives or judges the quality of his or her life. 
Health (Orem 1985, p.176-179), on the other hand is used in the sense of a state of a person that is characterized by soundness or wholeness of developed human structures and bodily and mental functioning. The term sound means possession of full vigor and strength and the absence of signs of disease and morbidity. The term whole means that nothing has been omitted, ignored or lessened. The terms whole and sound in relation to health signify human functional and structural integrity, and progressive integrated development of a human being as an individual unity moving towards higher levels of integration. Defined in this way, health state includes continuing human development. However, for practical purposes Orem considers health state and developmental state as separate entities.

On the other hand, Orem contends that a scientific appraisal of an individual's health state requires that the term state is used in the compound sense: This means that a person's health state is expressed as a set of determined values of specified human characteristics that simultaneously reveal some aspects of the person's existence. Varying combinations of components are indicators of different aspects of a person's health state. Within the different health sciences norms have been established and methods have been developed to determine physiological, anatomic, psychological and behavioral components of health state. Different health professionals focus on different components to fulfill their purposes.

Orem states that conceptualizations of health and well-being are related to points of view about human beings, and that these points of view should be made explicit for purposes of understanding human health and well-being (Orem 1985, p.179). The N.D.C.G. identified the following views of human beings as being useful in different nursing situations (N.D.C.G. 1985, p.175): human beings as persons, which subsumes man as symbolizer, agent and organism, and human beings as object, subject to physical forces. Orem describes a human being as a unity, that can be viewed as functioning biologically, symbolically, and socially. Next, Orem identifies two points of view about human beings that afford meaning to states of human health and well-being (Orem 1985, p.180). These are firstly, human beings as persons and secondly, the structural and functional differentiations of human beings.

The first conceptualization seems to have the most links with Orem's description of well-being, as well as with her definition of health as a state of being sound and whole, as it refers to 'personalization', and 'the achievement of the individual's human potential. It is explained that during the process of personalization individuals strive to achieve the potential of their natural endowments for physical and rational functioning while living a life of faith with respect to things hoped for and to perfect themselves as responsible human beings who raise questions, seek answers, reflect, and come to awareness of the relationship between what they know and what they do. The humanities, psychology and theology are thought to be helpful in the development of insight about human beings as persons (Orem 1985, p.181). 
The second view of human beings which focuses on the structural and functional differentiations seems especially meaningful in relation to Orem's use of the concept of health state in the compound sense. This view emphasizes that human beings have discernible parts, where each differentiated structure or system (kidneys, heart, gland, endocrine system, etc.) is an existent entity with its own operations and functions and with relations to other such differentiated parts. To prevent misunderstandings, Orem posits that each human being is a substantial or real unity, whose parts are formed and attain perfection through the differentiation of the whole during the processes of development. If there is acceptance of the real unity of individual human beings, there should be no difficulty in recognizing structural and functional differentiations within the unity. The various human and life sciences, like biochemistry, biophysics, human anatomy and pathology as well as psychology have developed and structured knowledge in this area.

In Orem's model of nursing, the concepts health and well-being play different roles. Well-being is used only as outcome variable of effective self-care, whereas health is used in two ways. Similar to the concept well-being it is seen as being positively affected by effective self-care. Secondly, health state is described as a basic conditioning factor, and thus partly determining the self-care of individuals. Moreover, health state is mentioned as the major underlying cause of self-care deficits, legitimating nursing intervention." "the human condition associated with requirements for nursing is the inability of a person to provide continuously for self the amount and quality of required self-care because of the situation of personal health" (Orem 1985, p.19); and "Action limitations that are related to the individual's health state constitute the reasons why people need nursing" (Orem 1985, p.122).

Orem does not refer directly to, nor explicate this dual role of the cancept of health in her model. It seems however, that when the concept is used as basic conditioning factor, Orem emphasizes health state in the compound sense. Health state as influencing the values of self-care agency and the self-care requisites is discussed by Orem in terms of specific characteristics, indicators or functions. For example, in indicating the types of data that nurses should obtain relative to the conditioning factors, Orem includes: "gross evidence of health state "for example, ability to control position and movement in space; signs of injury, debility, illiness, sensory impairment" (Orem 1985, p.164); and also it is stated that "information about the values of health state indicators and the probabilities attached to their values allows nurses to make judgments about the ... effects of these indicators on the indlividual's performance of self-care operations" (Orem 1985, p.183). A specified relationship between the value of a basic conditioning factor and values of patient variables, is an example of the type of 'laws' the N.D.C.G. refers to as necessary in nursing science.

On the other hand, the definition of health state as being sound and whole seems more emphasized when health state is used as outcome of self-care: "A single self-care practice is therapeutic to the degree that it actually contributes to the achievement of .......(1) support of life processes and promotion of normal 
functioning......" (Orem 1985, p.89); or "...a person is a good regulator if his or her self-care actions bring about internal and external conditions necessary to maintain life processes ........, integrity of human structure and functioning, and human developmental processes ${ }^{i}$ (Orem 1985, p.182). A similar interpretation of Orem's use of both definitions of health state is found with Denyes (Denyes 1988) and Hartweg (Hartweg 1990).

\subsubsection{The Relationship between Self-Care and Well-being}

Throughout her work Orem refers to the positive effect self-care has on well-being. Firstly it can be found in the definition of self-care: 'the production of actions directed to self or to the environment in order to regulate one's functioning in the interests of one's life, integrated functioning, and well-being'. Furthermore, Orem contends that "self-care is an adult's continuous contribution to his or her own continued existence, health, and well-being. Moreover, which is more interesting in the light of theory testing, it is formally stated in the 2nd presupposition of the theory of self-care deficit: 'Self-care as a form of self-regulation is necessary ........ for general well-being' (Orem 1985, p.35).

Orem defines the nature of the relationship as necessary. This means that without self-care there can be no well-being. However, self-care is not perceived as sufficient condition, since well-being is also defined as being associated with p.e. health, success in personal endeavors and sufficiency of resources.

When Orem identifies self-care as necessary for well-being, the emphasis is on selfcare in the sense of needfulfilment, and not on independent action, or ability for action. It is not the ability for self-care action, nor so much the performance of the action itself that is necessary for well-being. It is the result of the action, the achievement of self-care requisites that is required for individuals' positive perception of their state of existence. Orem describes this as follows (Orem 1985):

"When the three types of requisites are effectively met, they are productive of human and environmental conditions that ......... promote general well-being" (p.90);

"When it is effectively provided, self-care .... organized around the universal selfcare requisites fosters positive health and well-being" (p.91); and

"The results of meeting each of the eight universal self-care requisites contribute in different ways to health and well-being" (p.91).

Orem does not pose a direct relationship between self-care agency and well-being. The fact that in Orem's view it is the needfulfilment itself and not so much how it is accomplished also explains how nurses and/or dependent care agents can promote well-being in the care-receiver.

In this section, both the concepts which make up the research model, as well as 
the relationships between them have been described according to Orem's views. Self-care is the core concept of the theory, while the performance of it is proposed to be affected by the basic conditioning factors and a person's self-care agency. Fulfilment of the self-care requisites is assumed to be necessary for the individual's well-being.

In the next section the literature is reviewed for the identification of empirical predictors of well-being, as well as for the purpose of examining nursing studies which test Orem's theory.

\subsection{REVIEW OF THE LITERATURE}

The purpose of this study of the literature is threefold. Firstly, it reviews the literature on research dealing with predictors of well-being, particularly the role of what Orem describes as basic conditioning factors. Secondly, studies are reviewed that deal with the specific population of Coronary Artery Bypass patients with respect to their well-being. Lastly, it discusses research studies testing Orem's theory, especially in relation to self-care and well-being, as well as with respect to the influence of basic conditioning factors. The first section deals with the use and meaning throughout history of the concept of well-being itself, and how Orem's definition fits into this tradition.

\subsubsection{The Concept of Well-being}

Both the Oxford and the Webster's dictionaries indicate that the word 'well-being' was used first in 1613. It is defined as (Oxford): "the state of being or doing well in life; happy, healthy or prosperous condition; welfare" and "satisfactory condition (of a thing)". This last meaning appears since 1702. Although the word 'well-being' has only been used for a few centuries, the idea of striving for or seeking a happy life is of course much older. This dates back to the old Greeks. From Aristotle comes the word 'eudaemonia', in the Greek language indicating "the best possible way of life". Happiness, according to Aristotle is an activity of the soul. Happiness lies in virtuous activity, and perfect happiness lies in the best activity, which is contemplative activity; "supreme happiness is in the exercise of reason" (Russell $1945 ;$ p.181). Therefore, the highest happiness in Aristotle's view is only open to philosophers. For the Christian philosophers in the middle ages, the best activity was religious activity; a religious life was the way to reach satisfaction/happiness.

This notion of happiness/well-being as some state of perfect activity persisted until the 18th century (Tatarkiewicz 1975). By then it was replaced by a more experiential meaning; it was no longer the type of conduct (moral behavior) that brought happiness, but happiness came from feelings of pleasure and 
contentment. Happiness became the opposite of pain: "Happiness in its full extent is the utmost pleasure we are capable of" (Locke in Book II, cited in Russell 1945, p.613). The 19th century (Bentham, Mill) brought the doctrines of hedonism and utilitarianism: the best thing in life is pleasure or happiness, and the guiding principle of conduct should be the greatest happiness for the greatest number! Although these philosophies are now considered to be unrealistic as such, their influence can still be recognized in the 20th century. Nowadays, the dictionary definitions of well-being and happiness reflect the idea of enjoying life and having reasons for that. They include the experiential aspect, while Aristotle's notion of 'best way" of living no longer seems to matter. In everyday and scientific use the concept of well-being is used more or less interchangeably with the concepts happiness and quality of life.

Over the past 100 years the (utilitarian) notion of 'happiness/well-being for all' has become a political issue in especially the western countries. At first the elimination of poverty was perceived as the means to achieve such a purpose. However, when it became clear in the fifties and sixties that raising the standard of living did not automatically lead to a higher quality of life, research studies were initiated to explore what well-being exactly was, and how it could be accomplished.

In relation to the question what well-being is, a distinction can be made between firstly the well-being of the individual versus that of groups, and secondly between an evaluation of life-as-a-whole and the evaluation of certain domains of life (for example economic situation, work life). The concept is used in both ways. The emphasis however, is on the individual's evaluation of life-as-a-whole. In his extensive review of the literature Veenhoven identifies a few more differences in emphasis in existing definitions of happiness, which are also true for uses of the concept well-being. For example, the 'object' versus the 'subject' view. Object view refers to fixed and generally applicable standards of life, which can be judged by any observer, whereas subject definitions refer to the subjective personal perception, which can only be judged by the individual him/herself. Another distinction can be noticed between happiness as a one-moment-thing, and happiness as an appreciation of life-as-a-whole: a more or less passing experience of pleasure or a more continuous state of being (Veenhoven 1984). It depends on the discipline or background of the scientist, which aspects of well-being are emphasized. For example, economists tend to use a more objective view and focus on the well-being of groups, whereas psychologists will stress the subjective, individual experience; sociologists on the other hand, are often interested in the evaluation of certain domains of life, as well as in how feelings of well-being change over time; when people reach new phases in their life.

Except for differences in emphasis, there is also the question whether well-being is a uni- or a multidimensional concept. This discussion has mainly arisen from statistical analyses on empirical data, which sometimes revealed several factors that correlated differently with other variables. Chamberlain concludes in 1988 that "although considerable research has been devoted to examining the dimensionality 
of subjective wellibeing .......currently there is only limited consensus in the findings on this topic (Chamberlain (1988). Theoretically most support cian be found for a distinction in the concept between a cognitive and an affective dimension. Veenhoven describes these dimensions as respectively the degree to which $a$ person perceives that his/her aspirations are met, and the degree to which a person experiences pleasant affect (Veenhoven 1984). Empirically, there is strong support to divide the affective dimension in a negative and a positive component (Bradburn 1969); those things that make people happy (feel good) are not the same as those that make them unhappy. It is not clear whether these components are independent.

When Orem uses the concept of well-being in the sense of an individual's perceived condition of existence, she is referring to a person's evaluation of his/her life, a judgement on the quality of it. Orem includes experiences of contentment and movement towards fulfilment of one's self-ideal as well as experiences of pleasure and spiritual experiences. It seems that Orem's conceptualization of wellbeing reflects a subjective appreciation of the individual's life-as-a-whole containing cognitive and affective aspects. There are no indications that Orem distinguishes positive and negative elements within the affective dimension.

\subsubsection{Predictors of Well-being}

One of the formulated research questions (C) of this study dealls with the relationship between basic conditioning factors, self-care and well-being. It was postulated that the basic conditioning factors (age, sex, health state, health care system elements, family system elements, patterns of living, developmental state and sociocultural orientation) might have a direct or indirect (through self-care) effect on well-being. Therefore the literature has been reviewed for the identification of predictors of well-being, with emphasis on Orem's basic conditioning factors.

In this, Veenhoven's study 'Conditions of Happiness' (Veenhowen 1984) has been very helpful. The aim of his study was to identify the conditions that favor a positive appreciation of life'. He started out with clearly defining the concept of happiness. Next, he examined all possible measurement instruments of well-being, happiness and quality of life, and selected the ones that represented his conceptuallization. After a sharp selection with respect to these instruments, he then analyzed the findings of 150 publications up to 1975 , together reporting on 156 research projects invo|ving 245 research populations all over the world.

Veenhoven"s findings are useful for the current study, as his conceptualization of happiness resembles Orem's notion of well-being. Veenhoven defines happiness as "the degree to which an individual judges the overall quality of his life-as-a-whole favorably" (Veenhoven 1984; p.22). This definition includes the cognitive and affective dimensions: "When evaluating the favorableness of their lives, people tend to use two more or less distinct sources of information: their affects and their 
thoughts" (Veenhoven 1984; p.25). The two dimensions are called 'contentment' and 'hedonic level of affect'. They reflect respectively, the perception of success in one's: aspirations, and the experienced pleasantness in feelings, emotions and moods. Veenhoven's definition of happiness reflects like Orem's conceptualization of well-being, a subjective appreciation of the individual's life-as-a-whole containing cognitive and affective aspects.

Most of the findings that were analyzed by Veenhoven were of a correlational nature, which made it difficult to identify causal relationships. As far as 'causality' is concerned, Veenhoven concluded from the results of longitudinal studies, that the following variables proved to be involved in promoting happiness:

personal income (esp. in poor countries or areas);

income per head (national level):

being employed (for chief wage-owner);

having a life-partner (esp. in western nations);

having children (esp. in western nations);

number of and frequency of contacts with friends and relatives;

self-rated health; and

not being black or a member of an immigrated minority in the U.S.A.

Education was found to be involved indirectly by providing better income chances. Having a partner promotes happiness, but this relationship was proven to work both ways: happier people have a greater chance to find a partner. Self-rated health influenced the perception of degree of happiness, whereas a perception of great happiness makes that people report less health complaints and live longer. Gender and age by themselves were not correlated with happiness. In western countries however, an interaction effect of the two was found: older men were happier than older women, while young women appreciated their lives more than young men.

Other variables that Veenhoven found to be related to well-being were: physician's rated health; type of occupation (professionals emerged as the most happy, unskilled workers as the least); activity in leisure (happy people were more active (hobbies, etc.)); going to bed late was positively related); and satisfaction with (the domains): intimate ties, income, oneself, leisure, work, health, living environment and country. Since these are all correlational findings, the direction of the relationships could not be established.

The literature on well-being of the last fifteen years does not reveal many new insights. In general, the findings are more or less congruent with Veenhoven's conclusions. The focus on studying the well-being of large general populations changed somewhat in the direction of studies with specific populations like the elderly or the (chronically) ill. Schuessler and Fisher (Schuessler \& Fisher 1985) contribute this phenomenon to the fact that these are common target populations of government programs. The following section will summarize the results of studies on the well-being of cardiac surgery patients. 
Despite the considerable amount of research studies conducted in the field, no real comprehensive theories have been developed in relation to individual well-being. This is of course partly due to the lack of agreement and clarity on the conceptualization. Nevertheless, it makes it very difficult to place the findings of all these studies in a well-organized context. Veenhoven proposed a model based on his findings, picturing happiness as the result of various interactions between individual characteristics and the living conditions of the individual; but apparently it did not invite or motivate other scientists to place new findings in this or any other comprehensive model.

\subsubsection{The Well-being of CABS-patients}

From the moment the first Coronary Artery Bypass Surgery (CABS) was performed more than 20 years ago, evaluation studies have taken place. In the beginning this follow-up research was mainly done by medical researchers, followed by sociologists, and psychologists. The general question of this type of research is, whether patients are indeed better off after CAB-surgery than they were before. The reports on these studies use the term 'quality of life' rather than the concept of well-being. However, the term is rarely defined in these reports. Moreover, these studies seldomly include instruments that measure the concept of well-being or quality of life as such, but tend to use so-called indicators. In other words the underlying definition of the concept emphasizes the 'objective view".

This lack of interest in CABS-patients" perceptions of life-as-a-whole is probably due to the fact that in the (medical) literature in relation to CAB-surgery, the expression quality of life is used in the sense of 'treatment justification'. Implicitly it is assumed that every individual has certain goals and plans in life, that include the pursuit of one's vocation and the enjoyment of one's special pleasures. As certain experiences such as confinement to bed, fear or pain hinder the pursuit of these personal plans, it is useful to investigate to what degree a certain treatment (like CAB-surgery) produces conditions that promote or impede fulfilment of these lifeplans (Cohen 1982). As a consequence, the emphasis in the follow-up studies is on these favorable or unfavorable conditions that are thought predominant for people with coronary artery disease: chest discomfort, increased life-expectancy. length of hospital stay, anxiety, return to work, exercise tolerance, sexual activity. etc.

In the early follow-up studies in particular, the indicators for quality of life were of an objective nature, ignoring the individual's interpretation and experience. The subjective perception came somewhat more into focus when psychologists entered this area of study, although they also used objective standards to compare the personal experience with. Folks c.s. called their Psychosocial Adjustment to Iliness Scale (PAIS) a comprehensive measure of quality of life. It consists of seven subscales: sexual function, vocational status, domestic environment, extended family relationships, social activities, psychologic distress and health concerns 
(Folks; Blake et al. 1986). A total of 96 CABS-patients completed this scale prior to and 6 months after surgery. A significant improvement was found in 4 of the subscales: sexual functioning, vocational status; domestic environment and social activities. However, people reported more health concerns postoperatively than before surgery. Unfortunately, no results are shown with regard to the interrelations of the subscales. Age was found to be negatively related to psychologicall distress. Older people reported less distress.

Kornfeld et al. (Kornfeld, Stanley et al. 1982) attempted a follow-up study on 100 consecutive CABS-patients from a hospital in New York. From the 57 questionnalres they received back at $31 / 2$ years after surgery, it was concluded that overall pleasure in life had improved substantially, with reduced overall nervousness, improved mood, and improved job, family and sexual satisfaction. It is not clear how these variables were measured and whether they were interrelated.

The only (nonnursing) study of CABS-patients that included the measurement of well-being as a concept in itself, is one from a group of Dutch researchers (Rombouts, Jambroes et al. 1984). Unfortunately, the well-being questionnaire they used was not developed on the basis of a concept-analysis or theoretical framework, reflecting the general ideas discussed in section 2.2.1. The instrument for the measurement of well-being is the result of a factor-analysis on a 52-item questionnaire called the Medical Psychological Questionnaire for Cardiac Patients (Erdman 1982). The four factors that were identified were named 'well-being', 'handicap-experience', 'displeasure' and 'social inhibition'. From the description of the subscales 'well-being' and 'displeasure' it appears that they represent respectively the positive and negative affect dimension of the concept of well-being. Subjects with a high score on well-being are described as 'lately feeling at ease, cheerful, healthy, relaxed, full of self-confidence', whereas subjects scoring high on the displeasure scale report negative feelings and emotions, such as being depressive, easily irritated, restless, and/or having a bad temper (Erdman 1982).

Rombouts et al. (Rombouts, Jambroes et al. 1984) investigated which factors played a role in feelings of well-being in a.study among 150 CABS-patients, on the average two years after surgery. The average well-being score (as measured with Erdman's 'well-being'-subscale) for this group was significantly higher than that of a heterogenous group of heartpatients. Furthermore, well-being was negatively correlated with displeasure, (Spielberger's) trait-anxiety, neuroticism and selfesteem, as well as with the number of post-CABS readmissions. Age was not found to be related to well-being. The absence of both cardiac and noncardiac symptoms, and the ability to perform normal daily activities, were positively correlated with well-being.

In the eighties, a few (American) nurses became involved in research with CABSpatients. Interestingly enough, their studies are more often concerned with the experience of individual well-being as such. In 1984 Penckofer and Holm used Cantril's Self-Anchoring Scale to measure life satisfaction 3 to 5 and 6 to 8 months 
post-CABS (Penckofer \& Holm 1984). They found a mean life satisfaction score of $5.4(\mathrm{sd}=1.9)$ for the first group $(\mathrm{n}=17)$. The group $(\mathrm{n}=17)$ that was interviewed at 6 to 8 months after surgery scored an average of $8.0(s d=1.7)$. Cantril's Ladder" theoretically varies from 0 to 10 . Retrospectively, the 2 groups rated their preoperative life satisfaction at 3.6 and 3.4 respectively. Penckofer and Holm also found significant postoperative improvement in the life domains family, social and sexual life. There are no data on how these domains relate to overall life satisfaction.

One of the purposes of Flynn and Frantz's study was to find the greatest predictors of life satisfaction of 29 CABS-patients during early convalescence (Flynn \& Frantz 1987). The mean rating for life satisfaction on the Cantril Ladder of this group was 6.4 (sd unknown) at 6 to 10 weeks after CAB-surgery. Self-rated health was found to be moderately positively related to life satisfaction, while the latter was not correlated with health state indicators such as rehospitalizations, angina, shortness of breath, complications and exercise tolerance. The three most powerful predictors of satisfaction with life were mood or morale, satisfaction with wealth and relief of symptoms. Together with the other included variables (satisfaction with resp. family relationships, physical activity, leisure, social participation and sexual activity) they explained $56 \%$ of the variance in overall life satisfaction.

Gortner et al. asked patients pre-operatively about the expected benefits and postoperatively about the realization of these (Gortner, Gilliss et al. 1985). As expected benefits the prolongation of life, the prevention of a myocardial infarction, freedom from pain, improved quality of life and increased activity were mentioned by most respondents. At six month after surgery more than $80 \%$ reported the realization of the first 4 benefits, whereas only $61 \%$ had been able to increase their activity levels.

King and Parrinello investigated with a multiple measurement design how CABS= patients were 'feeling in general' from before to 8 weeks after surgery (King \& Parrinello 1988). Most subjects reported feeling fair or good during the first 2 weeks after discharge. The weekly reports from 2 to 8 weeks post-CABS show a gradual increase in the amount of people feeling good or excellent from 45 to 95 $\%$ ). Although they also find gradual improvement (starting in the first week after discharge) in the areas of sleeping, bowel function, appetite and somewhat less in fatigue, the authors do not relate these factors to the reported general feeling.

In summary, the studies on the well-being or quality of life of CABS-patients have focused mainly on the improvements after surgery. Mast studies used retrospective designs. As the concepts (well-being / quality of life) are rarely defined the operationalizations differ greatly among the studies, and are often limited to (objective) indicators. It seems that relief of symptoms and increased satisfaction with social activities contribute especially to perceived improvements of quality of life. 


\subsubsection{Testing of Orem's Theory}

Silva (Silva 1986) suggested that every report on a theory testing study ought to include an overview of the state of the art on testing that theory. In this case the literature has been reviewed for research studies examining the relationships as proposed by Orem. Several studies were found that either implicitly or explicitly aimed at testing Orem's propositions and assumptions. The majority dates from after 1985, which was the last year Silva included in her literature search.

Most of the studies testing Orem's theory deal with the influences of basic conditioning factors on self-care agency and/or self-care action, or with the relationship between the two latter concepts. A few include the outcome variables of state of health and well-being. Harper's study (Harper 1984), which was described by Silva as an example of theory testing research, is the only one found which involves propositions from Orem's Theory of Nursing Systems. The research studies that were found looking at basic conditioning factors, self-care agency, selfcare, health and well-being, all but one used correlational designs. They are discussed below in chronological order.

Brugge (1981) studied the influence of the basic conditioning factors health state, gender, and a specific aspect of family system elements (social support) on the exercise of self-care agency. From her discussion it does not become clear whether she intends to measure self-care or self-care agency. Brugge hypothesized that a curvilinear relationship exists between family as social support system and exercise of self-care agency, when the effect of gender was statistically controlled. This curvilinear pattern was not explicitly proposed by Orem, but Brugge derived it from the conceptualization of social support and the independence-component of self-care. Next, she expected health related dysfunction to be inversely related to exercise of self-care agency, again when the effect of gender was statistically controlled. Lastly, it was predicted that the cumulative predictive effect of social support and health status upon exercise of self-care agency was greater than the predictive ability of either independently. The hypotheses were tested in a sample of 51 adults with a diagnosis of diabetes mellitus of at least 3 months duration. It was found that social support and exercise of self-care agency were moderately, significantly, positively correlated. The pattern however, was linear rather than the hypothesized curvilinear relationship. Healthrelated dysfunction was indeed found to be negatively related to exercise of selfcare agency to a moderate degree. And also the cumulative predictive effect of the two independent variables was greater than that of either independently. However, gender was not found to be related to exercise of self-care agency. Additionally, Brugge ran analyses to examine the influence of other basic conditioning factors: age, education, and duration of sickness. Although the findings were in the expected direction, they were not significant. Brugge concludes that the findings support Orem's model. Nevertheless, she expresses some concerns about the validity of the Exercise of Self-Care Agency-instrument (Kearney and Fleischer 1979). 
The purpose of Dodd's study among cancer patients receiving chemotherapy was to assess the effect of different types of information on the patient's (1) chemotherapy knowledge, (2) self-care behavior, and (3) general affective state (Dodd 1984). Significantly positive effects were found for receiving drug information on chemotherapy knowledige, and for information on side effects management techniques on self-care behaviors. A group who received combined information did not have significantly higher scores for chemotherapy knowledge or self-care than the single information groups. Combined information did not produce a significantly improved affective state. The combined effect of more chemotherapy knowledge, which can be interpreted as increased self-care agency, and improvement in selfcare was not demonstrated to influence the cancer patient's mood (well-being), as measured with the Profile of Mood States Questionnaire.

Burns (Burns 1985) implicitly tested the influence of the basic conditioning factor of living arrangements on the relationship between self-care agency and self-care. She was mainly concerned with the relationship between self-care agency and the fulfilment of a specific uniwersal self-care requisite. The purpose of the study was to explore how chronically ill individuals utilized their self-care agency to meet the need for solitude and social interaction. The major problem was to identify if there was a difference in the way self-care agency was used to meet this need among three groups of chronically ill individuals: those living in a residence, those being cared for in a nursing home, and those being cared for in a hospital. It was concluded thiat there was no difference among these three groups, and that they all demonstrated the ability to meet this particular universal self-care requisite. Thus, no influence of the basic conditioning factor 'living arrangements' on the relationship between self-care agency and self-care could be identified.

Braun (Braun 1987) investigated the relationships between basic conditioning factors, self-care agency, self-care behavior with respect to health promotion (smoking, drinking, daily exercise, etc.), and health perception, in a sample of employed adults. None of the measured basic conditioning factors (age, gender, marital status and formal education) was significantly related to performance of health promoting self-care behaviors. Both gender and age however, emerged as more clearly related to self-care agency than the other two basic conditioning factors. Moreover, self-care agency was significantly correlated to health promoting self-care behaviors on the one hand, and health perception on the other.

The purpose of Bach's study (Bach 198i8) was to determine the extent to which certain basic conditioning factors, perceived control of activities of daily living, and depression explain life satisfaction in quadriplegic adults. Bach contends that she used Orem's model as conceptual framework for her study. However, she does not explain how she perceives that the concepts perceived control of activities of daily living and depression fit in Orem's Theory. It seems as though control of activities of daily living is perceived as equivalent to self-care. Bach states "If the client is able to meet his self-care needs, he should feel satisfied with his life. If he is unable to meet his self-care needs, depression may result" (Bach 1988, p.7). Putting it this 
way, depression can be interpreted as the negative component of well-being, or as an indicator of health state. Bach does not comment on this. Multiple regression analysis showed that the level of depression was the only direct indicator of quality of life. Some of the basic conditioning factors (age and duration of spinal cord injury) and one aspect of perceived control of activities of daily living (so-called evening-ADL) contributed indirectly to quality of life through their direct relationship with the depression variable. The unclear conceptualization of this study makes it very difficult to draw any conciusions about testing of relationships within Orem's theory.

Davidson (Davidson 1988) found in a study among 270 elderly Mennonite subjects, that health promoting behaviors as self-actualization, health responsibility, exercise, nutrition, interpersonal support and stress management related significantly to exercise of self-care agency. These behaviors were also significantly related to perceived health status and occupation.

Van Achterberg (Van Achterberg 1988) conducted a study among young, healthy Dutch adults (age 18-25), to test the proposed influence of gender on self-care agency. Although on the average the female subjects scored higher than the male subjects, this finding was not significant. In addition, Van Achterberg found that indicators of the basic conditioning factors sociocultural orientation, life experience and health were significantly related to self-care agency.

Hanucharumkul (Hanucharurnkul 1988) developed a research model based on Orem's theory to test the hypotheses that 1) the quality of life of cancer patients was predicted jointly by basic conditioning factors, self-care and social support; and 2) the self-care of cancer patients was predicted by basic conditioning factors and social support. The study was conducted in Thailand. Hanucharurnkul preferred the concept of quality of life over the concept of well-being, as in Thailand the latter carries the meaning of "healthy and wealthy". Unlike Brugge, Hanucharurnkul used social support as operationalization of the theoretical concept dependent care agency, and consequently predicted a linear relationship between social support and self-care. The basic conditioning factors included in this study among 112 Thai patients diagnosed with cervical cancer or head/neck cancer, were age, marital and socioeconomic status, living arrangements, stage and site of cancer (health state). Multiple regression analyses revealed that self-care accounted for the greatest portion of variance $(62 \%)$ in quality of life. Site of cancer and occupational prestige were two additional predictors of quality of life. Social support and stage of cancer contributed indirectly. Age, marital status, and living arrangements did not contribute to quality of life. The greatest predictor for self* care was social support $(35 \%)$. Occupational prestige was the only other variable explaining a significant portion of the variance in self-care. In this case the health state variables contributed indirectly to self-care. Age, marital status, and living arrangements did not relate significantly to self-care. 
Denyes (Denyes 1988) used data collected in five studies among a total of 369 American adolescents to test some of Orem's propositions from the theories of self-care and self-care deficit. She explored the problem of Orem's use of the concept of health state both as basic conditioning factor as well as outcome variable: Referring to Orem's dual use of the concept, and the different ways in which it is described, Denyes suggested different operationalizations for the concept of health state. Based on Orem's work, Denyes conceptualized presence or absence of health problems as basic conditioning factor, and a measurement of general health state as outcome. This interpretation is supported by the results of different regression analyses. Self-care and self-care agency were shown not to be predictors of presence of health problems. However, both concepts were significant predictors of general health state. Together they accounted for $39 \%$ of the variance, with self-care accounting for $35 \%$. Further, two stepwise multiple regression analyses showed that presence or absence of health problems was a significant predictor of both self-care agency, as well as self-care, albeit that it only explained less than $2 \%$ of the variance in both variables. The only other basic conditioning factor that showed as a predictor of self-care agency was the number of siblings. Self-care agency levels were higher in adolescents who had fewer siblings. However the contribution of this factor was wery small also. Age, gender, educational level and birth order were not related to self-care agency. In the case of explaining the variance in self-care, age was the only other predictor: Younger adolescents reported higher levels of self-care action. Still, together with presence of health problems, it only accounted for $3 \%$ of the variance in self-care. As far as the relationship between self-care agency and self-care was concerned, Denyes reported a Pearson product-moment correlation of $\mathrm{I}=.38, \mathrm{~g}=.000$. The combination of the available basic conditioning factors and self-care agency accounted for $16 \%$ of the variance in self-care.

In 1989 Frey and Denyes (Frey \& Denyes 1989) reported on another study among adolescents: 39 diabetics. The research model included basic conditioning factors (age, gender, health state as number of health symptoms, birth order, socioeconomic status, religious participation and mother'si employment outside the home), universal self-care, health-deviated self-care, general health state and control of pathology. Universal self-care was predicted to have a positive effect on general health state, while health-deviated self-care was predicted to have a positive effect on control of pathology. The basic conditioning factors age and health symptoms were the only predictors of universal self-care. Youths with fewer health symptoms and who were younger reported engaging in higher levels of universal self-care. Number of health-symptoms, together with universal self-care explained $64 \%$ of the variance in general health state. None of the basic conditioning factors correlated with health-deviated self-care. Health-deviated selfcare explained $21 \%$ of the variance in metabolic control of the pathology of the diabetics. The correlation between universal self-care and health-deviated self-care was moderately strong $\mathrm{r}=.62, \mathrm{p}<.001$. 
In summary, several of Orem's propositions have been tested in young, adult, elderly, healthy and not healthy populations, using different types of instruments. The results were not too different from one another, nor from predictions based on Orem. However, the basic conditioning factors gender, living arrangements, marital status and education were generally found to be unrelated to self-care and selfcare agency. Age sometimes showed to be unrelated, while in a few studies under adolescents age was slightly negatively related to self-care. Occupational prestige in Thai cancer patients was positively related to performance of self-care; whereas socioeconomic status showed to be negatively related with self-care in a sample of American adolescents. Social support was found to be positively related to selfcare and exercise of self-care agency. Since the concept of social support is not part of Orem's model, and since it is not obvious where to place it, it is not clear whether such a finding is supportive of Orem's theory. Several aspects of an individual's health state were shown to be related to self-care and self-care agency. Next, self-care agency continued to be related to self-care in different types of samples.

Only three studies dealt with the concept of well-being; although two researchers chose the term quality of life, and Dodd limited herself to measuring affective state. It was concluded that the significance of Bach's study in relation to the testing of Orem's theory is unclear, due to lack of concept clarification. The findings of Hanucharurnkul's study among Thai cancer patients were supportive of the proposed relationship between self-care and well-being. The lack of significant results in Dodd's study may be attributed to the small sample size (only 12 patients received combined information), as well as to the rather limited approach to operationalizing well-being.

One more publication deserves attention in the light of the formulated research question of this study; even though it does not concern a research study. Hartweg (Hartweg 1990) wrote a theoretical article integrating Pender's notion of health promotion with Orem's notion of self-care contributing to well-being. Hartweg contends that self-care directed to health can be distinguished from self-care directed towards well-being. The first type is called health-maintenance and illnessprevention self-care. It leads to health stability, to the structural and functional integrity of the individual. It includes all types of universal self-care requisites identified by Orem, except for the promotion of normalcy in the sense of individualization and personalization; plus the developmental self-care requisites of the first type. The self-care directed towards promotion of well-being includes all universal self-care requisites identified by Orem, except for those directed to prevention of hazards and the component of normalcy with the health stability goal; plus the developmental self-care requisites of the first type. 


\subsection{HYPOTHESES}

In the first chapter three sets of research questions were formulated that deal with the relationships as postulated by Orem. They are depicted in the research model (fig. 2.1.). Some of these questions are of a theory-testing nature, while others are more explorative. In this section, hypotheses in relation to these research questions are derived from Orem's theory and the review of the literature.

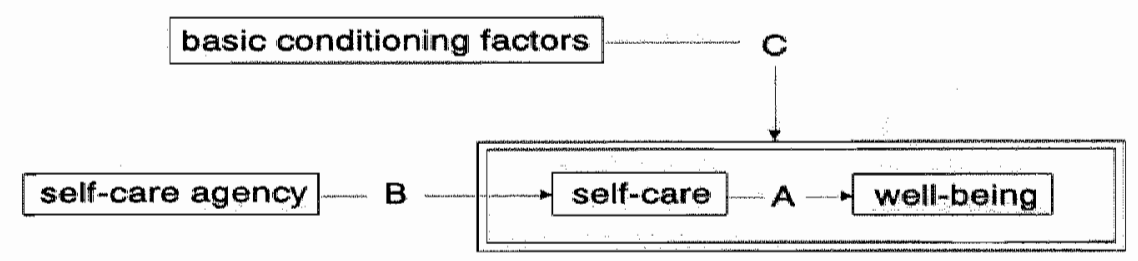

figure 2.1 Research model of this study.

The main research question is worded as:

A 1. Does achievement of self-care requisites contribute to state of well-being ?

It deals with the testing of the second presupposition of Orem's Theory of SelfCare Deficit:

$\star \star \star \star \star$ Self-care as a form of self-regulation is necessary for life itself, for health, for human development, and for general well-being (Orem 1985.

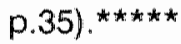

Hanucharurnkul (Hanucharurnkul 1988) studied this relationship among Thai cancer patients and found a strong and positive correlation between self-care and quality of life. A similar result is expected in this study with CABS-patients. The following 5 hypotheses are formulated, of which \#4 and \#5 deal with an attempt to determine time-sequence.

\#1 Achievement of universal self-care requisites is positively correlated with state of well-being.

\#2 Subjects who are successful in achieving specific health deviated self-care requisites have higher ratings of perception of state of well-being.

The disadvantage of the correlational design is that no causal relationships can be determined. However, in this study a longitudinal design with multiple measurements was chosen, which makes it possible to examine aspects of 'timeorder'. Here it is posed that changes that occur in self-care from one moment of 
measurement to the next, will relate to changes in state of well-being over the same period. Besides, it is expected that self-care at one moment is predictive of state of well-being at a later moment in time.

\#3 Changes in achievement of self-care requisites over time
are positively correlated with changes in state of well-being
over time.
Achievement of self-care requisites six months
postoperatively is predictive of state of well-being 12
months postoperatively.

An individual's state of well-being as defined by Orem was interpreted (see section 2.2.1.) as showing a certain amount of stability over time. How a person evaluates his/her life-as-a-whole (condition of existence) will under normal circumstances not change dramatically from day-to-day. Thus the assumption is that state of wellbeing measured at one moment in time is a predictor of, and thus will correlate positively with measurements at other moments in time. Next, achievement of selfcare requisites has also been proposed to contribute positively to state of wellbeing. It can be argued that if fulfilment of self-care requisites indeed contributes significantly to a person's state of well-being, the effect of this predictor should still show after controlling for the person's state of well-being some time before. Such a finding would lend support to the idea that changes that have occurred over time in a person's state of well-being can be attributed partly to achievement of self-care requisites.

\#5 Achievement of self-care requisites at a certain moment in time will be a significant predictor of perception of state of well-being at the same moment in time, when the effect of perception of well-being at an earlier moment in time is statistically controlled.

Research question $\mathrm{A} 3$ is of a more explorative nature:

A 3. Do different aspects of self-care contribute differently to state of well-being?

Orem does not elaborate much on the proposed relationship between self-care and well-being. There are no real clues as to which requisites are of more importance than others in relation to well-being. For example, do the health deviated requisites have more impact than the developmental, or does the maintenance of a balance between activity and rest have more relevance for perceived well-being, than the maintenance of a balance between solitude and social interaction? Orem does not make any order explicit. Most emphasis seems to be on the universal self-care requisites as they are always present, and in the description of what they are, Orem includes their association with general wellbeing (Orem 1985, p.90). On the other hand, Orem states on the same page that "When the thres types of requisites are effectively met, they are productive of 
human and environmental conditions that .......... promote general well-being 1 (Orem 1985, p.90); Thus it can be hypothesized that the greatest amount of variance in state of well-being can be explained by a combination of the three types of requisites:

\#6 The cumulative contribution of the achievement of healthdeviated and universal self-care requisites in the explanation of the variance in the state of well being is greater than the contribution of each of these types by themselves.

Still, no statements are made about the separate contributions of each of the requisites. On the contrary, Orem expresses the need for explication: "One aspect of the development of areas of knowledge about the self-care requisites is the explication of the relationships among them (Orem 1985, p.93). A clue can be identified in Orem's discussion on the fulfilment of universal self-care requisites. Orem states that when unfavorable conditions occur, the fulfilment of these requisites often looses its routinelike character (Orem 1985, p.95). In this study the self-care and the well-being of persons with cardiac health problems are examined. It is therefore not unlikely that for cardiac patients the achievement of some of the universal self-care requisites is of more importance than that of some of the others. Therefore it becomes interesting to investigate the following hypothesis:

\#7 The achievement of different aspects of the self-care requisites contribute equally to the state of well-being.

The results of the analyses in relation to the first seven hypotheses will also show some light on the matter of the stability of the relationship between self-care and state of well-being, as was worded in research question A2.

The second set of research questions is pictured as arrow $B$ : the effect of self care agency on self-care and well-being.

B 1. Does self-care agency relate to achievement of self-care requisites ?

B 2. Does self-care agency relate to state of well-being after controlling for achievement of self-care requisites ?

Obwiously, Orem puts forth a positive relation between abilities for and performance of self-care. Hypothesis \#8 tests the following propositions; from the theory of selfcare-deficit:

*** Persons who take action to provide their own self-care or care for dependents have specialized capabilities for action (Orem 1985, P.35).

A similar statement but in different wordings is found in the theory of self-care:

***** Self-care (or dependent care) as a process or system results from the individual's deliberate use of conceptualized processes or technologies to 
meet known self-care requisites (Orem 1985, p.36).

\#8 Self-care agency is positively correlated with achievement of self-care requisites.

It was discussed in paragraph 2.1.4. that Orem perceives fulfilment of self-care and not abilities for self-care as contributing to well-being. It follows that there can only be an indirect relationship between self-care agency and well-being. The next hypothesis combines all three aforementioned propositions and presuppositions.

\#9 Self-care agency is positively correlated with state of wellbeing; but this relationship disappears after statistically controlling for achievement of self-care requisites.

The findings of Burns (Burns 1985), Braun (Braun 1987) and Denyes (Denyes 1988 ) are in support of the expectation stated in hypothesis \#8. No studies were found in the literature that report on findings in relation to the 9 th hypothesis.

The third set of research questions relates to the influence of the basic conditioning factors.

C 1. To what extent do basic conditioning factors influence self-care?

As for this question Orem formally states the influence of particular basic conditioning factors in a proposition in the theory of self-care:

***** Universal self-care requisites and ways of meeting them may be modified by the age, sex, or developmental or health state of individuals (Orem $1985, \mathrm{p} .36)$.

Orem does not include all eight basic conditioning factors in this 'official' statements. However, based on her definition and description of basic conditioning factors it can be concluded that she postulates relationships between all factors and self-care.

The study at hand includes the measurement of 5 basic conditioning factors: age, sex, sociocultural orientation (socio-economic status), health care system elements and health state. Orem does not describe the direction of the influience of most of the basic conditioning factors. Except for the factor health state, the findings from other studies testing Orem's theory do not give strong indications either, as to what type of relations are to be expected. Therefore, no directions of correlations are predicted in the first three hypotheses related to the second research question.

\#10 Men and women differ in their achievement of self-care requisites.

\#11 Age is correlated with achievement of self-care requisites.

\#12 Socio-economic status is related to achievement of selfcare requisites. 
Orem describes Health Care Systems as being constituted from actions deliberately selected and performed by individuals. They include self-care within the context of daily living, but also the care and service provided by the different types of health care professionals. In the performance of their different roles, these professionals should be able to contribute to the formation of effective health care systems (Orem 1985, p.204). Health Care System Factors that influence the patient variables therapeutic self-care demand and self-care agenoy, include (1) the medical diagnostic and treatment measures used by the physician, (2) measures prescribed by the physician for performance by medical specialists or technicians, and (3) measures prescribed for incorporation into the continuing care systems of individuals (Orem 1985, p.221-222). In the case of CABS-patients such measures might include changes in lifestyle, engage in physical therapy, learning to live with the idea/consequences of being a heartpatient. It can be considered the task of the different health care professionals to perform or assist with these measures. If the health care system is not successful in this performance or assistance, individuals are likely to experience difficulties with their health-deviated and universal self-care. Therefore, received professional help after discharge from the hospital is predicted to have a positive influence on self-care.

\#13 Persons with sufficient posthospital professional help have better achievement of self-care requisites than persons with insufficient help.

Different indicators of cardiac health serve as operationalizations of health state. Pre-operative myocardial infarction, a long history of cardiac disease and postoperative recurrence of chest discomfort are indicators of a less good health state. Next, it is assumed that the health state improves after CAB-surgery.

\#14 Preoperatively, persons with a history of myocardial infarction have a lower achievement of self-care requisites than persons without a history of myocardial infarction.

\#15 Preoperatively, persons with a long history of cardiac disease, have a lower achievement of self care requisites than persons with a recent diagnosis of cardiac disease.

\#16 Postoperatively, persons have a higher achievement of selfcare requisites than before CAB-surgery.

\#17 Persons who experience a recurrence of chest discomfort after surgery have a lower achievement of self-care requisites than persons who do not.

It is conceivable that such basic conditioning factors as gender, age, health state and sociocultural orientation also affect individual well-being directly or that they have an impact on the relationship between self-care and well-being. Although there is no proposition formulated on this, it seems that in Orem's model the influence of basic conditioning factors on state of well-being would be explained by their effect on self-care. Nevertheless, research and theorizing in other disciplines 
Ink factors such as age, gender, and health state directly to concepts as wellbeing, life satisfaction or quality of life. To explore whether and how the basic conditioning factors and well-being are related, research question $\mathrm{C} 2$ is formulated:

C 2. To what extent do basic conditioning factors influence state of well-being ?

Seven hypotheses are derived in relation to this question. They are based on the literature study, and as such do not reflect the testing of Orem's propositions.

Veenthoven found that in Western countries older men were happier than older women, whereas young women were happier than young men (Veenhoven 1983). Besides, he found some indications for a relationship between happiness and personal income. In Thai cancer patients "occupational prestige" was found as a predictor for quality of life (Hanucharurnkul 1988). Thus, the hypotheses were formulated as follows:

\#18 There is an interaction effect of age and sex on state of well-being.

\#19 Sociomeconomic status is positively correlated with state of well-being.

Rombouts c.s. (Rombouts, Jambroes et al. 1984) found that post-CABS patients with an unanswered need for assistance, reported more often depression, anxiety, uncertainty, bad moods and being easily emotional and irritated, than patients without such an unanswered need.

\#20 Persons with sufficient posthospital professional help have higher states of well-being than persons with insufficient help.

Objective health state indicators, health complaints and self-rated health have all been found to be related to happiness, quality of life and well-being (veenhoven 1983; Aombouts, Jambroes et al. 1984; Flynn and Frantz 1987; Hanucharurnkull 1988).

\#21 Preoperatively, persons with a history of myocardial infarction report a lower state of well-being than persons without a history of myocardial infarction.

\#22 Preoperatively, persons with a long history of cardiac disease, report a lower state of well-being than persons with a recent diagnosis of cardiac disease.

\#23 Postoperatively, persons report a higher state of well-being than before $\mathrm{CAB}$-surgery.

\#24 Persons who experience a recurrence of chest discomfort after surgery report a lower state of well-being than persarus who do not. 
It was pointed out before that in the theory of Orem the relationships between basic conditioning factors and state of well-being could probably be explained through the achievement of self-care requisites. Therefore in the analysis chapter the hypotheses will also be examined after controlling for achievement of self-care requisites.

The last research question is again more explorative and expresses the possibility of an influence of the basic conditioning factors on the relationship between selfcare and well-being. It is not unthinkable that the relationship is different for men and women, or for the young and the old.

C 3. Do basic conditioning factors affect the relationship between self-care and state of well-being?

The literature shows no studies in favor of this type of influence. Thus, the hypothesis is formulated that no differences are expected in this regard.

\#25 The correlation between achievement of self-care requisites and state of well-being is not affected by the basic conditioning factors.

\subsection{SUMMARY}

In the first chapter three sets of research questions have been formulated for the purpose of testing and refining Orem's notions on the relationship between selfcare and state of well-being. This chapter has dealt with the theoretical framework of the study. Firstly, Orem's notions on the conceptualizations of and on the interrelationships between self-care, state of well-being, self-care agency and the basic conditioning factors have been presented. Then the literature was reviewed on predictors of well-being, and especially in relation to the well-being of persons undergoing coronary artery bypass surgery. The results of nursing studies which examined the relationships that are studied in this thesis, have been discussed as well. On the basis of Orem's propositions in combination with findings in the literature 15 hypotheses were formulated to actually test the theory. An additional 10 hypotheses were formulated for the purpose of refinement of Orem's theory. They stem from the exploring research questions (A3, C2 and C3), and are based on the research findings in the literature.

The next chapter presents the methods used in this study, as well as the descriptive statistics on the major variables of study. The results of the testing of the hypotheses which have been formulated here are described in chapter 4 . 


\section{CHAPTER 3 METHOD}

The study described here is part of a series of interrelated studies designed and conducted by a group of researchers from the nursing departments of the University of Limburg in Maastricht, the Netherlands, and Wayne State University in Detroit, U.S.A. The main purpose of this international research program is the testing of Orem's theory. The data described in this study stem from a project in which the major focus is on the testing of the relationships between health state, self-care agency and self-care. Changes in health state of cardiac patients, as induced by coronary artery bypass surgery (CABS) is hypothesized to have influence on the self-care needs and abilities of the individuals. The studies of this project are conducted in Detroit in the U.S.A., and in Groningen and Maastricht in the Netherlands. The Dutch studies are financially supported by the Netherlands Heart Association. In this thesis, only the data on the bypass patients from Limburg (the Netherlands) are used for the testing of the relationship between self-care and well-being. The projectleaders of the Limburg-study are prof. dr. M. Isenberg from Wayne State University in Detroit, and prof. dr. H. Philipsen from the University of Limburg.

In this chapter the research method of the study among the CABS-patients in Limburg is described. Firstly, design and sampling method are presented. The third section deals with the operationalization of the concepts identified in the research model. Next, the procedure followed in the data collection and data analysis is explained. The chapter ends with the presentation of the descriptive statistics of the variables used in this study.

\subsection{DESIGN}

For the purpose of examining the changes over time in the major variables, a longitudinal design is used in this study. The design includes four moments of measurement; one pre-operative, and 3 posthospitalization measurements at 3 predesignated time-intervals (figure 3.1 ).

Firstly, data have been collected before CAB-surgery. This phase took place in the hospital one day before surgery, usually the day of admission. The posthospitalization data collection was planned for both 6 and 12 months after surgery. In this phase subjects were visited twice in their homes. Later it was 


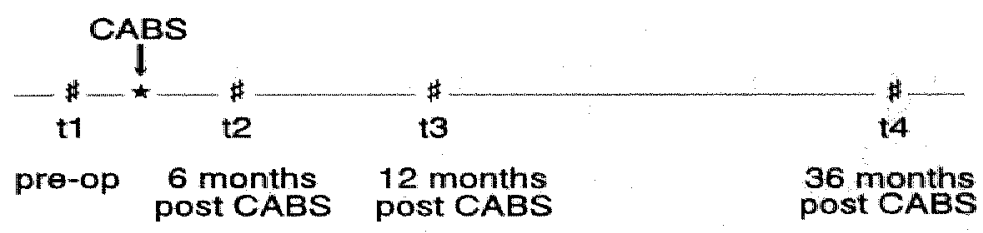

figure 3.1

Research Design

decided to conduct a third follow-up measurement. Three years after CAB-surgery subjects were contacted by phone, and those who were willing to continue participation received a mailed questionnaire. Data collection started January 1987 , and was completed June 1990.

\subsection{SAMPUNG-METHOD}

The method of time-bound sampling is used. All patients admitted to the Academic Hospital in Maastricht (AZM) for CAB-surgery within the designated research period of 5 months, who met the outlined study-criteria were asked to participate. Persons were excluded from the study if they

1) were to have emergency surgery;

2) were not able to read/write Dutch;

3) were not Dutch-born;

4) had a psychiatric disorder;

5) were suffering from another life-threatening disease;

6) suffered from a pre-operative infection; or

7) had next to CAB-surgery, another type of cardiac surgery (for example valve-replacement).

During the designated research period of 20 weeks a number of $152 \mathrm{CAB}$ surgeries were conducted in the Academic hospital. Of these 152, a total of 29 persons did not meet the outlined study-criteria (20 because of emergency surgery; 2 because they could not read or write; 4 were not Dutch; 1 was diagnosed with Hodgkin-disease, 1 other with severe kidney-problems; and 1 with pre-operative infection). Thus, a total of 123 persons were asked if they were interested in participating in this particular research study. They were 90 men and 33 women, with a mean age of $M=60.3$. Seven women and nine men refused to participate, mostly for reasons of minirnizing tension during their hospital stay. A total of 107 persons entered the study, and completed the first phase of data collection. 
At 6 and 12 months after CAB-surgery, 98 of these 107 persons were visited in their homes, and thus participated in the second phase of datacollection. Three men had died within a year after their surgery, while four women and two men preferred to discontinue their participation due to lack of time or interest. In the last phase of the study three years after their surgery, all 98 persons were contacted by phone. Eighty-nine of them indicated that they were interested in filling out the questionnaire one more time. One woman and one men had died since the last contact, whereas seven persons opted not to participate in the last phase. Thus, during the first 5 months of 1990, eighty-nine questionnaires were sent out. Eightytwo were received back without delay. After sending the other seven a written reminder, 4 more questionnaires were returned. A total of 86 completed questionnaires were received three years after CAB-surgery.

Only the data of the 86 persons who participated in all 4 phases of the study are used in the testing and exploring of the formulated research questions and hypotheses. Of the 123 persons who met the outlined study-criteria $26.8 \%$ were women; in the final sample $(\mathrm{N}=86) 23.2 \%$ were females. As relatively more women than men refused or discontinued participation, women seem to be slightly underrepresented in the research sample. However, analysis performed on the nonresponse $(\underline{n}=16)$ and the dropout $(\underline{n}=21)$ revealed (appendix l) that as far as mean age and gender-distribution are concerned, the final research sample is not significantly different from the original group of 123 persons who were eligible to participate.

\subsection{OPERATIONALIZATON OF THE CONCEPTS}

The four major concepts of this study have been identified in the research model as state of well-being, self-care, self-care agency and basic conditioning factors. In this section the operationalization of these concepts into fifteen variables will be described. State of well-being is measured with one instrument: Cantril's SelfAnchoring Life Satisfaction Scale (1). Universal self-care is measured with the SelfCare Inventory (2), in which three subscales are distinguished: NUB (2a), SIB (2b) and RAB (2c); whereas specific health deviated self-care requisites are operationalized in questions on smoking (3) and exercise (4). The Appraisal of Selfcare Agency Scale (5) is used to measure self-care agency. Indicators of the basic conditioning factor health state are history of myocardial infarction (6), duration of cardiac disease $(7)$, and chest discomfort (8). Moreover the pre- and postoperative health states are assumed to be different. Lastly, the other basic conditioning factors are operationalized by measures of age (9), gender (10), socio-economic status (11) and posthospital use of professional health care (12). 


\subsubsection{State of Well-being}

The first variable concerns the operationalization of state of well-being: It has been described in chapter 2 that Orem uses the concept of state of well-being in a subjective way. State of well-being in Orem's perspective cannot be observed by simply summing up the values of a set of certain objective factors like income, education, marital status, socio-economic status, etc. The state of well-being of the individual, according to Orem is determined by how the individual appraises his/her own situation. Or in Orem's words "the perceived condition of existence". For this reason, Cantril's Self Anchoring Life Satisfaction Scale was chosen in this study to measure the state of well-being. This instrument is based on a subjective and completely individual appraisal of a person's life in relation to his or her own expectations and ideals.

In using this instrument, the following text is read to the respondent:

"All of us want certain things out of life. When you think about what really matters in your own life, what are your wishes and hopes for the future? In other words, if you imagine your own future in the best possible light, what would your life look like then, if you are to be happy? Take your time in thinking about this.

Now taking the other side of the picture, what are your fears and worries about the future? In other words, if you imagine your future in the worst possible light, what would your life look like then ?"1

\begin{tabular}{|c|}
\hline 10 \\
\hline 9 \\
\hline 8 \\
\hline 7 \\
\hline 6 \\
\hline 5 \\
\hline 4 \\
\hline 3 \\
\hline 2 \\
\hline 1 \\
\hline 0 \\
\hline
\end{tabular}

BEST POSSIBLE LIFE

WORST POSSIBLE LFE

figure 3.2

Cantril's Self Anchoring Life Satisfaction Scale

Subsequently, the respondent is shown a ten-step ladder-like rating scale (figure 3.2), and asked to imagine that the top of that scale represents the best possible 
life as the respondent has just described it and the bottom the worst. Then the interviewer asks:

"Where on the ladder do you feel you personally stand at the present time ?"

Since its development in 1963 Cantril's instrument has been used continuously by researchers as a measurement of 'global well-being'. Veenhoven (1984) as well concluded that Cantril's instrument was a valid instrument for measuring the concept of overall happiness. His conceptualization of happiness was found to match Orem's notion of well-being. In her study among Thai cancer patients Hanucharurnkul (1988) applied Cantril's Ladder as a second measurement of quality of life, next to Padilla and Grant's Quality of Life Index for Patients with Cancer. She found a correlation of $\underline{r}=.76 \quad(\mathrm{p}<.01 ; n=111)$ between the two instruments, as well as similar patterns of correlations with the other variables in the study (among which basic conditioning factors and self-care).

The reliability of Cantril's instrument is more difficult to determine, as the error variance cannot be computed since there is no "true score". However, since the self-defined anchoring points are entirely' individual, these end points probably remain relatively constant over a short period of time which minimizes the error variance. The strength of this instrument, the allowance of the unique perspective of the respondents in establishing the extremes of the scale, can also mean at the same time a disadvantage, as it hinders the comparison of absolute scores between respondents. However, in this study we are not so much interested in differences in absolute scores between individuals. The intention of this study is to compare the ratings of individuals on the Ladder with the scores of these individuals on other instruments.

Cantril's Ladder was administered pre-operatively, 6, 12, and 36 months after CABsurgery.

\subsubsection{Self-care}

Orem describes self-care as purposeful action. The purposes to be attained through this type of action are the universal, developmental and health-deviated self-care requisites. The universal requisites represent needs for self-care that every human being has during all stages of the life cycle. Developmental self-care requisites are present during specific stages of the life cycle, and health-deviated self-care requisites arise from the presence of health problems. These requisites are directly or indirectly related to the underlying pathology. In this study, the focus is on universal and health-deviated self-care. The population at hand is not so much in a certain stage of life, but is better described as suffering from a specific health problem: coronary artery disease.

Action or behavior can be measured 'directly' by the method of observation. This method is very time-consuming (especially when measuring self-care action which takes place 24 hours a day); besides the criteria for scoring behavior are not as self-evident as they may seem. A more indirect way of measurement would be 
asking persons questions about their behavior or the type of actions they take. These would be questions like "what do you (usually) do"; what would your reaction be" or "what would you say". When the behavior that you want to know more about has a purpose, like self-care action, this behavior allows for another focus of measurement: Are the purposes met, has the behavior been successful ? We chose in this study for this last option; self-care is operationalized as the extent in which self-care requisites are achieved; in other words it is measured how effective the self-care has been. Operationalizing self-care in this way makes sense in this particular study, as it was derived from the theory that it is the satisfaction of the self-care needs, and not the self-care behavior that contributes to well-being.

\section{Universal self-care}

The extent in which people meet their universal self-care needs is measured by the Self-Care Inventory (SCl). This instrument is developed through adjustment of the Patient Recovery Inventory as developed by Eisler, Wolfer and Diers (Eisler, Wolfer and Diers 1972). The Patient Recovery Inventory elicits a subject's assessment of his/her condition. The adjusted version (SCl) includes all the aspects of the universal self-care requisites as stipulated by Orem (Gazda 1986). Patients are asked to rate on a five-point scale each need (the higher the score, the better the need is met). For example, how would you rate 'your sleep' over the course of the past month; or how would you rate 'your appetite' over the course of the past month, etc. Summation of the scores gives an overall assessment of achievement of a person's universal self-care needs. The SCl-instrument was translated into Dutch for this study. The original 5-point-scale was replaced by a 10-point-scale (figure 3.3), which was perceived to be more meaningful for Dutch persons. In the Netherlands a score of 10 is associated with 'excellent' / 'could not be better'. In the Dutch version of the $\mathrm{SCl}$ it signifies perfect fulfilment of the universal self-care requisite. As the instrument contains 11 items, the total score can vary theoretically from 0 (extremely poor achievement of universal self-care requisites) to 110 (excellent achievement of universal self-care requisites).

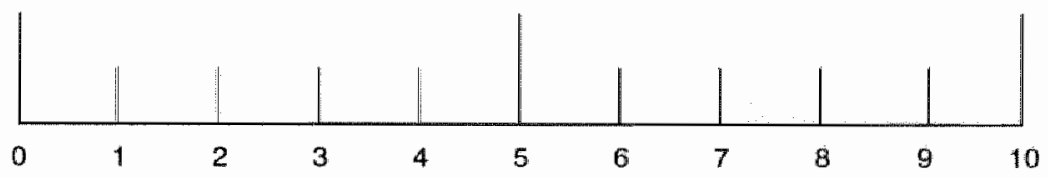

figure 3.3

The 10-point-scale on which the achevement of the universal requisites are rated.

In this study Cronbach's $\alpha$ has been computed for every measurement of the SelfCare Inventory $(\hat{N}=86)$, it can be concluded that the Inventory is internally consistent: pre-operatively

6 months post-CABS

$\alpha=.78$

12 months post-CABS

$\alpha=.81$

36 months post-CABS

$\alpha=.85$

$\alpha=.88$ 
Principal component factor analysis revealed 3 subscales within this instrument, which correspond with different types of Orem's universal self-care requisites (appendix II). The first subscale (NUB) consists of 4 items (appetite, stomach condition, bowel condition and urination) which describe the achievement of needs related to intakes of air, water and food, as well as those related to eliminative processes (the NUtrition Balance). The second subscale (SIB) consists of 2 items (interest in surroundings and social activities) which measure the fulfilment of needs for social interaction (Social Interaction Balance). Lastly, the third subscale (RAB) contains 5 items (sleep, strength and energy, movement, satisfaction with sexual activities and self-assistance) which can be grouped as reporting on the achievement of resit and activity needs (Rest - Activity Balance). The three subscales were standardized by the computation of mean scores over the items. The theoretical minimum score of each subscale then is 0 (extremely poor achievement), and the maximum score is 10 (excellent achievement).

The following Cronbach $\alpha$ 's for the 3 subscales, at the 4 points in time were found $(\mathbb{N}=86)$ :

$\begin{array}{llll} & \text { NUB } & \text { SIB } & \text { RAB } \\ \text { pre-operatively } & \alpha=.68 & \alpha=.59 & \alpha=.74 \\ 6 \text { months post-CABS } & \alpha=.75 & \alpha=.66 & \alpha=.73 \\ 12 \text { months post-CABS } & \alpha=.83 & \alpha=.65 & \alpha=.73 \\ 36 \text { months post-CABS } & \alpha=.78 & \alpha=.68 & \alpha=.79\end{array}$

The second variable of the study the Self-Care Inventory has been administered pre-operatively, as well as six, twelve and thirty-six months atter CAB-surgery.

\section{Health-deviated self-care}

The design of this study included the measurement of the attainment of healthdeviated self-care behaviors of the third category (section 2.1.2.): self-care aimed at the prevention of further development of the pathology. In the case of coronary artery disease, several factors have been identified by research that influence the process of coronary atherosclerosis. They include cigarette smoking, obesity, hyperlipidemia, heredity, emotional stress, physical inactivity and chronic health problems such as diabetes and hypertension (Solomon 1988). Therefore "healthdeviated self-care to prevent the development of new lesions in the arteries would include changing behaviors in relation to smoking, diet and life-style. In this study subjects were asked about their habits in relation to smoking and exercise. Chronic health problems and emotional stress were not part of the research model of the current study nor was heredity.

Variable 3: Subjects were asked whether they smoked cigarettes, how many they smoked, and since when they had been smoking. Subjects who were not smoking at the time of interview, were asked whether they had smoked cigarettes in the past, and since when they had stopped. These questions on the smoking habit were put to the respondent pre-operatively, and 6,12 , and 36 months after $C A B$ surgery. 
Variablle 4: Subjects were asked 6,12 and 36 months post-CAB-surgery whether they exercised routinely, and whether they felt their exercise habits were sufficient.

The answers of the respondents in relation to these 2 health-deviated self-care behaviors were dichotomized for data-analysis. Unfavorable self-care actions (smoking and insufficient exercise) were coded as a 1, whereas favorable self-care actions (not smoking and sufficient exercise) were coded as a 2.

\subsubsection{Self-Care Agency}

Self-care agency is defined by Orem as the complex, acquired capability to engage in self-care action. Based on both Orem's work and the comprehensive concept clarification done by the N.D.C.G. (N.D.C.G. 1979), Brouns, Evers, Isenberg, Philipsen, and Smeets developed the Appraisal of Self-care Agency (ASA) Scale. Based on the combination of the power components and the self-care operations. which are both identified in the concept self-care agency, items were formulated. The questionnaire consists of 24 items and measures the power to perform productive self-care operations. It is a self-appraisal instrument, which has a 5-point-Likert type of scaling. Total scores can vary from 24 to 120 , in which 24 represents minimal, and 120 maximal abilities for self-care. Examples of items included in the questionnaire are:

"l often lack the energy to care for myself in the way that I know I should" and "I eat in a way that maintains my body weight at an appropriate level"

The Dutch version of the ASA-scale was used in this study. Evers (Evers 1989) designed an extensive research program to test the validity and reliability of the questionnaire with a Dutch population. From the results of this study it was concluded that content and construct validity were sufficiently demonstrated, and that the ASA-scale was a reliable, imternal consistent instrument to measure selfcare agency. Evers found a Cronbach's alpha of .77 .

Internal consistency in this study was computed for every measurement. The following alpha"s were found $(\mathrm{N}=86)$ :
pre-operatively
6 months post-CABS
$\alpha=69(\underline{N}=85)$
12 months post-CABS
a. $=.69$
36 months post- Cabs
$\alpha=.75$
$\alpha=.76(\mathrm{~N}=83)$

Before surgery, one person did not complete all the items, while three years after surgery 3 persons failed to complete the ASA-questionnaire. Therefore no total score, nor Cronbach's $\alpha$ could be computed for these persons.

The Appraisal of Self-Care Agency Scale (variable 5) was administered at all four measurement intervals. 


\subsubsection{Basic Conditioning Factors}

The last concept in the research model of this study is basic conditioning factors. Orem identifies eight factors that influence the patient variables self-care agency and self-care needs at points in time. The following 5 factors are included in this study: health state, age, gender, sociocultural orientation and health care system elements. The operationalizations are described below.

\section{Health state}

In section 2.1.3. Orem's description of health state as a basic conditioning factor was interpreted as health in a compound sense. Several indicators of the severity and symptoms of coronary artery disease are used as operationalizations of the cardiac health state of the subjects. They are history of previous myocardial infarction, length of time with diagnosed heart problem, and chest discomfort.

Variable 6: History of Myocardial Infarction (MI). Before their surgery subjects were asked whether they had had a myocardial infarction in the past. The answers were compared with the information in the medical records in as far as such information was recorded. An experienced myocardial infarction was coded as a 1, whereas subjects who had not experienced an infarction were coded as a 2.

Variable 7: Duration of cardiac disease. Before their surgery subjects were asked how long ago they had been diagnosed with a heartproblem. This information was coded in two ways. Firstly, the number of months since the diagnosis of heart disease until the CAB-surgery was recorded. Secondly, this information was dichotomized: subjects who had been diagnosed with a heart problem for less than one year were coded as a 1, and subjects who had been diagnosed for more than one year were coded as a 2 .

Variable 8: Chest discomfort. Chest discomfort is the typical manifestation of coronary artery disease. In coronary artery disease the oxygen supply to the heart muscle is decreased, due to occlusion of the coronary arteries. The typical symptoms of this so-called state of "myocardial ischaemia" are episodes of chest discomfort, which are often related to exertion. Through (successful) CAB-surgery the oxygen supply to the heart is increased, which establishes an improvement in the heart function, and ideally puts an end to the occurrence of chest discomfort. Thus after successful surgical revascularization the health state can be assumed to be better than pre-operatively. However, after CAB-surgery recurrence of chest discomfort is possible. This can be due to incomplete revascularization or reocclusion of the coronary arteries. Recurrence of chest discomfort is interpreted as a sign of a less good postoperative health state.

Frequency of chest discomfort is measured as a product of subjects' self-reports of how many days in a usual week they experience at least one episode of chest discomfort and how many episodes of chest discomfort on the average they have on one of these days. Subjects are also asked to identify any associated 
symptoms that occur with chest discomfort, e:g., dyspnea, palpitations, nausea, etc.

These questions on the presence and manifestation of chest discomfort were asked pre-operatively as well as 6,12 , and 36 months after CAB-surgery. Presence of chest discomfort was coded as a 1 , whereas subjects who did not report chest discomfort were coded as a 2 .

\section{Sociodemographic characteristics}

Age, gender and marital status are interpreted as basic conditioning factors. Biological, developmental as well as cultural differences between younger and older persons as well as between men and women are expected to affect self-care. Marital status represents the factor 'patterns of living'. However, in the sample of this study, the variable marital status did not have sufficient variation $(82 \%$ of the sample was married), which made it irrelevant to conduct statistical analyses with this variable. Marital status is therefore not included in this study as a basic conditioning factor.

Variable 9: Age. The age of the respondent at the time of CAB-surgery has been recorded.

Variable 10: Gender. Men were coded as a 1; women as a 2.

\section{Sociocultural orientation}

Under this basic conditioning factor Orem groups the following characteristics: national origin, language, place of residence, religious orientation, and nature of occupational or education endeavors (Orem 1985, p.164). The bypass-patients in the sample of this study were all Dutch-born, living in their own homes in the south of Limburg, and were mostly catholic. The main aspect in which any differences in sociocultural orientation could be expected, was through their (former) occupation. Therefore, a measure to determine the socio-economic status was applied.

Subjects were asked about their employment status, about their current or latest occupation, as well as about the amount of years they had gone to school full-time. As the latter is not a very good predictor of socio-economic status in the generation of this sample, subjects were classified according to the social status they received based on their own, or in the case of housewives their husbands' occupation.

Variable 11: Socio-economic status. The classification that was used was developed by the Instituut voor Toegepaste Sociologie in Nijmegen (1975). This classification system contains six categories. The grouping of occupations is based on the following considerations: - whether it is mainly manual (blue or white collar) labor; - what level of schooling is required; - whether one is self-employed or not; if not self-employed: whether one has a supervisory position; - if self-employed: the size of the 'business'. 
The six categories are described as

1) unskilled labor;

2) skilled labor;

3) clerical;

4) owners of small businesses;

5) managerial or administrative employees; and

6) upper-middle class and professionals.

In some of the analyses these 6 categories are diminished to three groups of lower, middle and higher socio-economic status.

\section{Health care system elements}

Variable 12: Contacts with Health Care Professionals After Discharge. Six months after surgery subjects were asked whether they had had any contact with health care professionals after discharge from the hospital. If so, they were asked whether the received help of the specific health professional had been sufficient. If they had not had any contact, they were asked whether they had felt a need to have con-

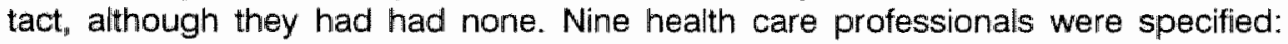
cardiologist, family physician, rehabilitation specialist, physical therapist ${ }_{n}$ dietician, community health nurse, home health aid, psychologist, social worker. The final coding was such that subjects who had experienced either insufficient help or an unanswered need for help were coded as a 1, and subjects who had altogether experienced sufficient heip were coded as a 2 .

\subsection{PRocedure In Data Collection AND DATA ANalysis}

Two weeks before admission, persons who were going to have cardiac surgery visited the cardiologist at the outpatient-clinic. After this visit, the future CABpatients were informed by the data-collectors about the goals and procedure of the study. Other CAB-patients were identified on the day of admission to the AZM. Persons who met the outlined study-criteria were informed about the study, and asked to participate. If they consented in participation, they signed an informed consent form (appendix III). Then, the first questionnaires (demographics, health state, self-care agency) were administered. Thirty-one subjects entered the study through the outpatient-clinic, the other 55 were contacted on their day of admission. Before surgery, data were gathered on demographics, basic conditioning factors, self-care, self-care agency and state of well-being.

Six months after surgery, subjects were contacted by phone at which time an appointment was made to visit them in their homes. Another 6 months later, a year after CAB-surgery, subjects were again contacted by phone, after which 33 participants received a mailed questionnaire, while the other 53 were visited once more by the data collector. The mailing of questionnaires was done for a purpose unrelated to the research questions of this study. It was a test of measurement 
table 3.1 Theoretical concepts and their operationatizations and the time of measurement

\begin{tabular}{|c|c|c|c|c|c|c|c|}
\hline \multirow[b]{2}{*}{ Concept } & \multirow[b]{2}{*}{ Nr. } & \multirow[b]{2}{*}{ Variable } & \multirow[b]{2}{*}{$\begin{array}{l}\text { Theoretical } \\
\text { Range }\end{array}$} & \multicolumn{4}{|c|}{ Data Collacted } \\
\hline & & & & $\begin{array}{l}\text { pre } \\
\text { CABS }\end{array}$ & $\begin{array}{l}6 \mathrm{mth} \\
\text { post }\end{array}$ & $\begin{array}{c}12 \mathrm{mth} \\
\text { post }\end{array}$ & $\begin{array}{c}36 \text { mth } \\
\text { post }\end{array}$ \\
\hline $\begin{array}{l}\text { State of Well- } \\
\text { being }\end{array}$ & 1 & $\begin{array}{l}\text { Cantril's } \\
\text { Ladder }\end{array}$ & $0-10$ & $*$ & $*$ & 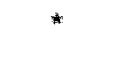 & $\star$ \\
\hline \multirow[t]{4}{*}{$\begin{array}{l}\text { Universal Self- } \\
\text { Care }\end{array}$} & 2 & $\begin{array}{l}\text { Self-Care } \\
\text { Inventory }\end{array}$ & $0-110$ & * & * & $*$ & * \\
\hline & $2 a$ & NUB & $0 \cdot 10$ & $*$ & * & + & $*$ \\
\hline & $2 b$ & SIB & $0-10$ & H & w & $*$ & $*$ \\
\hline & $2 \mathrm{C}$ & $\mathrm{AAB}$ & $0-10$ & $\star$ & $*$ & * & $\star$ \\
\hline $\begin{array}{l}\text { Health-devilated } \\
\text { Self-Care }\end{array}$ & 3 & Smoking & $\begin{array}{l}1=\text { yes } \\
2=\text { no }\end{array}$ & * & * & $\star$ & * \\
\hline $\begin{array}{l}\text { Health-deviated } \\
\text { Self-Care }\end{array}$ & 4 & $\begin{array}{l}\text { Exercise } \\
\text { Sufficient }\end{array}$ & $\begin{array}{l}1=\text { no } \\
2=\text { yes }\end{array}$ & & $*$ & $*$ & $*$ \\
\hline Self-Care Agency & 5 & ASA-A & $24 \cdot 120$ & * & * & * & * \\
\hline $\begin{array}{l}\text { B.C.F. } \\
\text { Health State }\end{array}$ & 6 & $\begin{array}{l}\text { History } \\
\text { of } \mathrm{MI}\end{array}$ & $\begin{array}{l}1=\text { yes } \\
2=n o\end{array}$ & * & & & \\
\hline $\begin{array}{l}\text { B.C.F. } \\
\text { Health State }\end{array}$ & 7 & $\begin{array}{l}\text { Duratiom } \\
\text { card. dis. }\end{array}$ & $\begin{array}{l}1=<1 \text { year } \\
2=>1 \text { year }\end{array}$ & $*$ & & & \\
\hline $\begin{array}{l}\text { B.C.F. } \\
\text { Heath State }\end{array}$ & 8 & $\begin{array}{l}\text { Chest } \\
\text { Discomfort }\end{array}$ & $\begin{aligned} 1= & \text { present } \\
2= & \text { nol } \\
& \text { present }\end{aligned}$ & * & th & * & * \\
\hline B.C.F. Age & 9 & Age & in years & * & & & \\
\hline B.C.F. Gender & 10 & Gender & $\begin{array}{l}1=\text { men } \\
2=\text { women }\end{array}$ & 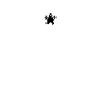 & & & \\
\hline $\begin{array}{l}\text { B.C.F. Socio- } \\
\text { Econ. Status }\end{array}$ & 11 & $\begin{array}{l}\text { Occupat. } \\
\text { Status }\end{array}$ & $1-6$ & $*$ & & & \\
\hline $\begin{array}{l}\text { B.C.F. Health } \\
\text { Care Systems }\end{array}$ & 12 & $\begin{array}{l}\text { Sufficient } \\
\text { Prof Help }\end{array}$ & $\begin{array}{l}1=\text { no } \\
2=\text { yes }\end{array}$ & & * & & \\
\hline
\end{tabular}

N.B. The scores on the subscales NUB, SIB, and FAB are standardized (see section 3.3.2). $N U B=$ nutritional balance; $S \mathrm{~B} B=$ social interaction balance; $R A B=$ rest-activity balance 
conditions in the light of reliability testing of the Appraisal of Self-Care Agency Scale (Evers 1989). No significant differences were found on any of the variables of study. Finally, three years after CAB-surgery subjects were again contacted by telephone, and were re-introduced to the study and its purposes. After this explanation subjects were asked whether they were interested in participating in this last phase of the study. Questionnaires were then mailed to those subjects who had indicated that they were willing to fill out the form once more. The outcome of the test of measurement conditions in the twelve months phase of data collection justified the method of mailing in this phase.

In all postoperative measurements, data were gathered on recurrence of chest discomfort, self-care agency, universal and health-deviated self-care, perception of state of well-being, readmissions, and employment status. Six months after surgery, data were also collected on received professional health care. Table 3.1 presents an overview of the variables of this study and the moments on which they were collected. Throughout all phases of datacollection. all information was gathered through the use of structured questionnaires. During the pre-operative phase the questionnaires were administered by 2 data collectors; the researcher and a nurse data-collector. The researcher collected all the data in the other phases of the study.

In all phases of the study, all questionnaires were coded according to the predesigned codebook by 2 persons: the researcher and the research-assistant. After comparison, the correct data were entered in the computer by the research assistant and checked one more time. The analyses were run with the computer program Statistical Package for the Social Sciences (SPSS-X). The analyses which are performed in relation to the formulated research questions and hypotheses, are described in chapter four. The descriptive statistics on the major variables are presented first. They are dealt with in the last section of this chapter.

\subsection{DESCRIPTIVE STATISTICS OF THE MAJOR VARIABLES}

In this section, the descriptive data on the identified study variables are presented. These data include the means, standard deviations, minimum and maximum scores of the scales that have been used, and the frequencies of the nominal variables. Besides the stability of the variables is examined, and the intercorrelations of the basic conditioning factors are presented. The descriptive statistics on the variables representing the basic conditioning factors encompass a description of the characteristics of the study sample. 


\subsubsection{State of Well-being}

State of well-being is measured with Cantril's Self Anchoring Ladder. Theoretically ratings can vary from 0 to 10 . Table 3.2 shows the means, standard deviations and ranges of the scores found for the research sample at 4 moments in time. Preoperatively, the mean rating is 6.0 , whereas postoperatively the mean rating varies from 7.0 to 7.5 .

table 3.2 Mean ratings, standard dewations and range for state of well being at four moments in time

\begin{tabular}{lcccc}
\hline interval & Mean & sd & min/max & \\
\hline pre-CABS & 6.0 & 2.4 & $0 / 10$ & $(\mathrm{n}=85)$ \\
6 months post-CABS & 7.5 & 1.6 & $2 / 10$ & \\
12 months post-CABS & 7.4 & 1.4 & $3 / 10$ & \\
36 months post-CABS & 7.0 & 2.0 & $1 / 10$ & $(n=83)$ \\
\hline
\end{tabular}

To determine the stability of the measurement for state of well-being the intercorrelations of the 4 ratings have been computed. They are presented in table 3.3. The three postoperative ratings are significantly and positively interrelated. The Pearson correlations between the pre-operative rating on the one hand and the three postoperative ratings on the other hand are also positive, though not significant. This is an indication of stability over only the last three measurements.

table 3.3 Pearson correlations between the 4 ratings of state of well-being

\begin{tabular}{lccc}
\hline interval & $\begin{array}{l}6 \text { months } \\
\text { post-CABS }\end{array}$ & $\begin{array}{l}12 \text { months } \\
\text { post-CABS }\end{array}$ & $\begin{array}{l}36 \text { months } \\
\text { post-CABS }\end{array}$ \\
\hline pre-CABS & .17 & .08 & .16 \\
6 months post-CABS & -- & $.66^{\text {*t }}$ & $.51^{\text {* }}$ \\
12 months post-CABS & &.. & $.43^{\text {*t }}$ \\
\hline
\end{tabular}

* $\mathrm{g}<.05 ; * * \mathrm{Q}<.01$

\subsubsection{Self-Care}

\section{Universal self-care}

Theoretically, the scores on the Self-Care Inventory vary from 0 to 110 . In this study scores were found between 38 and 110. The means, standard deviations and ranges of scores on the Self-Care Inventory at the four moments in time are presented in table 3.4. The pre- and postoperative scores are all interrelated positively at a significant level (table 3.5 ), which is an indication of stability. 
Table 3.6 presents the means and standard deviations of the three subscale scores. Here the theoretical minimum and maximum scores are 0 and 10 . The scores over the four measurements on the individual subscales are all positively and significantly correlated as is shown in table 3.7 . This indicates stability of the subscales.

table 3.4 Means, standard deviations and ranges of scores on Self-Care Inventory (SCI) at four moments in time

\begin{tabular}{lccc}
\hline interval & Mean & sd & min/max \\
\hline pre-CABS & 83.0 & 13.3 & $46 / 110$ \\
6 months post-CABS & 86.8 & 10.8 & $55 / 110$ \\
12 months post-CABS & 85.3 & 12.5 & $40 / 109$ \\
36 months post-CABS & 84.6 & 13.4 & $38 / 110$ \\
\hline
\end{tabular}

table 3.5 Pearson correlations between scores on the Self-Care Inventory

\begin{tabular}{lccc}
\hline interval & $\begin{array}{c}6 \text { months } \\
\text { post-CABS }\end{array}$ & $\begin{array}{c}12 \text { months } \\
\text { post-CABS }\end{array}$ & $\begin{array}{c}36 \text { months } \\
\text { post-CABS }\end{array}$ \\
\hline pre-CABS & $.60^{* *}$ & $.53^{* *}$ & $.53^{* *}$ \\
6 months post-CABS & - & $.74^{* *}$ & $.67^{\star *}$ \\
12 months post-CABS & & - & $.78^{* *}$ \\
\hline
\end{tabular}

${ }^{*} \mathrm{Q}<.05_{* * *}^{* *} \mathrm{P}<.01$

table 3.6 Means and standard deviations of subscales of the Self-Care inventory at four moments in time

\begin{tabular}{lcccccc}
\hline & \multicolumn{2}{c}{ NUB } & \multicolumn{2}{c}{ SIB } & \multicolumn{2}{c}{ RAB } \\
interval & Mean & sd & Mean & sd & Mean & sd \\
\hline pre-CABS & 8.1 & 1.3 & 7.6 & 1.9 & 7.0 & 1.7 \\
6 months post-CABS & 8.3 & 1.1 & 7.5 & 1.6 & 7.8 & $\sharp .2$ \\
12 months post-CABS & 8.2 & 1.2 & 7.8 & 1.2 & 7.5 & 1.3 \\
36 months post-CABS & 8.0 & 1.2 & 7.4 & 1.7 & 7.5 & 1.4 \\
\hline
\end{tabular}

$N U B=$ nutritional balance; $S B B=$ social interaction balance; $R A B=$ rest-activity balance 
table 3.7 Pearson correlations between scores on the subscates of the Self-Care inventory

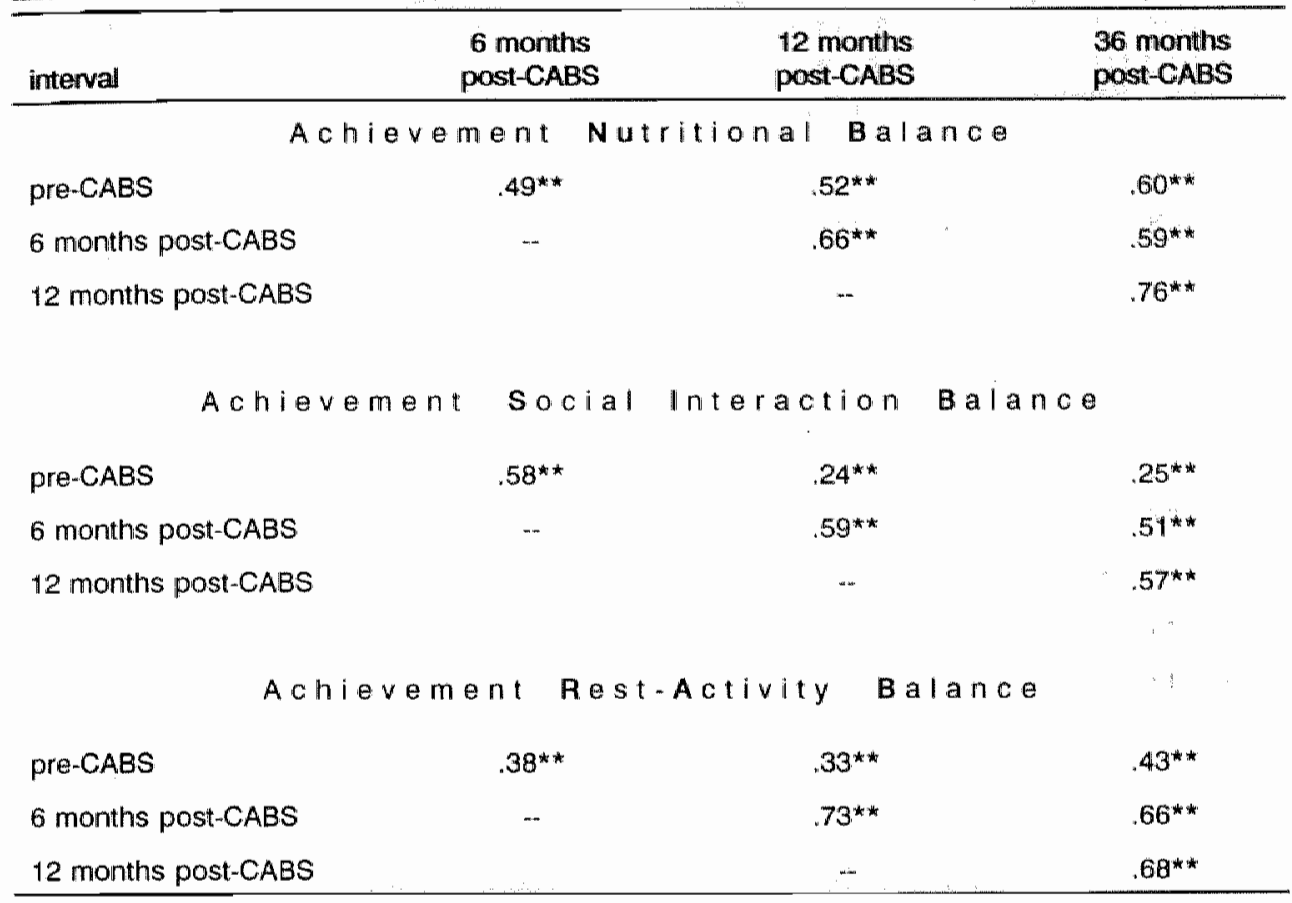

* $\mathrm{e}<.05 ; * * \mathrm{e}<.01$

\section{Health-deviated self-care}

Smoking: Before CAB-surgery 35 of the 86 subjects indicated that they smoked cigarettes. Fifteen subjects stated that they had never in their life smoked cigarettes. Seven persons reported that they stopped within the year prior to their CAB-surgery. The other 29 had stopped smoking for a much longer period ( 3 to 37 years before CAB-surgery).

Six months after CAB-surgery an additional 18 subjects had stopped smoking. They had not smoked cigarettes since their surgery. Thus, a total of 17 subjects still smoked cigarettes six months after CAB-surgery. The amount of cigarettes per day varied from 1 to 25 , with an average of 10.5 (s.d. $=7.5)$.

Twelve months after surgery 1 other person had stopped smoking. However, 1 of the persons who had quit the smoking habit at time of surgery had started again within a year after CAB-surgery. A year after surgery, the 17 smoking persons smoked on the average 13.5 cigarettes a day $(s . d .=6.7)$.

Three years after surgery 21 subjects reported a current smoking habit. Four more of the persons who had quit smoking cigarettes at time of surgery had taken up their habit again. 
Exercise: Six months after $\mathrm{CAB}$-surgery 61 subjects considered the amount of exercise they engaged in sufficient. Six months later, a year after surgery only 52 persons perceived their exercise as sufficient, whereas three years after surgery 63 persons $(73 \%)$ reported taking sufficient exercise. Eleven subjects continued to perceive their exercise level as insufficient, while 41 persons continued to perceive it as sufficient over all three moments of measurement. Table 3.8 presents the percentages of persons who were successful in achieving the specific healthdeviated self-care requisites at the different moments in time.

table 3.8 Percentage of persons successful in achieving specific health-deviated self-care requisites pre-and postoperatively

\begin{tabular}{lcc}
\hline interval & \% nonsmokers & \% sufficient exercise \\
\hline pre-CABS & 59 & -- \\
6 months post-CABS & 80 & 71 \\
12 months post-CABS & 80 & 60 \\
36 months post-CABS & 76 & 73 \\
\hline
\end{tabular}

Universal and health-deviated self-care are expected to be interrelated. To investigate the possible existence of intercorrelations between the achievement of universal and health-deviated self-care requisites, Pearson correlations have been computed (table 3.9).

In the first three measurements, smoking is found to correlate slightly but significantly positive with the SIB-subscale. Persons who do not smoke tend to have higher achievement of self-care requisites with respect to social interaction than persons who smoke. As far as the comparison between subjects who report sufficient exercise levels and subjects who report insufficient exercise levels is concerned, at 6 months the exercisers score significantly higher on the SIB- and the NUB-subscale. A year after surgery there are no significant differences between the groups. However, three years after surgery the exercisers report significantly higher scores on the total SC-Inventory, due to better performance on all the three subscales. The universal self-care requisites are all positively interrelated. 
table 3.9 intercorrelations between achievement of universal and health-deviated self-care requisites, at four moments in time

\begin{tabular}{|c|c|c|c|c|}
\hline Requisite & SIB & RAB & Smoking & Exercise \\
\hline \multicolumn{5}{|c|}{ pre-CABS } \\
\hline NUB & $.35^{*}$ & $.39^{*}$ & -.08 & $\cdots$ \\
\hline SIB & $-\cdots$ & $.28^{*}$ & $.21^{\star}$ & $-\infty$ \\
\hline \multirow[t]{3}{*}{ RAB } & & - & -.02 & -- \\
\hline & & & & - \\
\hline & \multicolumn{3}{|c|}{$6 \mathrm{months}$ post-CABS } & \\
\hline NUB & $.41^{\star}$ & $.43^{*}$ &. .02 & $.23^{*}$ \\
\hline SIB & -- & $.42^{\star}$ & $.18^{\star}$ & $.24^{\star}$ \\
\hline RAB & & $\ldots$ & .02 & .13 \\
\hline \multirow[t]{2}{*}{ Smoking } & & & $n$ & -.06 \\
\hline & \multicolumn{3}{|c|}{12 months post-CABS } & \\
\hline NUB & $.39^{*}$ & $.58^{*}$ & .01 & .07 \\
\hline SIB & - & $.57^{\star}$ & $.20^{\star}$ & .07 \\
\hline RAB: & & -- & .05 & .17 \\
\hline \multirow[t]{2}{*}{ Smoking } & & & $\ldots$ & .02 \\
\hline & \multicolumn{3}{|c|}{36 months post-CABS } & \\
\hline NUB & $.58^{*}$ & $.71 *$ & -.17 & $20^{*}$ \\
\hline$S \| B$ & - & $.60^{*}$ & .00 & $.25^{*}$ \\
\hline $\mathrm{RAB}$ & & - & -.03 & $.36 *$ \\
\hline Smoking & & & $\ldots$ & .06 \\
\hline
\end{tabular}

${ }^{*} \mathrm{p}<.05_{n * *}^{*} \mathrm{p}<.01$

$N U B=$ nutritional balance; $S \mid B=$ social interaction balance; $P A B=$ rest-activity balance

\subsubsection{Self-care Agency}

The descriptive data on the Appraisal of Self-Care Agency Scale (ASA) at four moments in time are presented in table 3.10 . 
Pearson correlations between scores on the ASA-A scale at the four moments in time are all significantly positive (table 3.11). They vary from .44 to .60 and indicate stability of the measurement of self-care agency over the three year period.

table 3.10 Means, standard deviations and range of scores on Appraisal of Self-Care Agency scale (ASA) at four moments in time

\begin{tabular}{lllll}
\hline interval & Mean & sd & min/max & \\
\hline pre-CABS & 89.7 & 9.2 & $63 / 116$ & $(n=85)$ \\
6 months post-CABS & 92.1 & 8.6 & $74 / 114$ & \\
12 months post-CABS & 92.8 & 9.2 & $74 / 113$ & \\
36 months post-CABS & 93.2 & 9.0 & $70 / 116$ & $(n=83)$ \\
\hline
\end{tabular}

table 3.11 Pearson correkations between scores on the Appraisal of Self-Care Agency scale (ASA)

\begin{tabular}{lccc}
\hline interval & $\begin{array}{c}6 \text { months } \\
\text { post-CABS }\end{array}$ & $\begin{array}{c}12 \text { months } \\
\text { post-CABS }\end{array}$ & $\begin{array}{c}36 \text { months } \\
\text { post-CABS }\end{array}$ \\
\hline pre-CABS & $.44^{\star \star}$ & $.46^{* \star}$ & $.53^{\star \star}$ \\
6 months post-CABS & $\cdots$ & $.66^{\star \star}$ & $.59^{\star \star}$ \\
12 months post-CABS & & $\ldots$ & $.59^{\star *}$ \\
\hline
\end{tabular}

${ }^{*} \mathrm{p}<.05^{* *} \mathrm{p}<.01$

\subsubsection{Basic Conditioning Factors}

\section{Health State}

Health state is defined by history of pre-operative myocardial infarction (MI), duration of cardiac clisease, and chest discomfort.

Myocardial Infarction: Of the 86 subjects $49(57 \%)$ had had a myocardial infarction (MI) prior to surgery.

Duration of cardiac disease: On the average subjects knew about having a cardiac problem for 4 years. A little more than half of the sample $(n=46)$ was diagnosed with a heartproblem for more than one year before CAB-surgery (range 1.5 to 20 years). The other half ( $\underline{n}=40) \mathrm{knew}$ about having cardiac disease for less than one year (range 2 weeks to 10 months).

Table 3.12 shows the interrelation between duration of cardiac disease and history of pre-operative myocardial infarction. As far as the pre-operative cardiac health 
state is concerned, the 25 persons who had not had a myocardial infarction, and had been diagnosed recently with cardiac disease have relatively the best health state. On the other hand, the 34 persons who had been diagnosed for more than a year and also experienced a myocardial infarction can be considered to have the least favorable pre-operative health state.

table 3.12 Crosstabulation of the variables duration of cardiac disease and history of myocardial infarction (M)

\begin{tabular}{lccc}
\hline duration & with MII & no MI & total \\
\hline$<1$ year & 15 & 25 & 40 \\
$>1$ year & 34 & 12 & 46 \\
& & & 86 \\
\hline
\end{tabular}

Chest discomfort: Prior to surgery 71 of the 86 subjects reported having chest discomfort on a regular basis. Fifteen subjects reported two or less episodes of chest discomfort in their life. Forty-one reported chest discomfort only during exertion, whereas the remaining subjects reported nonexertional as well as exertional chest discomfort. On the average, subjects $(n=71)$ reported more than $11(\mathrm{sd}=17)$ episodes of chest discomfort per week of such a degree that some kind of pain relief was used.

Six months after surgery 15 subjects reported a recurrence of chest discomfort. Three of them had only experienced one episode. A year after CAB-surgery 10 more subjects reported a recurrence of chest discomfort. Thus, a total of 25 subjects had experienced at least one episode of chest discomfort a year after $\mathrm{CAB}$-surgery; 23 on a regular basis and 2 had had only one experience of chest discomfort since surgery. The frequency of chest discomfort 1 year post CABsurgery of the subjects with regular episodes was 12.5 episodes per month. Twelve of the 25 subjects experienced chest discomfort only during exertion.

Then three years after CAB-surgery 15 of the 25 no longer reported experiencing chest discomfort, whereas 5 additional subjects reported a late recurrence. The fifteen subjects report a frequency of on the average 10 episodes per month, varying from daily episodes to twice a month.

\section{Age and gender}

The sample consists of 20 women and 66 men. Mean age at the time of surgery was 60.1 (s.d. $=7.4$ ). The youngest was 42 , the oldest 76 . The women were older (mean age $=64.7$; s.d. $=6.7$ ) than the men (mean age 59.7; s.d. $=7.1)(\mathrm{t}(84)=3.34$, $\mathrm{p}<.01)$. Table 3.13 shows that $65 \%(\underline{n}=13)$ of the women and $40 \%(\underline{n}=27)$ of the men were over 60 at the time of their surgery. 
table 3.13 Crosstabulation of the variables gender and age-groups (middle-aged and older)

\begin{tabular}{lccc}
\hline gender & $\begin{array}{c}42-60 \\
\text { middle-aged }\end{array}$ & $\begin{array}{c}61-76 \\
\text { older }\end{array}$ & total \\
\hline men & 39 & 27 & 66 \\
women & 7 & 13 & 20 \\
& & & \\
total & 46 & 40 & 86 \\
\hline
\end{tabular}

\section{Socio-Economic Status}

At the time of surgery, only 21 patients had a job, 16 were housewife, 1 unemployed, 19 retired and 29 were receiving disability-pensions (WAO). Table 3.14 shows how the subjects were divided based on their (former) occupation, or in the case of the housewives based on their husbands' occupation, over the 6 categories of socio-economic status.

table $3.14 \quad$ Socio-economic status according to fevel of occupation $(\underline{N}=86)$

\begin{tabular}{lc}
\hline \multicolumn{1}{c}{ category } & frequency \\
\hline 1) unskilled labor & 3 \\
2) skilled labor & 30 \\
3) clerical workers & 18 \\
4) owners of small businesses & 12 \\
5) managerial personnel & 12 \\
6) professionals & 11 \\
\hline
\end{tabular}

In the analyses in the next chapter, the 6 categories of occupational level are diminished to three groups: subjects with a lower (laborers $\underline{n}=33$ ), with a middle (clerical workers and owners of small businesses $n=30$ ), and with a higher (managers and professionals $\underline{n}=23$ ) socio-economic status.

\section{Health Care System Elements}

Six months postoperatively, subjects were asked whether they had had any contact with a health care professional after discharge from the hospitall. If so, they were asked whether the received help had been sufficient. If not, they were asked whether they had felt any need to have contact with such a professional.

After discharge all 86 subjects did have contact with at least one health professional. Fifty-six of them were satisfied with the amount of help/support they received. Eighteen subjects perceived a lack of help/support from 1 professional; nine subjects from 2 professionals; two persons experienced a lack of help/ 
support from 3 professionals and one subject was not sufficiently helped by 4 professionals. Only 13 subjects expressed a need for contact with at least one health care professional that was not answered. Of these thirteen 7 subjects identified an unanswered need for contact with one professional, 3 subjects identified an unanswered need for contact with two professionals, and 3 subjects reported an unanswered need for contact with three professionals. Six persons perceived both an unanswered need as well as insufficient help from one or more professionals. To give an overview of how the lack of sufficient help was divided over the different professionals table 3.15 is included. It shows which professionals were contacted, how many subjects felt that the contacts were insufficient, as well as whose additional help was needed but not received.

table 3.15 Number of contacts, sufficiency of contacts, and unanswered need for contacts with health care professionals during the first six months after CAB-surgery

\begin{tabular}{|c|c|c|c|}
\hline professional & $\begin{array}{l}\text { \# subjects who } \\
\text { did have contact }\end{array}$ & $\begin{array}{l}\text { \# contacts } \\
\text { not sufficieint }\end{array}$ & $\begin{array}{c}\text { \# unanswered } \\
\text { need }\end{array}$ \\
\hline cardiologist & 86 & 12 & - \\
\hline physical therapist & 83 & 7 & 2 \\
\hline family physician & 76 & 9 & 1 \\
\hline rehabilitation specialist & 55 & 8 & 5 \\
\hline dietician & 37 & 4 & 4 \\
\hline psychologist/psychiatrist & 14 & 2 & 1 \\
\hline sociall worker & 9 & 2 & 4 \\
\hline home health aid & 8 & 1 & 3 \\
\hline community health nurse & 6 & 1 & 2 \\
\hline
\end{tabular}

Variable 12: The variable professional help after discharge is dichotomized. Adding up subjects who had not sufficiently been helped and subjects who had experienced an unanswered need for help, gives a total of 37 subjects who perceived posthospital professional care as insufficient. The other 49 can be considered satisfied with the posthospital professional care.

\section{Intercorrelations basic conditioning factors}

To examine the relationships between the different basic conditioning factors, Pearson correlations have been computed. The results are presented in table 3.16 The only significant correlations are observed between age and gender, between the different cardiac health indicators, and between gender and recurrence of chest discomfort three years after CAB-surgery. Since most basic conditioning factors are not significantly correlated, their effects on self-care and well-being can be studied separately. 

Pearsion correlations between the basic conditioning factors

\begin{tabular}{|c|c|c|c|c|c|c|c|c|}
\hline basic conditioning factor & (2) & (3) & (4) & (5) & (6) & (7) & (8) & (9) \\
\hline 1) myocardial infarction & $-.37^{*}$ & .04 & .09 & .15 & .04 & .02 & .03 & .04 \\
\hline 2) duration cardiac disease & - & .00 & -.08 & -.05 & .17 & -.04 & -.06 & .01 \\
\hline 3) chest disc. at $6 \mathrm{~m}$ post & & $-\infty$ & $.65^{* *}$ & .08 & -.06 &. .14 & .09 & -.02 \\
\hline 4) chest disc at $12 \mathrm{~m}$ post & & & $\cdots$ & $.38^{* * *}$ & -02 & -.19 & .11 & .06 \\
\hline 5) chest disc. at $36 \mathrm{~m}$ post & & & & -- & -.06 & $-.26^{\star}$ & -.111 & .03 \\
\hline 6) age & & & & & -. & $.20^{*}$ & -.02 & .15 \\
\hline 7) gender & & & & & & - &,- 12 & -.08 \\
\hline 8) socio-economic status & & & & & & & -- & .09 \\
\hline 9) postop professional help & & & & & & & & -- \\
\hline
\end{tabular}

${ }^{*} \mathrm{e}<.05_{* * *}^{* *}<.01$ 


\section{CHAPTER 4 RESULTS}

\subsection{THE RELATIONSHIP BetWEen Self-CARE AND State of WELL-BEING}

This section deals with the testing of hypothesis \#y through \#7. These were all formulated for the purpose of examining the first set of research questions:

A1: "Does achievement of self-care requisites contribute to state of well-being ?": A2: "Is the relationship between self-care and state of well-being consistent over time ?"; and

A3: "Do different aspects of self-care contribute differently to state of well-being ?".

Hypothesis \#1 predicts a positive correlation between achievement of universal self-care requisites and state of well-being. Pearson correlations were computed between the Self-Care Inventory scores and Cantril's Ladder ratings, for all four moments of measurement. It can be seen in table 4.1 that at moments in time moderately strong positive correlations at a significance level of $\mathrm{Q}<.01$ were found. The Pearson correlations range from .40 to .60. The first hypothesis is supported by these results.

table 4.7 Pearsan correlations between achievement of universal self-care needs (SCl- and subscales) and perception of state of well-being, at four moments in time

\begin{tabular}{lllll}
\hline interval & SCI & NUB & SIB & AAB \\
\hline pre-operative & $.42^{\star *}$ & $.32^{* *}$ & $.28^{* *}$ & $.35^{* *}$ \\
6 months post-CABS & $.57^{\star *}$ & $.29^{* *}$ & $.37^{* *}$ & $.62^{* *}$ \\
12 months post-CABS & $.58^{* *}$ & $.32^{* *}$ & $.63^{* *}$ & $.511^{* *}$ \\
36 months post-CABS & $.60^{* *}$ & $.49^{* *}$ & $.53^{* *}$ & $.59^{* *}$ \\
\hline
\end{tabular}

* $\mathrm{p}<.05 ; * * \mathrm{p}<.01$

NUB $=$ nutritional balance; $S I B=$ social interaction balance; $R A B=$ rest-activity balance

The second hypothesis predicts that persons who do not smoke report higher states of well-being than persons who smoke; and that persons who take sufficient exercise report higher states of well-being than persons who do not take sufficient exercise. T-tests for independent samples have been conducted to compare the levels of well-being of subjects who are successful in achieving these specific health deviated self-care requisites with subjects who are not successful (table 4.2 and 4.3). The group of nonsmokers consistently rates its state of well-being at a higher level than the group of smokers. Postoperatively the composition of these 2 
groups is rather stable over time. The difference in state of well-being between the 2 groups is significant during the first year after CAB-surgery. However, before $\mathrm{CAB}-$ surgery and at the three years postoperative measurement the difference is not large enough to be significant.

table 4.2 Comparison of pre-and postoperative ratings for state of well-being for subjects who smoke and subjects who do not

\begin{tabular}{lccccccccc}
\hline & \multicolumn{3}{c}{ smokers } & \multicolumn{3}{c}{ nonsmokers } & & & \\
interval & $N$ & Mean & sd & N & Mean & sd & df & t \\
\hline pre-operative & 35 & 5.5 & 2.5 & 51 & 6.3 & 2.3 & 84 & 1.55 \\
6 months post-CABS & 17 & 6.6 & 1.8 & 69 & 7.7 & 1.5 & 84 & $2.64^{*}$ \\
12 months post-CABS & 17 & 6.8 & 1.7 & 69 & 7.5 & 1.3 & 84 & $1.90^{*}$ \\
36 months post-CABS & 21 & 6.9 & 2.1 & 62 & 7.0 & 1.9 & 81 & 0.25 \\
\hline
\end{tabular}

* $\mathrm{p}<.05 ; * * \mathrm{p}<.01$

table 4.3 Comparison of postoperative ratings for state of well-being for subjects who exercise sufficiently and subjects who do not

\begin{tabular}{|c|c|c|c|c|c|c|c|c|}
\hline \multirow[b]{2}{*}{ interval } & \multicolumn{3}{|c|}{$\begin{array}{c}\text { exercise } \\
\text { not sufficient }\end{array}$} & \multicolumn{3}{|c|}{$\begin{array}{l}\text { exercise } \\
\text { sufficient }\end{array}$} & \multirow[b]{2}{*}{ df } & \multirow[b]{2}{*}{$t$} \\
\hline & $\mathbb{N}$ & Mean & sd & $N$ & Mean & sd & & \\
\hline 6 months post-CABS & 25 & 7.4 & 1.7 & 61 & 7.5 & 1.5 & 84 & 0.39 \\
\hline 12 months post-CABS & 34 & 7.1 & 1.4 & 52 & 7.5 & 1.4 & 84 & 1.33 \\
\hline 36 months post-CABS & 20 & 6.1 & 2.6 & 63 & 7,2 & 1.7 & 81 & $1.83^{\star}$ \\
\hline
\end{tabular}

${ }^{*} \mathrm{e}<.05 ;{ }^{* *} \mathrm{e}<.01$

Subjects who perceive the amount of exercise they engage in as sufficient, tend to rate their state of well-being higher than those subjects who report insufficient exercise. This difference in ratings of well-being is found to be significant at the measurement 3 years after CAB-surgery. It has been described in section 3.5.2. that three years after CAB-surgery those subjects who report sufficient exercise have significantly higher $\mathrm{SCl}$-scores than subjects with insufficient exercise levels. Since state of well-being relates significantly to both the SCl-score and exerciselevel, an analysis of covariance (ANCOVA) was conducted to examine the effects. It was found that the covariate SCl explained a significant amount of the variance of the 36 month well-being rating $(E(1,81)=44.8, \underline{p}<.01)$, and that no significant main effect of the exercise-level remained.

In conclusion, the mean ratings of state of well-being continues to be higher for subjects who are successful in their behavior with regard to smoking and exercise. Still the differences are not in all instances of a large enough level to reach 
statistical significance. Besides, the effect on state of well-being of the healthdeviated requisite in relation to sufficient exercise does not remain after entering the $\mathrm{SCl}-\mathrm{score}$ as a covariate in the analysis. The results are only partly supportive of hypothesis \#2.

The third hypothesis reflects the expectation that changes that occur in the achievement of self-care requisites from one moment of measurement to the next, relate to changes in state of well-being over the same period. For the examination of this hypothesis change scores have been computed for both the SCl-scores and the well-being ratings. By subtracting the pre-operative score from the 6 months score, the 6 months score from the 12 months score, and the 12 months score from the 36 months score, three change scores for both variables have been calculated. The mean change scores and standard deviations for the Self-Care Inventory are presented in table 4.4 . The changes in ratings of state of well-being are also included in the table.

Next, Pearson correlations between SCl change scores and the well-being change scores over the same period were computed. As predicted, three positive Pearson correlations of moderate strength were found (table 4.4).

table 4.4 Mean SCH- and Well-being. change scores over the three time intervals, and the Pearson correlations between them $(N=86)$.

\begin{tabular}{lcccccc} 
& \multicolumn{4}{c}{ change in } & & \\
\cline { 2 - 5 } interval & \multicolumn{2}{c}{ SCl-score } & \multicolumn{2}{c}{ WB-rating } & & Pearson's I \\
\hline pre- to 6 months post-CABS & +3.9 & 10.9 & +1.5 & 2.6 & $.40^{\star *}$ \\
6 to 12 months post-CABS & -1.5 & 8.6 & -0.1 & 1.3 & $.28^{\star *}$ \\
12 to 36 months post-CABS & -0.8 & 8.6 & -0.4 & 1.9 & $.37^{* * *}$ \\
\hline
\end{tabular}

$* \mathrm{E}<.05 ; * \mathrm{p}<.01$

Additionally, to investigate these relationships in more detail, three subgroups were formed consisting of subjects with respectively low, middle and high pre-operative $\mathrm{SCl}$-scores. Theoretically, only subjects with low scores can make large improvements, whereas subjects with a high score cannot increase their score much more. It follows that dividing the sample in subgroups in this way may provide additional information on how the changes in the two scores correlate. The following groups were created:

$$
\begin{array}{ll}
\text { pre-op low (total SCl }<79) \text { scorers } & \underline{n}=29 \\
\text { pre-op middle }(78<\text { total SCl }<90 \text { ) scorers } & \underline{n}=29 \\
\text { pre-op high (total SCl }>89 \text { ) scorers } & \underline{n}=28
\end{array}
$$

Table 4.5 shows the mean change scores " the standard deviations and the Pearson correlations between the SCl-change score and the Well-being change score for the three groups over the three time periods. Eight out of the nine subcorrelations in table 4.5 are again found to be of a positive nature. Four of them 
are of a statistically significant level. The other four do not reach the level of significanice, due to the small size of the subsamples. Only in the group of subjects who score high pre-operatively on the Self-Care Inventory, is no relation found between the change in SCl-score and change in well-being-rating over the first time interval. However, the overall picture shows that even in samples in which the changes over a certain period are small, the correlations between the changes in Self-Care Inventory and well-being-rating are still of a positive nature.

Changes in achievement of self-care requisites seem to be parallel to changes in state of well-being. Hypothesis \#3 is supported.

table 4.5 Mean SCl and Well-being change scores for three subgroups, over the three time intervals, and Pearson correlations between them $(N=86)$.

\begin{tabular}{|c|c|c|c|c|c|}
\hline \multirow[b]{3}{*}{ interval } & \multicolumn{4}{|c|}{ change in } & \multirow{3}{*}{$\begin{array}{c}\text { Pearson's } \\
\underline{\square} \\
\end{array}$} \\
\hline & \multicolumn{2}{|c|}{ SCl-score } & \multicolumn{2}{|c|}{ WB-rating } & \\
\hline & Mean & sd & Mean & sd & \\
\hline \multicolumn{6}{|c|}{ pre- to 6 months post-CABS } \\
\hline llow scorers & 10.8 & 11.8 & 2.4 & 2.9 & $.56^{* *}$ \\
\hline middle scorers & 2.5 & 9.3 & 1.0 & 2.2 & $.30 *$ \\
\hline hight scorers & -1.9 & 7.4 & 1.0 & 2.5 & -.03 \\
\hline \multicolumn{6}{|c|}{6 to 12 months post-CABS } \\
\hline low scorers & -1.3 & 10.7 & 0.0 & 1.2 & $.31 *$ \\
\hline middle scorers & -0.3 & 6.7 & -0.1 & 1.4 & .26 \\
\hline high scorers & $-3,0$ & 7.9 & -0.3 & 1.1 & .25 \\
\hline \multicolumn{6}{|c|}{12 to 36 months post-CABS } \\
\hline low scorers & -1.7 & 8.4 & -0.9 & 1.7 & .27 \\
\hline middle scorers & .0 .5 & 8.4 & 0.0 & 2.1 & .18 \\
\hline high scorers & -0.2 & 9.3 & -0.3 & 1.7 & $.66^{* \star}$ \\
\hline
\end{tabular}

${ }^{*} \mathrm{p}<.05^{* * *} \mathrm{p}<.01$

In hypothesis \#4 it is stated that the achievement of self-care requisites six months postoperatively is predictive of state of well-being 12 months postoperatively. For this purpose the Pearson correlation between the 6 months SCl-scores and the 12 months well-being ratings has been computed. A significant positive correlation is found: $r=.37^{* *}$. As both these scores also correlate significantly with the SClscore of 12 months post-CABS, the correlation was computed again after partialling out the effect of the 12 months SCl-score. The partial correlation then between 6 months $\mathrm{SCl}$ and 12 months Well-being was $(r=.01)$ not significant. It seems that the relationship between the achievement of self-care requisites 6 months post$\mathrm{CABS}_{\mathrm{n}}$ and the state of well-being 12 months post-CABS can be explained by the 
achievement of self-care requisites at 12 months post CAB-surgery. Hypothesis \#4 is not supported.

The fifth hypothesis predicts that there will be a positive relationship between the 6months $\mathrm{SCl}$-score and the 6-months well-being rating, when the effect of the preoperative well-being rating is statistically controlled; that there will be a positive relationship between the 12-months $\mathrm{SCl}$-score and the 12-months well-being rating, when the effect of the 6-months well-being rating is statistically controlled; and that there will be a positive relationship between the 36-months SCl-score and the 36months well-being rating, when the effect of the 12-months well-being rating is statistically controlled. Three hierarchical multiple regressions were conducted, of which the results are presented in table 4.6. After controlling for the effect of the previous well-being rating, in all three regressions the concurring SCl-scores are found to contribute a significant extra amount to the explanation of the current well being rating. The partial correlations for the three analyses are respectively $\mathrm{I}=.56$ $(\underline{p}<.01) ; r=.33 \quad(\underline{p}<.01) ; r=.52 \quad(\underline{p}<.01)$. Hypothesis $\# 5$ is supported by these results.

\section{table 4.6}

Results hierarchical regressions with state of well-being as dependent and previous state of well-being (firstly) and the SCl-score (secondly) as independent variables

\begin{tabular}{|c|c|c|c|c|}
\hline Dependent Variable & Forced Step & Predictor Variable & B & $\mathbf{R}^{\mathbf{a}}$ \\
\hline \multirow[t]{2}{*}{6 months Well-being } & 1 & pre-op Well-being & .03 & .03 \\
\hline & 2 & 6 months SCl & .57 & .33 \\
\hline \multirow[t]{2}{*}{12 months Well-being } & 1 & 6 months Well-being & .48 & .43 \\
\hline & 2 & 12 months $\mathrm{SCl}$ & .57 & .49 \\
\hline \multirow[t]{2}{*}{36 moriths Well-being } & 1 & 12 months Well-being & .24 & .20 \\
\hline & 2 & 36 months $\mathrm{SCl}$ & .50 & .41 \\
\hline
\end{tabular}

The sixth hypothesis predicts that a combination of the universal and the healthdeviated self-care requisites account for a greater amount of the variance in the well-being ratings than each by themselves. To investigate this hypothesis four multiple regression analyses have been conducted. For the pre-operative and each of the postoperative measurements a stepwise regression analysis was performed, with state of well-being as the dependent, and the three SCl-subscales and the dichotomous variables smoking and exercise (only postoperative) as the independent variables (table 4.7). The stepwise method selects at each step that independent variable which accounts for the greatest proportion of variance in the dependent variable, and enters it into the equation. This process continues, until no independent variables remain whose inclusion into the equation would add significantly to the amount of explained variance of the dependent variable. 
The regression over the pre-operative variables selects three significant predictors of the pre-operative rating of state of well-being. RAB (rest-activity balance) explains $12 \%$ of the variance, while NUB (nutritional balance) and NON-SMOKING each add another $4 \%$ in the well-being rating. A total of $20 \%$ of the variance is accounted for by these three predictors. In the regression of the 6 months postCABS variables onlly two variables are selected, though together they account for a higher percentage of explained variance $(46 \%)$. The 6 -months RAB-score is the first variable selected and is found to explain $39 \%$ of the variance in state of well-being. The second variable 'NON-SMOKING' contributes another $7 \%$.

The regression conducted over the measures of one year after surgery selects two variables for the equation. Firstly, the SIB-subscale (social interaction) is entered; it explains $38 \%$ of the variance. Subsequently, RAB is selected, which adds another $5 \%$ of explained variance; a total of $43 \%$ of the variance in the 12 month rating of well-being is explained by the SIB- and RAB-subscales. Lastly, the regression over the 36 months postoperative variables selects the same two subscales, albeit in another sequence. Firstly, RAB is selected and this explains $34 \%$ of the variance. With SIB added to the equation in the second step a total of $39 \%$ of the variance in the three years postoperative rating of well-being is explained.

table 4.7 Significant results stepwise regressions with state of well-being as dependent and the SCl-subscales and smoking- and exercise-variables as independent variables, at four moments in time

\begin{tabular}{|c|c|c|c|c|}
\hline Dependent Variable & Step & Predictor Variable & B & $\mathrm{B}^{2}$ \\
\hline \multirow[t]{3}{*}{ pre-op Well-being } & 1 & RAB & .26 & .12 \\
\hline & 2 & NUB & .23 & .16 \\
\hline & 3 & Non-Smoking & .19 & .20 \\
\hline \multirow[t]{2}{*}{6 months Well-being } & 1 & RAB & .62 & .39 \\
\hline & 2 & Non-Smoking & .26 & .46 \\
\hline \multirow[t]{2}{*}{12 months Well-being } & 1 & SIB & 47 & .38 \\
\hline & 2 & RAB & .26 & .43 \\
\hline \multirow[t]{2}{*}{36 morths Wellibeing } & 1 & RAB & .42 & .34 \\
\hline & 2 & SIB & .27 & .39 \\
\hline
\end{tabular}

$N U B=$ nutritional balance; $S I B=$ social interaction balance; $R A B=$ rest-activity balance

These results show that for the pre-operative and six months postoperative ratings of state of well-being, the stepwise method indeed selects a combination of universal and health-deviated self-care requisites as significant predictor variables. 
However, for the one and three years postoperative ratings of state of well-being only elements of the universal self-care are selected. Hypothesis \#6 is partially supported.

The seventh hypothesis was formulated for the purpose of examining the relative contribution of the different aspects in the achievement of self-care to the individuals' state of well-being. Table 4.7 shows that for each moment of measurement the combination of selected predictor variables is slightly different. The only variable which is constantly selected as a significant predictor of state of well-being is the RAB-score. In three of the regressions it is even the first variable selected, and thus the greatest predictor of the state of well-being. For this group of CAB-surgery patients, the performance of self-care in relation to physical activities seems to contribute most to their state of well-being. Hypothesis \#7 is not supported.

\subsection{The Relationships Between Self-CARE Agency, Self-Care and State of WELL-BEING}

In this section the role of self-care agency in rellation to self-care and well-being is investigated. The results of the analyses conducted in relation to the second set of research questions are presented. These questions were:

B 1. Does self-care agency relate to achievement of self-care requisites ?; and

$B$ 2. Does self-care agency relate to state of well-being after controlling for achievement of self-care requilsites?

The eighth hypothesis reflects the test of the proposition that abilities for self-care are related to fulfilment of self-care needs. To examine this hypathesis, Pearson correlations are computed between the pre- and postoperative ASA and SClscores. Four positive correlations of similar strength are found (table 4.8). The findings suggest a stable relationship between self-care agency as measured by the ASA-scale and achievement of self-care requisites measured by the Self-Care Inventory. Hypothesis \#8 is confirmed.

table 4.8 Pearson correlations berween ASA- and SCl-scores, at four moments in time

\begin{tabular}{lc}
\hline interval & Pearson's I \\
\hline pre-CABS & $25^{\star}$ \\
6 months post-CABS & $.28^{* \star}$ \\
12 months post-CABS & $.24^{\star}$ \\
36 months post-CABS & $.26^{*}$ \\
\hline
\end{tabular}

$\mathrm{D}<.05 ; * \mathrm{p}<.01$ 
Hypothesis \#9 predicts that the correlation between self-care agency and state of well-being can be explained by achievement of self-care requisites. In other words, as self-care agency determines for a significant part how well the universal self-care needs are met, it contributes indirectly to state of well-being. Pearson correlations have been computed between the pre- and postoperative ASA-scores and wellbeing-ratings. These analyses reveal positive but not in all cases significant correlations (table 4.9). The correlations were computed again while controling for the SCl-scores. Then, no significant partial correlations are found between ASAand well-being-ratings at any point in time (table 4.9).

table 4.9 Pearson correlations and Partial correlations (contralled for SC/-scores) between ASA scores and perception of state of well-being, at four moments in time

\begin{tabular}{lcc}
\hline interval & Pearson & Partial \\
\hline pre-CABS & .12 & .02 \\
6 months post-CABS & $.27^{\star *}$ & .14 \\
12 months post-CABS & .17 & .04 \\
36 months post-CABS & $.27^{\star}$ & .13 \\
\hline
\end{tabular}

$* \mathrm{p}<.05^{* *} \mathrm{p}<.01$

Hypothesis \#9 is supported in that after controlling for achievement of self-care requisites no statistically significant correlations remain between self-care agency and state of well-being.

\subsection{The Relationships between the basic Condmoning factors, Self-Care AND STATE OF WELL-BEING}

The last set of research questions formulated deals with the influence of the basic conditioning factors. Firstly, the extent in which the basic conditioning factors affect the achievement of self-care requisites is examined. Then the hypotheses which reflect the influence of the factors on state of well-being are tested. Finally, possible effects of the basic conditioning factors on the relationship between self-care and well-being are investigated.

\subsubsection{To What Extent Do Basic Conditioning Factors Influence Self-care?}

In hypothesis \#10 the expectation is formulated that men and women differ in their achievement of self-care requisites. The mean SCl-scores of the group of men and the group of women are depicted in figure 4.1. It shows that men tend to have higher SCl-scores than women. A two-group Multivariate Analysis of Variance (MANOVA) with repeated measures was conducted to examine the significance of 
these differences between men and women. The overall effect of gender on the total SCl-scores was found to be close to statistically significant $(\mathbb{E}(1,83)=3.46$ $\mathrm{p}=.067)$.

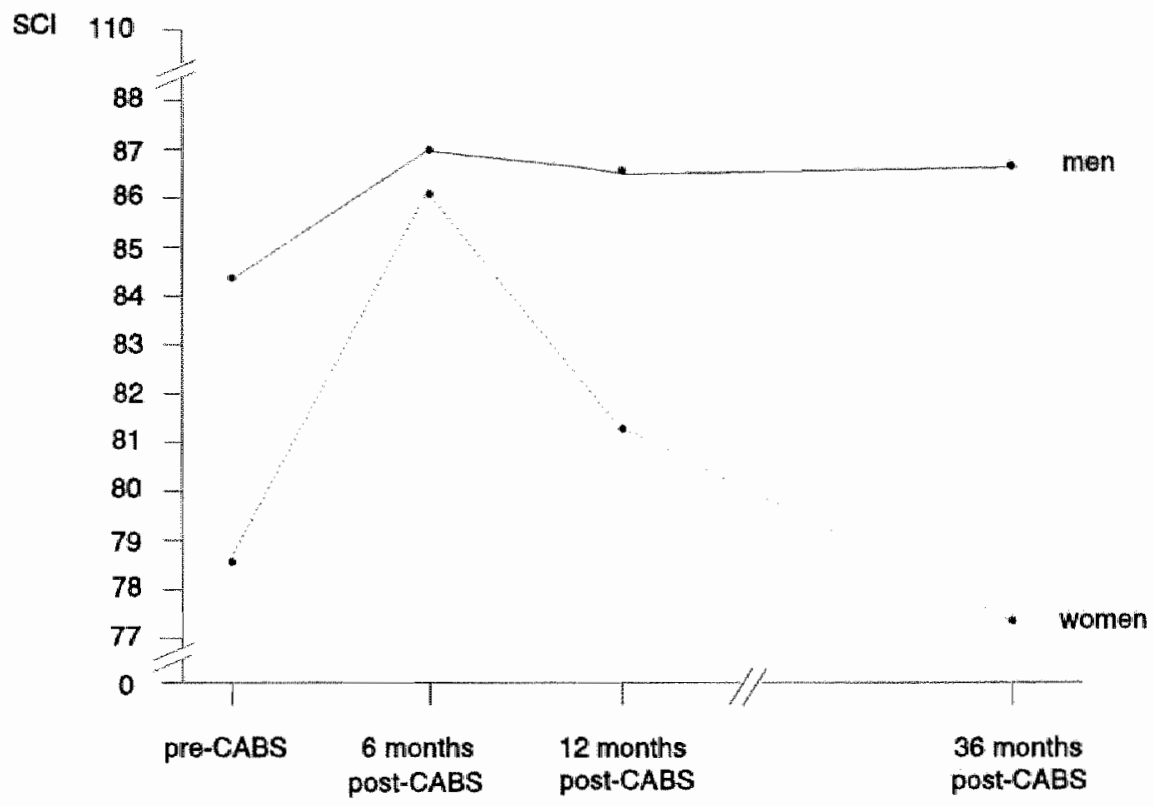

figure $4.1 \quad$ SCl-scores over time for $m e n(n=66)$ and women $(n=20)$

Further analyses revealed that the differences between men and women were mainly due to differences on the NUB-subscale (overall effect: $F(1,84)=11.4$ $\mathrm{e}=.001$ ). Men continue to have better achievement in the area of appetite, digestion and bowel movement. Thus, hypothesis \#10 is supported: men and women differ in their achievement of self-care requisites.

The eleventh hypothesis predicts a correlation between age and achievement of self-care requisites. For all moments of measurement Pearson correlations hiave been computed between age and the SCl-scores. Four negative correlations were found; pre-operative $\mathrm{I}=-.06$; at 6 months $\mathrm{I}=-.01$; at 12 months $\mathrm{I}=-.12$; and at 36 months $\underline{I}=-.22^{\star}$. Only the last one is of a significant level. This last measure. ment is done 3 years after CAB-surgery, at which time the mean age of the sample is $\underline{M}=63.1$. The finding that the negative correlation between age and achievement of self-care requisites is only significant at the moment the sample has become three years older, could be an indicator for the existence of a negative correlation only in older people. If that is the case, then it can be predicted that within the subgroup of subjects older than $60 \quad(n=40)$, a significant negative correlation between age and achievement of self-care requisites can be found at all 
four maments in time. However, the computation of these 4 Pearson correlations yields the following results, which are not statistically significant: $r$ (pre-op) $=-.05$; $r(6$ months $)=.08 ; \underline{r}(12$ months $)=.09$; and $\underline{r}(36$ months $)=.02$. The results are not (unambiguously) supportive of hypothesis \#11.

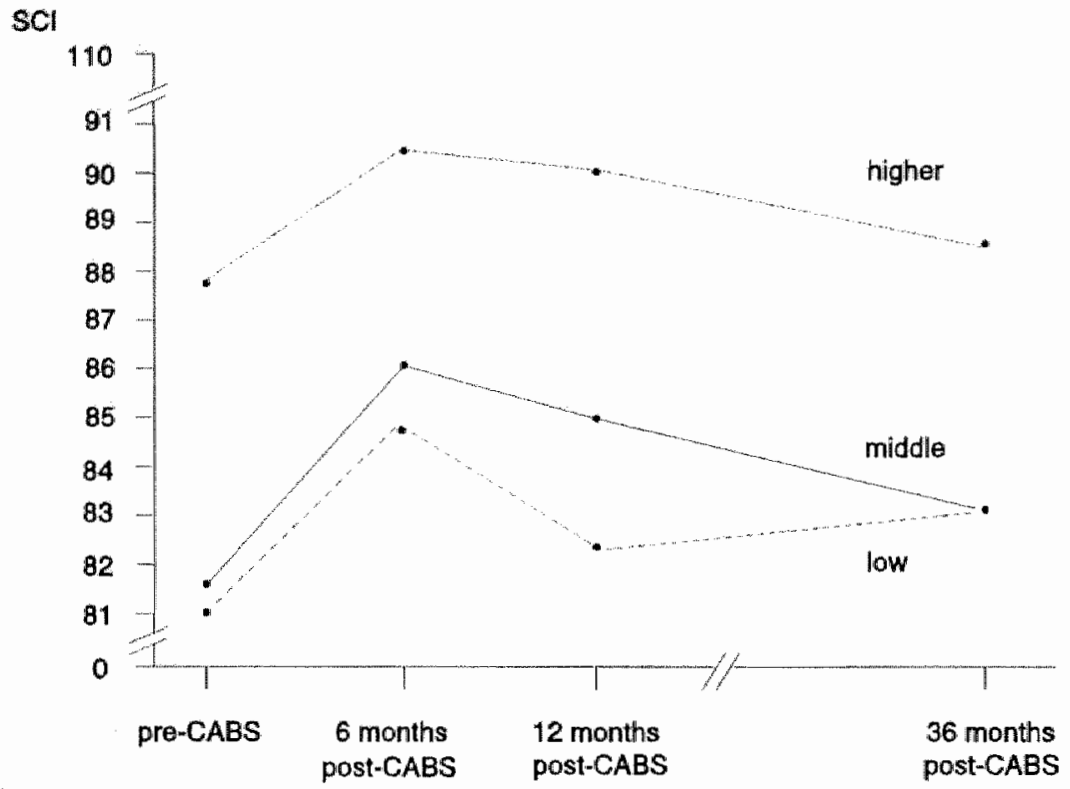

figure 4.2 SCl-scores over time for subjects of lower $(n=33)$, middle $(n=30)$ and higher $(n=23)$ socio-economic status

In hypothesis \#12 it is expected that subjects with different socio-economic status have different levels of achievement of self-care requisites. Figure 4.2 shows that subjects from the group with the lowest socio-economic status continue to have the lowest mean scores on the Self-Care inventory, whereas the subjects from the group with the highest socio-economic status continuously show the highest mean SCl-scores. Three group MANOVA with repeated measures reveals an overall effect of socio-economic status on SCl-scores $(E(2,82)=2.61)$ on a level of significance of $\mathrm{p}=080$. To investigate this effect further, MANOVA's with repeated measures over the subscales were conducted. The results showed that the differences between the 3 groups of lower, middle and higher socio-economic status were only significant on the RAB-scale $(\mathrm{F}(2,83)=3.78 \quad \mathrm{p}<.05)$. Professionals and administrative personnel who undergo CAB-surgery tend to have better achievement of self-care in especially maintaining the balance between activity and rest. Laborers seem to have the least good achievement of self-care requisites in this area. Hypothesis \#12 is supported by the data; differences in achievement of self-care requisites can be found between subjects with different levels of socio-economic status. More specifically, the higher the status, the better the self-care performance in relation to 
taking sufficient rest and activity.

Hypothesis \#13 predicts that subjects who receive sufficient help from health care professionals after discharge from the hospital have better achievement of self-care requisites than subjects who do not receive sufficient help. The amount and kind of professional help received has been measured over the 6 months post-CABS interval. Thus, one-tailed t-tests for independent samples have been computed comparing the group with sufficient help with the group with insufficient help on their SCl-and subscale-scores (table 4.10). The 49 subjects who received sufficient posthospital help had on the average significantly higher SCl-scores $(t(84)=2.28$, $\mathrm{p}<.05)$ than the 37 subjects who had not received sufficient professional help after discharge from the hospital. This difference could be traced back to differences on the SIB- and RAB-subscales.

table 4.10 Total SCI- (and subscale) scores for subjects with versus subjects without sufficient professional help 6 months after CAB-surgery

\begin{tabular}{|c|c|c|c|c|c|c|}
\hline \multirow[b]{2}{*}{ Scale } & \multicolumn{2}{|c|}{$\begin{array}{c}\text { sufficient } \\
\text { help }(n=49)\end{array}$} & \multicolumn{2}{|c|}{$\begin{array}{l}\text { insufficient } \\
\text { help }(n=37)\end{array}$} & \multirow[b]{2}{*}{$d f$} & \multirow[b]{2}{*}{$t$} \\
\hline & Mean & sd & Mean & sd & & \\
\hline $\mathrm{SCl}$ & 89.1 & 10.1 & 83.9 & 10.9 & 84 & $2.28 *$ \\
\hline NUB & 8.3 & 1.1 & 8.2 & 1.2 & 84 & 0.38 \\
\hline$S \| B$ & 7.9 & 1.4 & 7.1 & 1.9 & 84 & $2.18^{*}$ \\
\hline RAB & 8.0 & 1,1 & 7.4 & 12 & 84 & $2.63^{*}$ \\
\hline
\end{tabular}

${ }^{*} \mathrm{p}<.05 ;{ }^{* *} \mathrm{p}<.01$

$N U B=$ nutritional ballance; $S I B=$ social interaction balance; $R A B=$ rest-activity balance

Hypothesis \#13 is supported. Subjects who report insufficient professional help after discharge from the hospital have less good performance of self-care needs in the area of maintaining balances between activity and rest and between solitude and social interaction.

It is stated in mypothesis \#14 that persons who have experienced a myocardial infarction prior to surgery have a lower achievement of self-care requisites preoperatively than persons without a history of myocardial infarction. For the 49 subjects who have had a myocardial infarction a mean SCl-score of $\mathrm{M}=81.3$ ( $\mathrm{sd}=15.2$ ) was found. The 37 subjects who have not experienced a myocardial infarction (MI) had a pre-operative SCl-score of on the average $\mathrm{M}=85.2(\mathrm{~s} d=10.0$ ). A one-tailed $t$-test for independent samples showed that this difference, although in the expected direction was not of a statistically significant level $(\mathrm{t}(84)=1.46, \mathrm{p}>05)$. One-tailed t-tests comparing the subjects with $\mathrm{MI}$ with the subjects without $\mathrm{MI}$ on their mean subscale-scores, revealed a small but significant difference $(t(84)=1.73$, $\mathrm{p}<.05$ ) in NUB-scores (nutritional balance). Subjects who did not have a history of myocardial infarction scored pre-operatively $M=8.4(s d=1.1)$, whereas the others 
scored on the average $\mathrm{M}=7.9(\mathrm{sd}=1.5)$. Hypothesis \#14 is partly supported.

Hypothesis \#15 predicts that preoperatively, persons with a long history of cardiac disease, have a lower achievement of self-care requisites than persons with a recent diagnosis of cardiac disease. The 40 subjects who were diagnosed with cardiac disease for less than a year prior to their CAB-surgery, had a pre-operative mean $\mathrm{SCl}$-score of $\mathrm{M}=85.0$ ( $\mathrm{sd}=11.6$ ). The 46 subjects who had had cardiac problems for more than one year before surgery had a mean score of $M=81.2$ $(s d=14.5)$ on the Self-Care Inventory. This difference is not significant $(t(84)=1.32$, $\mathrm{p}>$.05). However, one-tailed t-tests comparing the means on the subscales of the two groups revealed that subjects with a short history of cardiac disease scored significantly higher $(t(84)=2.11, p<.05)$ on the RAB-subscale $(M(R A B)=7.4 ; \underline{s d}=1.3)$ than subjects who had been diagnosed with cardiac disease for more than one year $(M(R A B)=6.7 ; s d=1.8)$. The mean scores on the other two subscales did not differ significantly. Hypothesis \#15 is partly supported.

table 4.11 Mean pre-operative SCl-and subscale scores for subjects with different histories of cardiac disease

\begin{tabular}{lrrrrrrrrr} 
& \multicolumn{2}{c}{$\begin{array}{l}\text { long history } \\
\text { and MI }(\mathbf{n}=34)\end{array}$} & \multicolumn{2}{c}{$\begin{array}{c}\text { others } \\
(\mathbf{n}=27)\end{array}$} & \multicolumn{2}{c}{$\begin{array}{c}\text { short history } \\
\text { no MI }(\mathbf{n}=25)\end{array}$} \\
Scale & Mean & sd & \multicolumn{2}{c}{ Mean } & sd & Mean & sd & $F$ & F(lin) \\
\hline SCl & 80.0 & 15.7 & 84.4 & 12.3 & 85.5 & 10.2 & 1.48 & 2.68 \\
NUB & 7.9 & 1.5 & 8.2 & 11.2 & 8.4 & 1.2 & 1.00 & 1.98 \\
SIB & 7.6 & 2.0 & 7.9 & 1.8 & 7.3 & 1.8 & 0.56 & 0.28 \\
RAB & 6.6 & 1.8 & 7.2 & 1.7 & 7.5 & 1.3 & 1.98 & $3.88^{*}$ \\
\hline
\end{tabular}

${ }^{*} \mathrm{p}<.05_{n}^{* *} \mathrm{~g}<.01$

$N U B=$ nutritional ballance; $S I B=$ social interaction balance; $R A B=$ rest-activity balance

The combination of hypothesis \#14 and \#15 leads to the prediction that the 34 subjects who have a long history of cardiac disease which includes a myocardial infarction, would have a lower pre-operative achievement of self-care requisites than the 25 subjects with a short history of cardiac disease without experiencing a myocardial infarction. The latter can be assumed to have a better pre-operative state of health. The health state of the other 27 subjects, who have either had a myocardial infarction (combined with a short duration) or have had coronary disease for more than one year (without experiencing a myocardial infarction) can be expected to be in between that of the first two groups. Analyses of variance have been computed to compare the mean $\mathrm{SCl}$ - and subscale-scores of the three groups. The results are presented in table 4.11. To examine whether subjects with a relatively better health indeed have better performance of their self-care a test of linearity is performed as well.

Although the difference in SCl-scores is in the predicted direction, it is not of a statistically significant level. However, the test of linearity over the three mean RAB- 
scores is significant. There is a tendency that less severe cardiac health problems are associated with a better performance of self-care in relation to the maintenance of a balance between activity and rest. Moreover, an additional one-tailed t-test shows that the difference in mean RAB-score between the group with the least favorable and the group with the most favorable cardiac health state is significant $(\mathrm{t}(57)=2.06 ; \mathrm{p}<.06)$. Subjects with a long history of cardiac disease including a myocardial infarction have a lower pre-operative achievement of self-care requisites in the area of activity and rest than subjects with a short history of cardiac disease without experiencing a myocardial infarction.

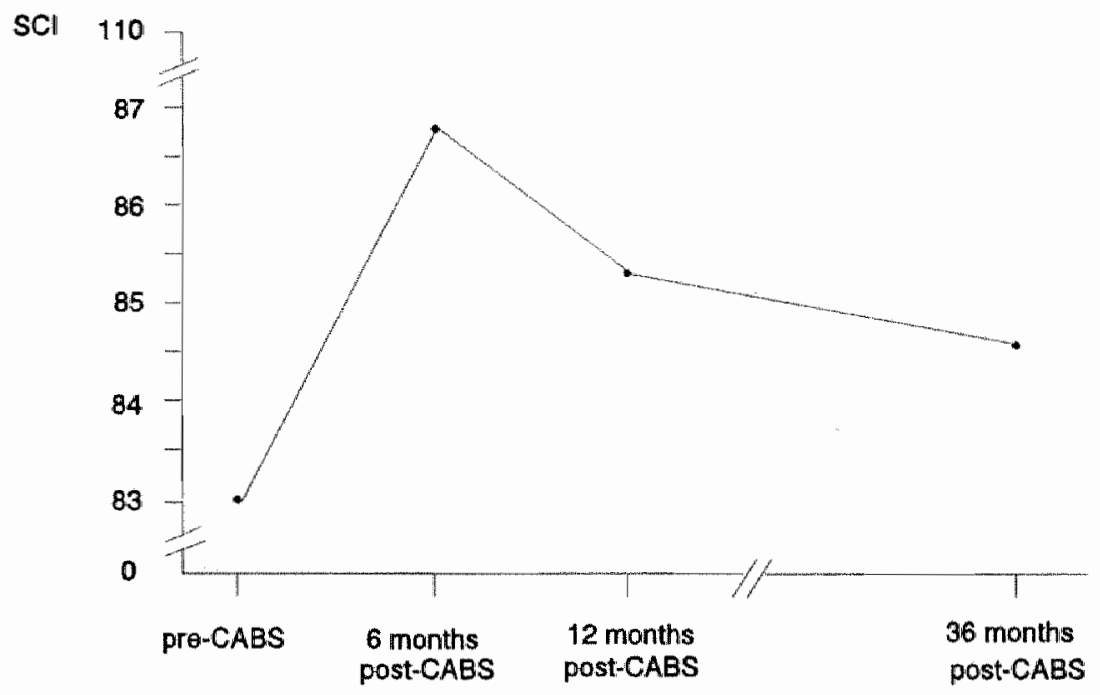

figure 4.3 Changes in SCl-scores ower time $(n=86)$

In the sixteenth hypothesis it is predicted that after CAB-surgery subjects have a higher achievement of self-care requisites than before CAB-surgery. Table 3.4 in section 3.5.2. presents the mean SCl-scores, and they are depicted in figure 4.3. To examine hypothesis \#16, a MANOVA with repeated measures testing the contrast $(-3,1,1,1)$ was performed. This test yielded a statistically significant outcome: $\mathrm{E}(1,84)=4.15$ with $\mathrm{g}<.05$. Next, this test was repeated for the pre- and postoperative subscale-scores. It was found that the previous detected differences in SCl-scores over time were due to significant increases in RAB-scores over time. The MANOVA with repeated measures testing the contrast $(-3,1,1,1)$ over the RABscores revealed a large $F: \underline{F}(1,84)=14.0$ with $\mathrm{p}<.01$. Hypothesis $\# 16$ is supported.

The last hypothesis in relation to the influence of the basic conditioning factors on achievement of self-care requisites deals with the effect of postoperative recurrence of chest discomfort. Six months and three years after CAB-surgery only 15 subjects report a recurrence of chest discomfort. This is not a great enough percentage of 
the sample to perform relevant analyses with. Thus, hypothesis \#17 is only tested in the measurements of one year after CAB-surgery. It is expected that subjects who experience a recurrence of chest discomfort 12 months after surgery have lower SCl-scores than subjects who do not. One-tailed t-test revealed that the mean SCl-score of the 25 subjects who experience a recurrence of chest discomfort one year after surgery is significantly lower than the mean SCl-score of the 61 subjects who do not (table 4.12). Further t-tests comparing the two groups on their mean subscale-scores show that this difference is related to higher scores of the latter group on both the NUB- and the RAB-subscale.

table 4.12 Mean sciores of SCI and subscales, 12 months after surgery, comparing subjects with recurrence of chest discomfort with subjects without recurrence

\begin{tabular}{|c|c|c|c|c|c|c|}
\hline \multirow[b]{2}{*}{ Scale } & \multicolumn{2}{|c|}{$\begin{array}{c}\text { subjects } \\
\text { with }(n=25)\end{array}$} & \multicolumn{2}{|c|}{$\begin{array}{l}\text { subjects } \\
\text { without }(n=61)\end{array}$} & \multirow[b]{2}{*}{$\mathrm{dff}$} & \multirow[b]{2}{*}{$t$} \\
\hline & Mean & sd & Mean & sd & & \\
\hline 12 months $\mathrm{SCl}$ & 78.8 & 14.6 & 818.0 & 10.5 & 84 & $3.26^{* *}$ \\
\hline NUBB & 7.6 & 1.6 & 8.5 & 0.9 & 84 & $3.25 * *$ \\
\hline SIB & 7.1 & 1.9 & 7.6 & 1.6 & 84 & 1.30 \\
\hline $\mathbb{P A B}$ & 6.9 & 1.4 & 7.8 & 1.1 & 84 & $2.92^{k * *}$ \\
\hline
\end{tabular}

${ }^{*} \mathrm{D}<.05^{* * *} \mathrm{p}<.01$

$\mathrm{NUB}=$ nutritional balance; $\mathrm{SIB}=$ sociall interaction balance; $\mathrm{RAB}=$ rest-activity balance

Subjects who experience a recurrence of chest discomfort after CAB-surgery have a lesser performance in achievement of self-care needs in the area of activity and rest, as well as in relation to appetite, digestion and bowel movement. These results are in support of hypothesis \#17.

The combined effect of the basic conditioning factors

The different analyses of this section revealed significant relationships between on the one hand achievement of self-care requisites and on the other hand, the basic conditioning factors gender, socio-economic status, posthospital professional help, the combination of myocardial infarction and duration of cardiac disease, and recurrence of chest discomfort. In addition it was found that the change in health state which is induced by the CAB-surgery also contributed to the increase in selfcare performance. To determine the combined effect of the basic conditioning factors and the relative contribution of each of them to the explained variance in the $\mathrm{SCl}$-scores, multiple regressions were computed for the pre-operative and the three postoperative measurements. The results are summarized in table 4.13 (more detailed statistics are in appendix IV).

Pre-operatively, three of the five basic conditioning factors are selected as significant predictors. Together these three explain $10 \%$ of the variance in the pre- 
operative SCl-score. Having a higher socio-economic status, not having experienced a myocardial infarction and being a man contributes to higher pre-operative scores on the Self-Care Inventory.

table 4.13 Significant results of stepwise multiple regression analyses predicting the SChscores at the four moments of measurement

\begin{tabular}{lcccc}
\hline Predictor Variables & pre-CABS & $\begin{array}{c}6 \text { months } \\
\text { post-CABS }\end{array}$ & $\begin{array}{c}12 \text { months } \\
\text { post-CABS }\end{array}$ & $\begin{array}{c}36 \text { months } \\
\text { post-CABS }\end{array}$ \\
\hline $\begin{array}{l}\text { history of MI } \\
\text { duration of card. dis. }\end{array}$ & $(2)$ & & & \\
chest discomfon & $\ldots$ & & $(1)$ & $(2)$ \\
age & & & & $(1)$ \\
gender & $(3)$ & $(2)$ & $(2)$ & $(3)$ \\
soc. economic status & $(1)$ & $(1)$ & $\ldots 9$ & $-\ldots$ \\
professional thelp & $\cdots$ & .09 & .14 & .15 \\
\hline $\mathrm{R}^{2}$ & .10 & & & \\
\hline
\end{tabular}

(1)/(2)/(3) selected first, second or third as predictor ... not includied in the analysis

Six months after CAB-surgery, the only significant predictors are posthospital professional help and socio-economic status. Having received sufficient professional help after discharge from the hospital, and having a high socio-economic status result in higher 6-months-SCl-scores. The combined effect of these two basic conditioning factors accounts for only $9 \%$ of the variance in the 6-months-SClscore.

Twelve months after CAB-surgery, the basic conditioning factors recurrence of chest discomfort and socio-economic status are selected as significant predictors of the 12 -months-SCl-score. They explain a total of $14 \%$ of the variance. Experiencing chest discomfort a year after CAB-surgery and having a low socio-economic status result in lower 12-months-SCl-scores.

Finally, three years postoperatively, the combined set of three basic conditioning factors gender, recurrence of chest discomfort and socio-economic status explains $15 \%$ of the variance in the 36 -months-SCl-score. Next to being a woman, experiencing chest discomfort three years after CAB-surgery and having a low socioeconomic status result in lower $\mathrm{SCl}$-scores.

These multiple regressions were computed another time, with the ASA-scores included (table 4.14 and for more detail appendix IV). Then, the total explained variance of the Self-Care Inventory increased to respectively 14\% (pre-operatively), $11 \%$ (6-months), $18 \%$ (12-months), and $21 \%$ (36-months). It was found that the ASA-scores contributed significantlly and positively to the explained variance in the Self-Care Imventory at all four moments of measurements. In addition, pre-operati- 
vely being a male and having cardiac disease for a relatively short time also coritributed to higher SCl-scores. Six months after surgery, having received sufficient posthospital professional help added positively to the score on the SelfCare inventory. Whereas one and three years after CAB-surgery, next to higher ASA-scores, being a male and not experiencing chest discomfort contributed to higher achievement of self-care.

table 4.14 Significant results of stepwise multiple regression analyses predicting the SClscores over the four moments of measurement, including the ASA-scores as potential predictor

\begin{tabular}{|c|c|c|c|c|}
\hline Predictor Variables & pre-CABS & $\begin{array}{l}6 \text { months } \\
\text { post-CABS }\end{array}$ & $\begin{array}{l}12 \text { months } \\
\text { post-CABS }\end{array}$ & $\begin{array}{l}36 \text { months } \\
\text { post-CABS }\end{array}$ \\
\hline ASA score & (1) & (1) & (2) & (2) \\
\hline \multicolumn{5}{|l|}{ history of MI } \\
\hline duration of card. dis. & (3) & & & \\
\hline chest discomfort & $\ldots$ & & (1) & (3) \\
\hline \multicolumn{5}{|l|}{ age } \\
\hline gender & (2) & & (3) & (1) \\
\hline \multicolumn{5}{|l|}{ soc. economic status } \\
\hline professional help & -- & (2) & $\cdots$ & $\ldots$ \\
\hline$R^{2}$ & .14 & .11 & .18 & .21 \\
\hline
\end{tabular}

$(1) /(2) /(3)$ selected first, second or third as predictor

... not included in the analysis

For the purpose of investigating the effect of self-care agency and the basic conditioning factors on the different aspects of universal self-care, three more sets of multiple regressions have been conducted with respectively the subscales NUB, $\mathrm{SIB}$ and RAB as dependent variables. The tables 4.15 to 4.17 present the results.

With exception of the 6-months measurement, fulfilling the self-care requisites in relation to sufficient intake of nutrients and the eliminative processes is predicted mainly by gender and self-care agency, and to a lesser degree by health state indicators and age. Men achieve this category of self-care requisites better than women, and greater abilities for self-care also lead to better achievement. Preoperatively, not having had a myocardial infarction and being younger account for an extra $7 \%$ of the variance in the achievement of self-care requisites in relation to the intake of nutrients. Experiencing chest discomfort one year after CAB-surgery is the main predictor of the NUB-score at that moment, it explains $11 \%$ of the variance. 
table 4.15 Significant results of stepwise muttiple regression analyses predicting the NUB. (nutritional balance) scores over the four moments of measurement, including the ASA-scores as potential predictor

\begin{tabular}{|c|c|c|c|c|}
\hline Priedictor Variables & pre-CABS & $\begin{array}{l}6 \text { months } \\
\text { post-CABS }\end{array}$ & $\begin{array}{l}12 \text { months } \\
\text { post-CABS }\end{array}$ & $\begin{array}{l}36 \text { months } \\
\text { post-CABS }\end{array}$ \\
\hline ASA score & (2) & & (3) & (2) \\
\hline history of Ml & (3) & & & \\
\hline \multicolumn{5}{|l|}{ duration of card. dis. } \\
\hline chest discomfort & - & & (1) & \\
\hline age & (4) & & & \\
\hline gender & (1) & & (2) & (1) \\
\hline \multicolumn{5}{|l|}{ soc. economic status } \\
\hline professional help & -- & & $\cdots$ & $\cdots$ \\
\hline $\mathbf{R}^{2}$ & .24 & .00 & .19 & .20 \\
\hline
\end{tabular}

(1)/(2)/(3) selected first, second or third as predictor

... not included in the analysis

table 4.16 Significant results of stepwise multiple regression analyses predicting the SIB(social interaction balance) scores over the four moments of measurement, including the ASA-scores as potential predictor

\begin{tabular}{lcccc}
\hline & & 6 months & 12 months & 36 months \\
Predictor Variables & pre-CABS & post-CABS & post-CABS & post-CABS \\
\hline
\end{tabular}

ASA score

(11)

(2)

(1)

(1)

history of MI

duration of card. dis.

chest discomfort

(2)

age

gender

soc. economic status

professional help

\begin{tabular}{lllll}
\hline $\mathrm{R}^{2}$ & .09 & .09 & .10 & .11 \\
\hline
\end{tabular}

(1)/(2)/(3) selected first, second or third as predictor ..- not included in the analysis 
As far as the prediction of the achievement of self-care requisites in relation to social interaction is concerned, self-care agency seems to be the greatest predictor (table 4.16). The basic conditioning factors do not clearly affect the self-care in this area. The exception is the variable 'lack of professional care' after discharge from the hospital, which leads to lesser achievement. This variable accounts for the explanation of almost $6 \%$ of the variance in the 6 -months SIB-score. In addition, experiencing chest discomfort three years after CAB-surgery contributes to lesser achievement at that moment in time, it explains $3 \%$ of the variance in the $36-$ months SilB-score.

Lastly, the regressions over the RAB-scale show varying results at the different moments in time. A higher socio-economic status continues to contribute positively to the achievement of self-care requisites in the area of preserving a balance between rest and activity. One and three years after CAB-surgery, the experience of a recurrence of chest discomfort leads to lesser self-care performance in this area. Self-care agency only contributes significantly to the achievement of self-care requisites in the area of preserving a balarice between activity and rest 6 and 36 months after CAB-surgery. Before surgery, being diagnosed with cardiac disease relatively recently contributes to better performance, whereas 3 years after CABsurgery men do better than women.

table 4.17 Significant results of stepwise multiple regression analyses predicting the RAB (restactivity balancel scores over the four moments of measurement, including the ASAscores as potential predictor

\begin{tabular}{|c|c|c|c|c|}
\hline Predictor Variables & pre-CABS & $\begin{array}{l}6 \text { months } \\
\text { post-CABS }\end{array}$ & $\begin{array}{l}12 \text { months } \\
\text { post-CABS }\end{array}$ & $\begin{array}{l}36 \text { months } \\
\text { post-CABS }\end{array}$ \\
\hline
\end{tabular}

ASA score

(1)

(2)

history of MI

duration of card. dis.

(2)

chest discomfort

age

gender

soc. economic status

(1)

(3)

(2)

(3)

professional help

(2)

\begin{tabular}{lll}
\hline $\mathrm{B}^{2}$ & .11 & .16 \\
\hline
\end{tabular}

(1)/(2)/(3) selected first, second or third as predictor

-... not included in the analysis 


\subsubsection{To What Extent Do Basic Conditioning Factors Influence State of Well- being ?}

Hypothesis \#18 reflects the expectation that there is an interaction effect of age and sex on the perception of state of well-being. The mean pre- and postoperative ratings of state of well-being of the middle-aged and older groups of men and women are depicted in figure 4.4. MANOVA's with repeated measures did not reveal any significant main effects of either age nor gender on ratings for state of well-being. However, MANOVA with repeated measures did reveal a statistically significant interaction effect of age and gender: $E(2,76)=4.29$ with $p<.05$. In general alder women scored slightly higher than older men, while middle-aged men continued to give higher ratings for state of well-being than the women in that agegroup. Hypothesis \#18 is supported.

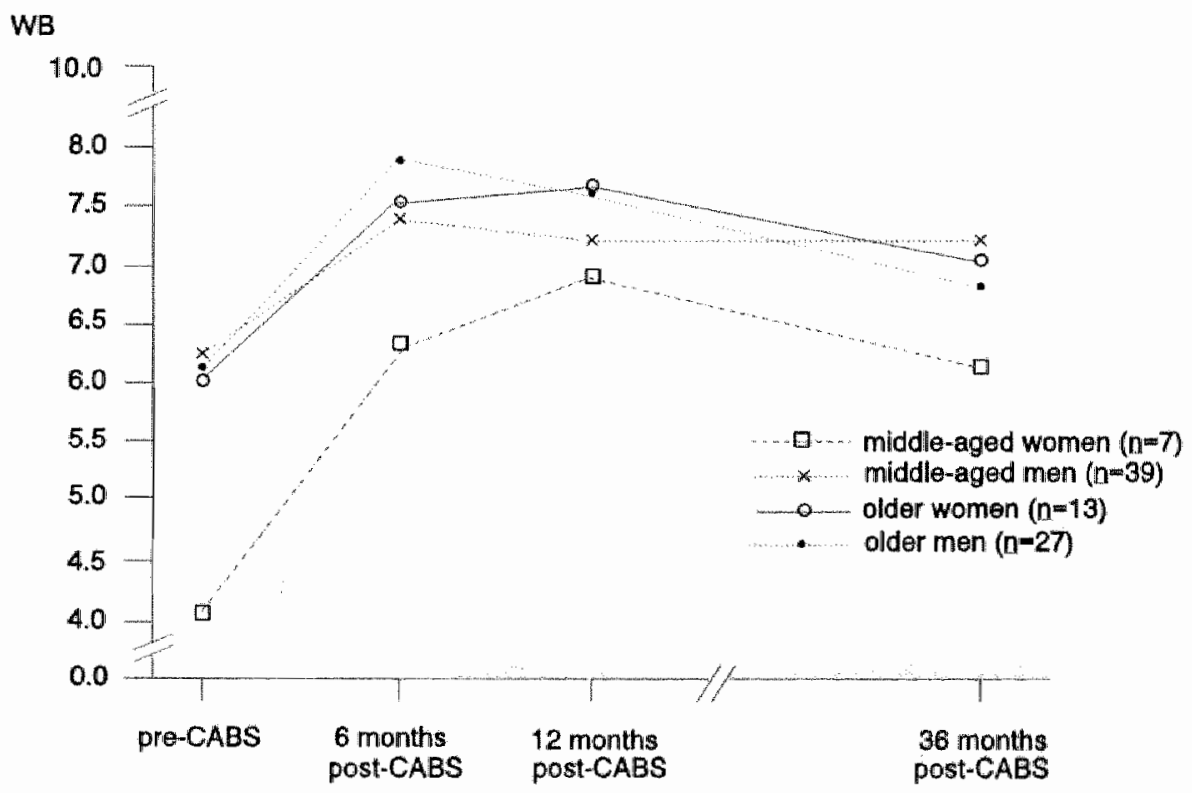

figure 4.4 Interaction effect of age and gender on well-being ratings

It is predicted in hypothesis \#19 that subjects from a group of higher socioeconomic status have higher ratings for state of well-being than subjects from a group of lower socio-economic status. The pre-and postoperative mean ratings of state of well-being of the three groups distinguished as lower, middle and higher socio-economic status are pictured in figure 4.5. On the day before CAB-surgery the well-being ratings are in the opposite direction of what was expected. Subjects from the group with lower socio-economic status have the highest ratings, whereas subjects from the group with the higher socio-economic status rate their well-being 
the lowest. However, postoperatively the group of higher socio-economic status continues to rate their well-being at the highest level. Besides, at one and at three years after CAB-surgery, the group with the lowest socio-economic status also have the lowest ratings for state of well-being. MANOVA with repeated measures over the four measurements was conducted to examine the overall effect of socioeconomic status on ratings for state of well-being. The F-test showed an overall effect of an almost significant level: $\mathrm{F}(2,82)=2.61$ with $\mathrm{p}=.080$. The findings are in support of hypothesis \#19.

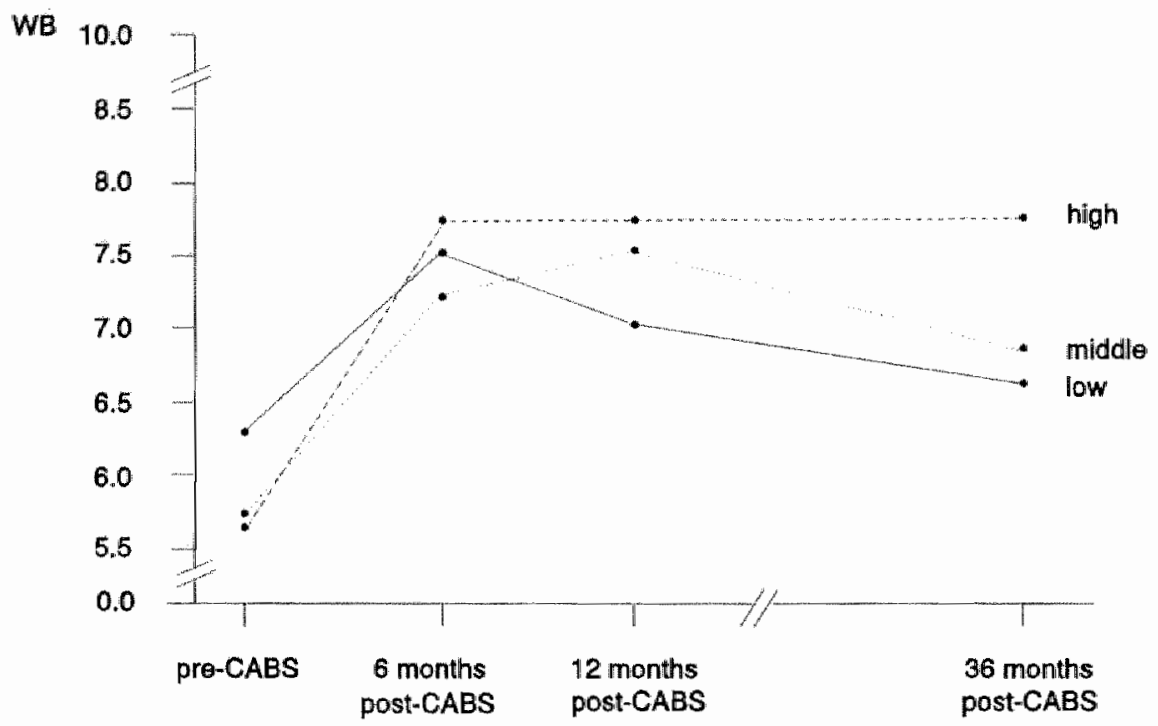

figure 4.5 Effect of socio-economic status on well-being ratings

Hypothesis \#20 predicts that subjects who receive sufficient professional help after their discharge from the hospital have higher states of well-being than the subjects who receive insufficient help. A one-tailed t-test for independent samples was computed to compare the mean ratings for state of well-being 6 months after surgery. The test yielded a significant difference: $t(84)=3.05, p<.01$. The mean rating of the subjects who received sufficient posthospital professional help of $M=7.9$ ( $\mathrm{sd}=1.2$ ) was found to be significantly higher than the mean rating of the 37 subjects who did not receive sufficient help $(M=6.9 ; s d=1.8)$. Hypothesis \#20 is supported.

In hypothesis \#21 the expectation is formulated that subjects with a history of myocardial infarction report pre-operatively a lower state of well-being than persons without a history of myocardial infarction. The mean pre-operative rating for state of well-being of the group with infarction is $M=5.9(s d=2.3)$. The mean pre-operative rating for state of well-being for the subjects without myocardial infarction is $M=6.1$ 
( $s d=2.4$ ). A one-tailed t-test was conducted to examine the significance of this difference. The t-value is $t(83)=.49$, which is not significant. Hypothesis \#2t is not supported by the results.

Hypothesis \#22 predicts that subjects with a long history of cardiac disease; report pre-operatively a lower state of well-being than persons with a recent diagnosis of cardiac disease. The mean pre-operative ratings of the 2 groups were as follows: for the group with a long history $M$ (well-being) $=5.9(\mathrm{sd}=2.5)$, and for the group with a short history $M$ (well-being) $=6.1 \quad(\mathrm{sd}=2.3)$. The one-tailed t-test revealed that this difference was not of a statistically significant level $(t(83)=40)$. Hypothesis \#22 is not supported.

Next, a one-tailed t-test for independent samples was conducted to compare the pre-operative ratings for state of well-being of the 34 subjects with a long history of cardiac disease which includes a myocardial infarction $\underline{M}($ well-being $)=5.6 ; s d=2.2)$ with the rating of the 25 subjects with a recent diagnosis and without a history of myocardial infarction ( $M$ (well-being $)=5.9 ; s d=2.1)$. The difference between these two ratings was found to be not of a significant level $(t(57)=.47)$.

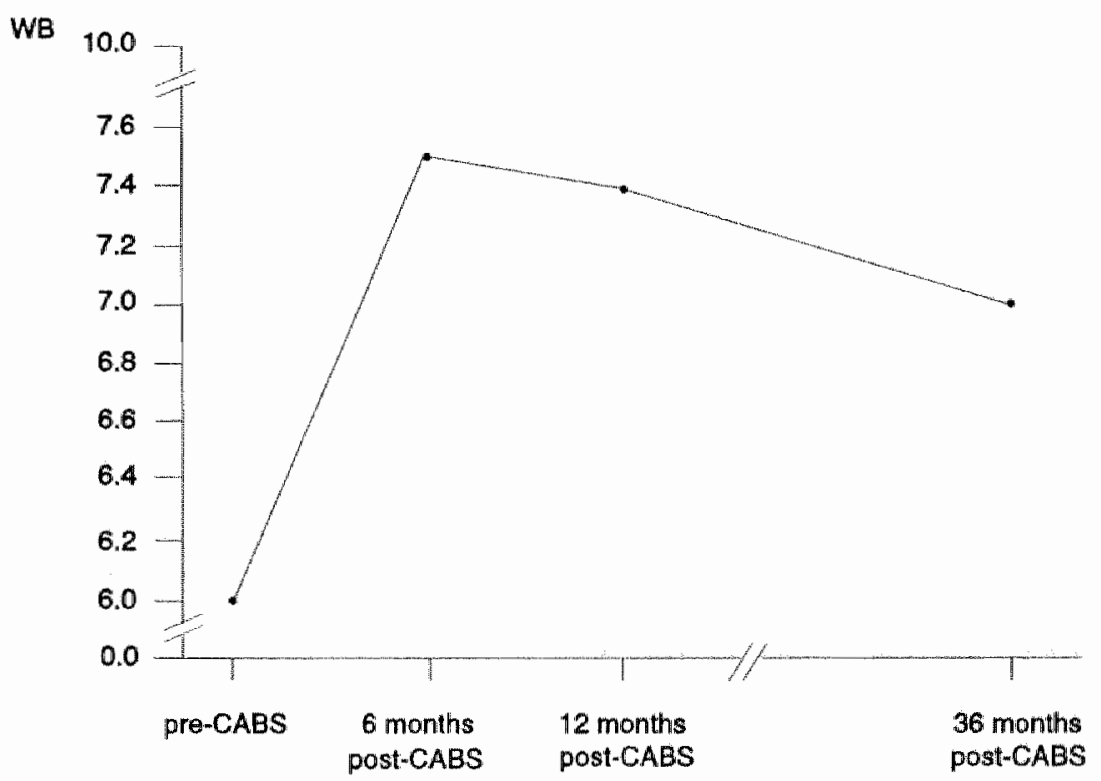

figure 4.6 Changes in well-being ralings over time

The twenty-third hypothesis predicts that postoperatively, subjects rate their state of well-being at a higher level than before CAB-surgery. Table 3.2 in section 3.5 .1$. presents the four mean ratings for state of well-bieing, which are depicted in figure 4.6. To examine hypothesis \#23, a MANOVA with repeated measures testing the contrast $(-3,1,1,1)$ was performed. The outcome of this test was statistically 
significant: $\mathrm{E}(1,81)=24.0 \quad \mathrm{Q}=.001$. Besides, separate t-tests for paired measures were computed comparing the pre-operative well-being score with each of the three postoperative scores. It was found that all three postoperative scores were significantly higher than the pre-operative score. These results are supportive of hypothesis 23.

Finally, hypothesis \#24 predicts that persons who experience a recurrence of chest discomfort one year after surgery report a lower state of well-being than persons who do not. The mean rating for state of well-being of the 25 subjects who report a recurrence of chest discomfort is $M=6.9$ ( $s d=1.3$ ). The mean rating for state of well-being of the 61 subjects who report no recurrence of chest discomfort one year after $\mathrm{CAB}$-surgery is $\mathrm{M}=7.5$ ( $\mathrm{sd}=1.4)$. The one-tailed $\mathrm{t}$-test shows that this difference is statistically significant $(\mathrm{t}(84)=1.96 ; \mathrm{p}<.05)$. Thus, hypothesis $\# 24$ is supported.

\section{The combined effect of achievement of self-care requisites and basic conditioning factors}

The different analyses of this section revealed significant relationships between on the one hand state of well-being and on the other hand, the basic conditioning factors gender, age, socio-economic status, posthospital professional help, and recurrence of chest discomfort. In addition it was found that the change in health state which occurs through the CAB-surgery also contributed to higher ratings of state of well-being postoperatively. It has also been found that achievement of universal self-care requisites and achievement of the specific health-deviated requisite in relation to smoking were significantly related to state of well-being.

To determine the combined effect of achievement of self-care requisites and the basic conditioning factors and the relative contribution of each of them to the explained variance in the SCl-scores, multiple regressions were computed for the pre-operative and the three postoperative measurements. the results are presented in table 4.18. It appears that with the measures for universal and health-deviated self-care only ittle of the effect of the basic conditioning factors remains (more detailed statistics are in appendix IV).

Pre-operatively, the RAB- and NUB-scores and the smoking variable together explain $20 \%$ of the variance in perception of pre-operative state of well-being. Of the basic conditioning factors only socio-economic status contributes significantly to the explanation of well-being. In this case the beta is of a negative nature, which implies that pre-operatively, subjects with a higher social status tend to have a lower rating of state of well-being. It adds an extra $3 \%$ to the explanation of the variance in the pre-operative rating of well-being.

Six months after CAB-surgery, the RAB-score explains $39 \%$ of the variance in perception of 6 months-well-being. Smoking adds another $7 \%$ of explanation. The basic conditioning factors gender (with a negative beta, indicating higher well-being for women) and age (with a positive beta, indicating higher well-being for older persons) each account for an additional proportion of $2 \%$. 
table 4.18 Significant results of stepwise multiple regression analyses predicting the Well. being-ratings at the four moments of measurement

\begin{tabular}{|c|c|c|c|c|}
\hline Predictor Variables & pre-CABS & $\begin{array}{l}6 \text { months } \\
\text { post-CABS }\end{array}$ & $\begin{array}{l}12 \text { months } \\
\text { post-CABS }\end{array}$ & $\begin{array}{l}36 \text { months } \\
\text { post-CABS }\end{array}$ \\
\hline NUB-score & (2) & & & \\
\hline SIB-score & & & (1) & (2) \\
\hline RAB-score & (1) & (1) & (2) & (1) \\
\hline Non-Smoking & (3) & (2) & & \\
\hline Sufficient Exercise & -- & & & \\
\hline \multicolumn{5}{|l|}{ histony of MI } \\
\hline \multicolumn{5}{|l|}{ duration of card. dis. } \\
\hline chest discomfort & $\ldots$ & & & \\
\hline age & & (4) & & (3) \\
\hline gender & & (3) & & \\
\hline soc. ecionomic status & (4) & & & \\
\hline professional help & $\cdots$ & & $\cdots$ & $\cdots$ \\
\hline $\mathrm{R}^{2}$ & .23 & .50 & .43 & .41 \\
\hline
\end{tabular}

$\mathrm{NUB}=$ nutritional balance; $\mathrm{SIB}=$ social interaction balance; $\mathrm{RAB}=$ rest-activity balance

(1)/(2)/(3) selectled first, second or third as predictor

... not included in the analysis

Twelve months after CAB-surgery, the SIB and RAB-score together explain $43 \%$ of the variance in the perception of 12 -months-well-being. None of the basic conditioning factors is selected as significant predictor of the 12-month rating.

Finally, three years after $\mathrm{CAB}$-surgery, the $\mathrm{RAB}$ and $\mathrm{SIB}$-scores are again the main predictors for the state of well-being of that moment; they account for $39 \%$ of the total variance. The basic conditioning factor age adds another $2 \%$. With the effect of achievement of universal self-care requisites controlled for, older persons tend to perceive their state of well-being 3 years after CAB-surgery better than younger persons.

\subsubsection{To What Extent Do Basic Conditioning Factors Affect the Relationship Between Self-care and State of Well-being ?}

The last formulated hypothesis reflects the expectation that the basic conditioning factors do not affect the relationship between self-care and state of well-being. For the examination of this hypothesis the z-test for comparing two correlation coefficients has been applied. With this test it is possible to check the significance of the 
difference between the correlation coefficients between two variables in two populations. In this test the quantity $\underline{\underline{ }}$ is computed. This $\underline{u}$ follows a normal distribution, with mean 0 , and standard deviation 1 . The test tests the working hypothesis that the two correlation coefficients are of equal size. When $\underline{u}$ is larger than 1.96, the hypothesis can be rejected (with a minimum significance level of $0.05)$.

The three variables representing the sociodemographic basic conditioning factors are expected to have a potential effect on all four measurements. The Pearson correlations and related $\underline{\underline{u}}$ are given in table 4.19 .

The first presented basic conditioning factor is gender. The Pearson correlations between the SCl-score and the well-being-rating at four moments in time have been computed for men and for women. Only pre-operatively is the correlationcoefficient for men significantly lower than the coefficient for the women $(u=2.31$, $\mathrm{p}<.05)$. For the postoperative measurements the correlations are not significantly different.

table 4.19 Pearson correlations between SCl-score and well-being ratings for subgroups based on differences in gender, age and socio-economic status, at four moments in time

\begin{tabular}{|c|c|c|c|c|}
\hline Demographics & pre-CABS & $\begin{array}{l}6 \text { months } \\
\text { post-CABS }\end{array}$ & $\begin{array}{l}12 \text { months } \\
\text { post-CABS }\end{array}$ & $\begin{array}{l}36 \text { months } \\
\text { post-CABS }\end{array}$ \\
\hline \multicolumn{5}{|l|}{ Gender } \\
\hline men $(n=66)$ & $.27^{*}$ & .54 & .55 & .61 \\
\hline women $(n=20)$ & $.72^{\star}$ & .62 & .68 & .64 \\
\hline \multicolumn{5}{|l|}{ Age } \\
\hline under $61(n=46)$ & .38 & .68 & .70 & $.76^{*}$ \\
\hline over $61(n=40)$ & .48 & .48 & .46 & $.48^{*}$ \\
\hline \multicolumn{5}{|c|}{ Socio-aconomic Status } \\
\hline lower $(n=33)$ & .54 & .46 & .54 & .57 \\
\hline middie $(n=30)$ & $.65^{*}$ & .71 & .65 & $.71^{*}$ \\
\hline higher $(n=23)$ & $.10^{*}$ & .57 & .51 & $.29^{*}$ \\
\hline
\end{tabular}

${ }^{*} \mathrm{~g}<.05 \mathrm{n}^{* *} \mathrm{~g}<.01$ in relation to quantity $\underline{\underline{H}}$

The second basic conditioning factor presented in table 4.19 is age. The Pearson correlations between the SCl-score and the well-being-rating at four moments in time have been computed for middle-aged and older subjects. Postoperatively, the coefficients of the older people continue to be lower than for the subjects under 61 . 
However, only at the three years measurement is this difference significant $\underline{\underline{u}}=\mathbf{2} .11$, $\mathrm{p}<.05)$.

In relation to the next basic conditioning factor socio-economic status, two sets of significantly different Pearson correlations are found. The pre-operative Pearson correlation between SCl-score and well-being rating for the subjects from the group of higher socio-economic status is significantly lower than the coefficient for the middle group $(\underline{L}=2.29, \mathrm{p}<.05)$. The difference with the coefficient of the group with low socio-economic status is not significant. At six and at twelve months after $\mathrm{CAB}$ surgery no significant differences are found between any of the groups. However, three years after surgery, the Pearson correlation between SCl-score and wellbeing rating for the subjects from the group of higher socio-economic status is again significantly lower than the coefficient for the middle group $(\underline{u}=2.00, \mathrm{p}<.05)$. The difference with the coefficient of the group with low socio-economic status is again not statistically significant.

The fourth identified basic conditioning factor is the receiving of sufficient versus insufficient professional care after discharge from the hospital. The Pearson correlation between the 6-month SC-score and the 6-month well-being-rating has been computed for both the group of subjects with sufficient help, and the group of subjects not receiving sufficient professional help (table 4.20 ). The two coefficients are not significantly different $(\underline{u}=1.53, \mathrm{~ns})$.

table 4.20 Pearson correlations between SCl-score and well-being ratings for subjects with and subjects without sufficient posthospital professional help, 6 months post-CABS

\begin{tabular}{lc}
\hline Postoperative Prof. help & 6 months post-CABS \\
\hline sufficient & .42 \\
insufficient & .66 \\
\hline
\end{tabular}

" $\mathrm{E}<.05 * * \mathrm{E}<.01$ in relation to quarntity $\underline{\mathrm{L}}$

The last identified basic conditioning factor is health state. The results are presented in table 4.21. Pre-operatively health state has been operationalized as having a short versus a long history of cardiac disease; and as having (or not) experienced a myocardial infarction prior to CAB-surgery. As for duration, this was found not to have a significant effect on the correlation between the pre-operative $\mathrm{SCl}$-score and the pre-operative well-being-rating $(u=1.86, n s)$. Besides, table 4.21 shows that the pre-operative Pearson correlation between SCl-score and well-being-rating is also not significantly different for subjects who have, and subjects who have not had a myocardial infarction $(\underline{u}=.79, \mathrm{~ns})$.

Postoperatively, health state has been operationalized as the recurrence (or not) of chest discomfort. The Pearson correllation between the 12-month SCI-score and the 12-month well-being-rating has been computed for both the group of subjects with 
recurrence, and the group of subjects without recurrence. The two coefficients are not significantly different $(\mathrm{u}=.99, \mathrm{~ns})$.

table 4.21 Pearsion correlations between SCl-scores and well-being ratings for subgroups based on differences in their pre-operative health state and at 12 months after surgery based on differences in presence of chest discomfort

\begin{tabular}{lcc}
\hline Mealth State Variable & pre-CABS & 12 months post-CABS \\
\hline Duration of cardiac disease & .21 \\
$<1$ year $(\mathrm{n}=40)$ & .56 \\
$>1$ year $(\mathrm{n}=45)$ & \\
Myocardial Infarction & .48 \\
yes $(\mathrm{n}=49)$ & .33 \\
no $(\mathrm{n}=36)$ & \\
Chest Discomfort & \\
yes $(\mathrm{n}=25)$ & .67 \\
no $(\mathrm{n}=61)$ &
\end{tabular}

Thus, under certain circumstances significant differences have been found in the Pearson correlations between achievement of self-care requisites and state of wellbeing, for men and women, for middle-aged versus older people, as well as for persons with higher and lower socio-economic status. Health state indicators do not affect the relationship between self-care and well-being in this study. Hypothesis \#25 is partially supported. 


\section{CHAPTER 5 DISCUSSION}

The research model as depicted in figure 5. 1. reflects the scope of this study. The major focus of this thesis is the examination of the relationship between self-care and well-being as proposed in Orem's conceptual framework. Next to this relationship, the influences of self-care agency and five of the basic conditioning factors have been examined. In the first section of this chapter the results in relation to the major focus of study (arrow A) are discussed. The second part deals with self-care as the dependent, and self-care agency and the basic conditioning factors as the predictor variables. In 5.3. the combined effects on state of wellbeing of basic conditioning factors and self-care are discussed. A summary of the major results is depicted in a new picture of the research model in 5.5. The next section discusses issues in relation to the internal and external validity of the study. In the last part conclusions are drawn with respect to the validity of Orem's model. Besides, implications for nursing practice and suggestions for further study are proposed.

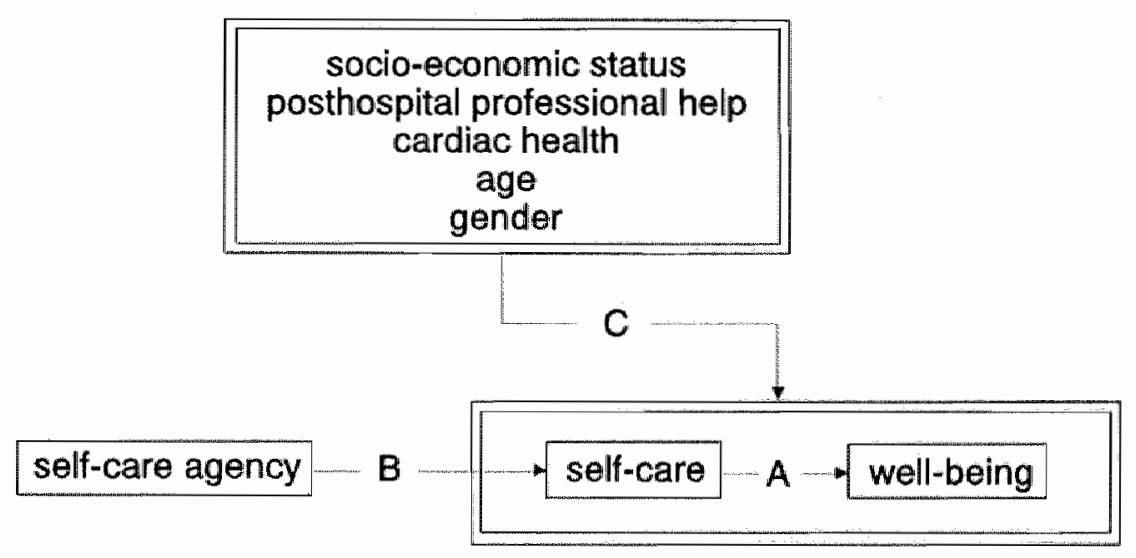

figure 5.1

Research Model 


\subsection{THE RELATONSHIP BETWEEN SELF-CARE AND STATE OF WEL-BEING}

The separate and combined effects of the universal and the health-deviated selfcare requisites on well-being have been investigated. The measure used for achievement of universal self-care requisites, the Self-Care Inventory, consistently showed a positive and strong correlation with ratings for state of well-being under different circumstances. This suggests that indeed, the better a person fulfills his/her universal self-care needs, the better he/she perceives his/her state of wellbeing. The results in relation to the health-deviated self-care requisites pointed in the same direction. Persons who do not smoke and persons who take sufficient exercise tended to perceive their well-being at a higher level than persons who do smoke and persons who do not engage in sufficient exercise. These findings are in agreement with Orem's theoretical proposition on the existence of a relationship between self-care and well-being. In this theoretical statement, Orem proposes that meeting the self-care requisites effectively, enhances the individual's well-being. The empirical data of this study support this theoretical notion. The better the individuals meet their universal requisites in relation to the intake of nutrients, the eliminative processes, social interaction and the balance between activity and rest, and the more successful they are in achieving the health-deviated self-care requisites in relation to nonsmoking and exercise, the better they perceive their state of well-being.

Further support for the existence of such a relationship was found in the analyses examining the changes over time in both variables. The longitudinal design of the study made it possible to investigate whether changes in achievement of universal self-care requisites over a certain period were paralleled by changes in perception of well-being in the same direction, over the same period. The correlations between the changes in the two variables over the three time periods were positive and of moderate strength (varying from 28 to $.40 ; \mathrm{p}<.01$ ). To determine whether these results were valid for both subjects undergoing a small change as well as for subjects undergoing a large change, the sample was divided in three subgroups. It was found that in the subgroups, representing subjects with relatively low, middle and high pre-operative SCl-scores, the correlations between changes in achievement of self-care requisites and changes in state of well-being were of comparable strength.

There was only one exception. For the interval from pre-operative to 6 months postoperative, there was no significant correlation found for the group of subjects who scored pre-operatively relatively high on the Self-Care Inventory. In this interval the mean SCl-score of this group decreased, whereas the mean well-being rating increased in a similar way as in the other subgroups. The self-care of this group is obviously very good before CAB-surgery, and the subjects feel therefore probably rather healthy. Despite of this they are in need of CAB-surgery, which affects their sense of well-being. The surgical procedure and the hospital-stay seems to affect their self-care in such a way that six months after surgery, it has not reached the 
old level yet, whereas their state of well-being has increased since surgery.

Nevertheless, in general the findings are such that it can be concluded that changes in achievement of universal self-care requisites, whether they are small or large, positive or negative, were found to be accompanied by similar changes in ratings of state of well-being.

Another set of analyses was directed to the question whether the cross-sectional findings on the relationship between self-care and state of well-being could not be explained away by the amount of well-being in an earlier stage. An individual's wellbeing (in Orem's definition) can be assumed to be rather stable. Thus, a person's well-being rating at one moment in time can be expected to be positively correlated to his/her rating at a later moment in time. However, if the achievement of self-care needs is a major predictor of an individual's well-being as well, the effect of the selfcare performance on state of well-being should still show after the perception of well-being of some time earlier has been controlled for.

The assumption that an individual's state of well-being shows a certain amount of stability over time, was found to be true in this study for at least the three postoperative well-being ratings. The intercorrelations of these three measurements were $r=.43$ or higher. The pre-operative rating for state of well-being correlated positively with the other three, but not on a statistically significant level.

The results of the hierarchical multiple regressions were in favor of the expectation that achievement of self-care requisites remains a significant predictor of state of well-being after controlling for the person's well-being of some time before. Especially the finding that the one-year and three-years state of well-being were predicted by both the well-being rating of respectively a half and two years before, and the self-care performance at respectively one and three years postoperatively is meaningful, since in these intervals the state of well-being was found to be stable. These outcomes are also in support of the idea that changes that have occurred over time in a person's state of well-being can be attributed at least for a part to self-care performance, and as such lend support to the existence of a positive relationship between self-care and well-being.

An attempt to demonstrate time order "which could have given extra support to the notion that it is self-care which influences well-being, and not the other way around was not entirely successful. It was predicted that a significant positive correlation existed between the 6-months Self-Care Inventory score and the 12-months wellbeing rating, and that this correlation would remain significant after controlling for the 12-months score on the Self-Care Inventory. Although the performance of selfcare six months after surgery was significantly and positively correlated with the state of well-being twelve months after surgery, this relationship disappeared after statistically controlling for achievement of self-care requisites 12 -months post-CABS. This can probably be ascribed to the existence of a high correlation $(r=.74)$ between the performances of self-care at six and twelve months after CAB-surgery. Despite the lack of 'proof' for a causal relationship, the results in relation to the first five formulated hypotheses are in support of Orem's presupposition in which it is stated that self-care is necessary for general well-being. Additional hypotheses 
have been derived for the purpose of further investigation into this relationship.

Firstly, from Orem's statement that all three types of self-care requisites (universal, developmental, and health-deviated) need to be met to promote well-being, it was derived that the combined effect of meeting universal and health-deviated self-care requisites would account for the greater proportion of variance in the rating of wellbeing in this study. However, the operationalization of health-deviated self-care in this study was limited to only one aspect. Orem distinguishes six categories of health-deviated self-care requisites, and here only the category of 'effectively carrying out medically prescribed diagnostic $c_{n}$ therapeutic and rehabilitative measures directed to the prevention of specific types of pathology and to the pathology itself' was partly represented. Nonsmoking and regular exercise were interpreted as measures of secondary prevention. Moreover, the variable 'engaging in exercise" was found to be significantly related to achievement of universal selfcare requisites. This can be explained by the fact that exercising in itself is also recognized as a universal self-care requisite. The need for exercising is universal, is valid for everyone. However, for cardiac patients it is even more desirable that they exercise regularly, as it is identified as a factor in the prevention of the process of atherosclerosis. This makes exercise part of secondary prevention and thus a health-deviated self-care requisite for cardiac patients.

Stepwise multiple regression analyses were performed to examine the combined effect of nonsmoking and exercise, and the achievement of universal self-care requisites on the perceived state of well-being at the four moments of measurement. Despite the underrepresentation of health-deviated self-care requisites in the operationalization, smoking was selected in two of the four analyses as adding a significant amount of explanation in the variance of wellbeing, after the effect of the universal self-care was already partialled out. The variable exercise did not contribute significantly. This is probably due to its relation with the universal self-care requisites. Still, the outcome of the analyses lend support to the idea that indeed a combination of achieving both universal and health-deviated self-care requisites is necessary for reaching a certain level of wellbeing. The limited approach of the operationalization of health-deviated self-care requisites though, makes it necessary to investigate in new studies the effects of the achievement of other categories of health-deviated self-care on state of wellbeing. Other studies may also contain a measurement of developmental self-care requisites, which were not included in this study. A combination of universal, healthdeviated and developmental self-care requisites is likely to explain the greatest proportion of variance in state of well-being.

Another hypothesis was formulated to investigate the relative contribution of the different aspects of self-care to state of well-being. In the regression analyses with the self-care variables as predictors and state of well-being as the dependent variable, the subscale RAB was consistently selected as significant predictor. This subscale represents the universal requisite 'maintaining the balance between activity and rest'. In the explaining of the pre-operative and 6-months ratings of 
state of well-being, the variable smoking contributed significantly as well. Whereas in the one- and three-years well-being rating, the subscale SUB was the other selected predictor. The subscale SIB stands for the fulfitment of the universal requisite of social interaction. In her work, Orem does not indicate whether some requisites are more important in relation to the promotion of well-being than others. However, in relation to the fulfilment of universal self-care needs, she states that in times of unfavorable conditions the performance of universal self-care may loose its routinelike character. Health problems, and more specifically coronary artery disease can be interpreted as a form of unfavorable conditions. In the case of cardiac patients undergoing or having undergone $\mathrm{CAB}$-surgery, the achievement of the self-care needs in relation to activity and rest was found to contribute the most, and the most consistently to the state of well-being. This finding seems congruent with the literature on the quality of life of post-CABS patients. Exercise tolerance and activity levels associated with chest discomfort are often discussed as indicators of their quality of life. Persons suffering from coronary artery disease are often hindered in or experience difficulties with their (physical) activities. In other words, the taking care of their needs in relation to "the maintenance of a balance between activity and rest" may well have lost its routinelike character. And for this reason, this particular universal self-care requisite may become more important in relation to well-being than other care needs for this group of patients.

What remains to be explained is the finding that in the first two measurements the second variable which was found to contribute to higher levels of well-being is nonsmoking, whereas in the last two measurements the self-care requisite in relation to social interaction was found to be the second predictor. An explanation might be found in the different manifestations of the health state at the different moments in time. According to Orem, health-deviated self-care requisites arise from the disease state. Just before and shortly after CAB-surgery the cardiac disease is more apparent, more prominent, than a year or longer after CAB-surgery. This may cause that the achievement of health-deviated self-care requisites are more important in relation to state of well-being before and shortly after surgery, than later when the disease is not revealing itself so much anymore. This argument can be carried on in the explaining of why during the later period (one and three years after CAB-surgery) the achievement of the self-care need in relation to social interaction becomes a major contributor to state of well-being. Veenhoven found in general (healthy) populations that the number and frequencies of contacts with friends and relatives was a proven fact in promoting a certain level of well-being (Veenhoven 1984). It could be argued that within about a year after CAB-surgery. life has returned to normal for most people as their cardiac disease is no longer as dominantly present as before. This might mean that their ideas on achieving wellbeing will be more congruent with those of the general population again. 


\subsection{THE EFFECT OF SELF-CARE AGENCY AND BASIC CONDTIONING FACTORS ON THE ACHIEVEMENT OF SELF-CARE REQUISTIES}

It is the goal of this study to test two more sets of Orem's theoretical propositions. They are firstly, the propositions that define the existence of a relationship between abilities for self-care and performance of seli-care. Secondly, hypotheses have been formulated and analyses have been conducted with regard to the proposed relationships between basic conditioning factors and performance of self-care. The results of these tests will be discussed in this section.

In all measurements, both pre- and postoperatively the instrument for self-care agency was found to be significantly and positively correlated to the achievement of self-care requisites. A greater ability for self-care was associated with a better performance of self-care. Moreover, there was hardly any variation in the size of the correlations $(\underline{r}=.24$ to $\underline{r}=.28)$, which indicates a stable relationship. At each moment of measurement, the ability of self-care as measured with the ASA-scale accounted for about $10 \%$ of the variance in the scores on the Self-Care Inventory. Thus, the relationship persisted under conditions of both not such a good health state as well as under conditions of an improved health state. At first sight, the relationship may not seem as strong as might have been expected. However, it should be taken into account that the ASA-scale was designed to measure the power to perform self-care actions, which does not necessarily imply the power to perform therapeutic, that is effective, self-care. It measures "how much self-care agency is in operation (is available)' and not necessarily how adequate it is. The Self-Care Inventory on the other hand, measures the effectiveness, which is more like the adequacy of the performance of universal self-care. Similar findings on the relationship between self-care and self-care agency have been reported by other authors. Denyes (Denyes 1988) found a Pearson correlation which was only a little higher $(r=.38)$ between self-care agency as measured with the Denyes' Self-care Agency Instrument, and self-care as measured with the Denyes' Self-care Practice Instrument. These two instruments have a similar structure. In her study with adolescents, self-care agency explained $14.7 \%$ of the variance in self-care. It can be concluded that the finding in this study that four positive correlations of similar strength were found is supportive of Orem's proposition which states that persons who take action to provide in their own self-care have specialized capabilities for action (Orem 1985; p.35).

As far as the basic conditioning factors are concerned, measures of health state, gender, socio-economic status, and professional health care system elements have been found to be related to the achievement of self-care requisites. Analyses with the different measures of cardiac health state (history of myocardial infarction, duration of cardiac disease, postoperative chest discomfort, and pre-CABS health state versus post-CABS health state) indicated that a relatively better health state is associated with a better performance of self-care. Most of these outcomes 
suggested that it is the self-care in relation to the maintenance of a balance between activity and rest that is affected by cardiac health state indicators. Only in relation to the postoperative recurrence of chest discomfort, it was found that the self-care in the area of intake of nutrients and the area of eliminative processes was negatively influenced as well. However, having experienced a myocardial infarction. suffering from cardiac disease for a long time and undergoing CAB-surgery mainly affected the self-care in the area of activity and rest. Considering the health problem of the sample under study, this finding is not surprising. It has already been stated that coronary artery disease often hinders people in their physical activities, decreases their endurance and disturbs their sleep. Since only measures of cardiac health have been chosen as representation of the basic conditioning factor health state, it is not surprising that these indicators are found to have their impact mainly on this particular self-care requisite. The literature shows that in other studies with CABS-patients, the improvements after surgery were also related to activity and rest. However, as far as postoperative gain is concerned many authors report improvements in the area of social activity after CAB-surgery as well (Kornfeld \& Stanley et al. 1982; Penckofer \& Holm 1984; Folks \& Blake et al. 1986). Such a finding was not replicated in this study, no postsurgical improvements in the self-care in relation to social interaction were observed.

Two of the three demographic basic conditioning factors showed relations with achievement of self-care requisites. Firstly, men continued to have better self-care performance than women, especially in relation to the self-care in the areas of the intake of nutrients and the eliminative processes. Next, people with higher socioeconomic status had better achievement of universal self-care requisites than people with lesser socio-economic status. This difference was found both pre- and postoperatively, and was mainly due to better performance of the people with higher status in the area of activity and rest. As there was no relationship found between socio-economic status and health state indicators, this finding cannot be ascribed to differences in health state between persons with a higher and persons with a lower occupational status. The finding that people with a higher socioeconomic status do better in their self-care is in accordance with the outcome of Hanucharurnkul's study. Greater occupational prestige of Thai cancer patients was associated with significantly higher levels of self-care (Hanucharurnkul 1988).

The factor age was not found to have a significant impact on the achievement of self-care requisites. In relation to self-care agency the N.D.C.G. (N.D.C.G. 1979) states that self-care agency develops over time, that it attains a degree of perfection during adulthood, but that it declines with advancing age. Since self-care performance results from self-care agency, a similar pattern may be expected. The average age of this sample at the time of CAB-surgery was 60 , varying from 42 to 76. Although the correlations of age with the four SCl-scores were negative, only the correlation with the three-year SCl-score was statistically significant. The interpretation in line with the N.D.C.G. would be that a significant relationship only exists for older people. However, additional computed correlations of age with the first three SCl-scores for only the people over 60 did not support this idea. The 
lack of observed relationship between age and achievement of self-care requisites may be caused by the health state of the sample. It is not unlikely that health state is a greater predictor of performance of self-care than age, at least in a population which is not a healthy one. Moreover, as there were no real old nor real young people in the sample the effect of age might have stayed completely hidden. Having cardiac disease may have more impact on the achievement of self-care requisites than being 50,60 or 70 years old. In the study with the Thai cancer patients age was also found to be unrelated to self-care. In that sample the average age was $53(\mathrm{sd}=12)$.

The last basic conditioning factor included in this study is an operationalization of the factor 'health care system elements'. One of the tasks of health care professionals is to assist persons with health problems in, and advice people with health problems about performance of self-care. Persons who are discharged from the hospital after having undergone coronary artery bypass surgery have to deal with some new experiences related to their self-care. Some of these are: chest and legwounds that are in a healing process; learning about (physical) limitations, which may have changed since surgery, and may continue to change during the recovery period; recovery from major surgery; possible return to work or household activities; new physical sensations; new medication; anxiety of themselves and/or their relatives; reconsider lifestyle; etc. The health care professionals identified in this study are expected to help in some way or another with one or more of these experiences CABS-patients have to deal with. The only other study found in the literature which investigated this aspect in relation to well-being was the study of Rombouts C.S. among a group of Dutch patients on the average two years after CAB-surgery (Rombouts, Jambroes et al. 1984). They reported that patients who had not received (sufficient) help from physical therapists, social workers and psychologists were more often depressed, more anxious, more uncertain, suffered more often from bad moods, were easily irritated and emotional, and also slept less good than people who had received sufficient help. The results of the current study are comparable with the findings of Rombouts c.s. Here, it was found that if persons had experienced a lack of, or insufficient help from one or more of the health professionals after their discharge from the hospital they had on the average a lower achievement of self-care than persons who had received sufficient help. The lesser performance was rellated to self-care in the area of the maintenance of a balance between activity and rest and in the area of the maintenance of a balance between solitude and interaction. Such a difference did not already exist between these two groups before surgery. Thus, a lack of professional support was associated with a lesser gain in achievement of self-care requisites after CAB-surgery, In other words, if the posthospital professional help is not "complete", persons do not gain all the possible benefit from their improved health state in relation to increased levels of self-care.

Lastly, multiple regressions have been computed to examine the combined effect of the basic conditioning factors on the achievement of the universal self-care requisites. Over the four measurements the total explained variance in the self-care 
performance, which could be attributed to the set of basic conditioning factors varied from 9 to $15 \%$. This result is comparable with findings from other studies. In Denyes' study only $3 \%$ of the variance in self-care was explained by two factors: age and presence or absence of disease (Denyes 1988). In the study among Thai cancer patients (Hanucharurnkul 1988) the health state indicators stage and site of cancer, plus the socio-economic status accounted for $27 \%$ of the variance in selfcare. Interestingly enough, in this study with CAB-surgery patients, health state indicators and socio-economic status were also the main and most consistent predictors of self-care performance. Thus, these two studies have comparable results with this respect. A relatively good health and having a higher occupational status contributes to greater achievement of self-care requisites. Only three years after CAB-surgery, gender was found to play a significant role as well, in that men had better performance.

When the measures for self-care agency were included in the regression analyses, the percentages of explained variance in self-care performance varied from 11 to $21 \%$. The pattern of main predictors than changed somewhat. Self-care agency was the main or second predictor. Socio-economic status however, was no longer contributing directly to self-care, while gender was, next to health state indicators, selected as the other main predictor of achievement of self-care requisites. It seems that socio-economic status contributed to self-care through its effect on self-care agency. A higher occupational status leads to a greater capacity for self-care, and thus affects self-care performance indirectly. The increased significance of gender when self-care agency is included, seems to indicate that the relationship of gender with achievement of self-care requisites is reverse to the relationship of gender with self-care agency. In other words, it seems that with comparable capacities for selfcare, men have greater achievement of self-care requisites than women. This result is not easy to explain. Further study and analyses are required on the relationship between gender and self-care agency. As this goes beyond the scope of this study, the finding is only reported here and not further investigated.

The finding that self-care agency is a main predictor of the fulfilment of self-care needs can be interpreted as a validation of Orem's theorizing. Orem emphasizes the need for nurses to assess both the self-care agency of the client as well as his/her therapeutic self-care demand. The outcome of the regression analyses signifies the importance to learn about a person's abilities for self-care for the understanding of the person's self-care. It indicates that it is more or at least as important for nurses to determine a patient's self-care agency, as it is to assess his/her age, gender, health and developmental state.

Additional multiple regressions have been computed to examine the combined effect of the basic conditioning factors and self-care agency on the different aspects of universal self-care. In three of the four regressions on the achievement of self-care requisites in the area of sufficient intake of nutrients and the eliminative processes, self-care agency was a significant predictor; in all four regressions it was a significant predictor of the achievement of self-care requisites in relation to social interaction; and in two of the four analyses, self-care agency contributed to 
the explanation of the variance in the measure for fulfilment of self-care in relation to maintaining a balance between activity and rest. The outcomes in relation to the effects of the basic conditioning factors resembled the results of the analyses in relation to the separate effects of each of the factors. Next to self-care agency, gender was the main predictor of the achievement of self-care requisites in the area of sufficient intake of nutrients and the eliminative processes. Insufficient professional care after discharge was, next to low self-care agency associated with lesser achievement of self-care in relation to keeping a balance between solitude and social interaction. And indicators of relatively good cardiac health state contributed to better achievement of self-care in the area of activity and rest. Despite the inclusion of self-care agency in the regression analyses, socioeconomic status was consistently selected as a predictor of achievement of selfcare requisites in relation to activity and rest. In other words, this seems to be an indication of a direct relationship between socio-economic status and this particular self-care requisite, where only an indirect relationship was found between socioeconomic status and the total achievement of universal self-care requisites.

\subsection{THE EFFECT OF BASIC CONDITIONING FACTORS AND SELF-CARE ON STATE OF WEL-BEING}

It has been pointed out in chapter 2 that Orem does not explicitly propose any direct relationship between the basic conditioning factors and state of well-being. Although she also does not state that such a relationship does not exist it seems to fit her model that the basic conditioning factors affect self-care, and as such indirectly affect the individual's well-being. In other words, this is an area that deserves examination, which could lead to extension or refinement of the theory. In this study, both the single effects of the basic conditioning factors, as well as the combined effects with achievement of self-care requisites have been examined. The well-being and quality-of-life literature served as the base to derive hypotheses fram.

By themselves, the factors age and gender were not found to be related to state of well-being. However, when the effect of achievement of self-care requisites on wellbeing was controlled for, age became an extra predictor in two of the three measurements of well-being after CAB-surgery. This means that with the same level of fulfilment of self-care needs, older people rated their well-being at a higher level than younger persons. This could be explained as an indication for the thought that in getting older, the achievement of self-care becomes less important for promoting well-being. Another indication for this thought is found in the comparison of the postoperative correlations between achievement of self-care requisites and wellbeing for the older and the middle-aged persons. Although only significantly different at the three years measurement, there was a tendency of relatively higher 
Pearson correlations for the middle-aged persons. Thus, for the middle-aged achievement of self-care requisites seems more important in relation to well-being than for older people.

Based on Veenhoven's literature study an interaction effect of age and gender on state of well-being was predicted. In other studies it was found that older men were happier than older women, while young women were happier than young men. As the sample of this study did not have 'real young" people, it was divided in middleaged (42 till 60) and older (61 till 76) persons. Aithough an interaction effect was found, it had a different direction than was expected. The differences between the older men and women were small, but older women perceived their state of wellbeing slightly better than older men. Yet, the differences in the middle-aged group were more considerable. The middle-aged men rated their well-being at a similar level as the older group. However, the middle-aged women scored relatively low at all moments of measurement. The difference was the greatest before CAB-surgery. This may be a clue to the explanation of this unpredicted result. Traditionally, coronary artery disease has been a 'male' health problem. Untill recently women were hardly ever diagnosed with heartproblems of this kind, and if they were, it were only the relatively old women who also suffered from diabetes or other related health problems. (This tendency can also be recognized in the age of this sample: the women are on the average 5 years older than the men.) Nevertheless, this trend is changing in the last decade with more women, including younger ones, suffering from coronary artery disease. However, the public opinion still considers coronary artery disease a disease for men. Because of this, the relatively young women in this study might experience more grief from being diagnosed with coronary artery disease than the others. It is possible that they had a harder time to accept that they had a heartproblem and needed open heart-surgery than the men and the older women, which resulted in lower states of well-being.

Next ${ }_{1}$ as has been identified in many other studies, it was found that a higher socioeconomic status led to higher levels of well-being. Figure 4.5 in chapter 4 shows that in the current study this was true only for the postoperative measurements, since with major surgery awaiting in the very near future (d.i. the day after). persons with a higher occupational status seemed to report lower levels of wellbeing than persons with a lower status. In the measurement of the day before $\mathrm{CAB}$-surgery, the variable socio-economic status had a significant but negative predictive capacity towards pre-operative state of well-being, also after controlling for self-care. Thus, with equal fulfilment of self-care requisites, persons with a higher socio-economic status reported lower levels of well-being before surgery. This is congruent with two other findings that have been reported: The high pre-operative achievement of self-care requisites of the persons with the highest socio-economic status, and the lack of correlation between the pre-operative self-care performance and the pre-operative well-being rating in this group of persons with the highest socio-economic status. It seems that subjects from this group are more inclined to consider their need for CAB-surgery as a sign that their health is in a real bad shape, which affects their well-being. Besides, they may, more than others, 
perceive the open heart-surgery as a major threat to their life. However, when the immediate threat of major surgery is over, the relationship between socio-economic status and well-being was in the expected direction. Postoperatively, persons with a higher status reported high levels of well-being, and persons with a lower status reported lower levels of well-being. When the variance in state of well-being accounted for by differences in self-care was statistically controlled, socio-economic status was no longer a predictor for state of well-being. At least in the postoperative measurements. This points at an indirect relationship between socioeconomic status and well-being under 'normal' circumstances: A higher status leads to better self-care performance (due to greater self-care abilities), which leads to a higher level of well-being.

The basic conditioning factor lack of or insufficient postoperative help was also found to have a negative effect on the individual's state of well-being. However, this effect seemed to be indirect, since after controlling for achievement of self-care requisites, the professional help did not account for a significant extra amount of variance in the 6-months state of well-being ratings. Receiving sufficient professional care after discharge from the hospital contributed to better achievement of the requisites in the areas of social interaction and rest and activity, which led to higher levels of well-being. These results are supportive of the conclusion of Rombouts c.s. that for the well-being of the ex-patients, multidisciplinary professional care after $\mathrm{CAB}$-surgery is a necessity.

The last basic conditioning factor that has been examined for its influence on state of well-being consists of indicators of cardiac health state. The results are different for the separate indicators. Having suffered from cardiac disease for a long time and/or having experienced a myocardial infarction in the past, did not affect the subjects' state of well-being before nor after CAB-surgery. However, after CABsurgery the reported levels of state of well-being continued to be significantly higher than before surgery, indicating increased well-being after an improvement in the cardiac health state. Such a finding has been reported in many follow-up studies on CABS-patients, although most of them report retrospectively on the quality of life or well-being before surgery. The average well-being rating prior to CAB-surgery in this study was 6.0. No other studies were found that reported Cantril Ladder ratings before CAB-surgery. In the retrospective study of Penckofer and Holm, among 34 American post-CAB-surgery patients, the subjects rated their pre-operative life satisfaction at 3.5 on Cantril's Ladder. (Penckofer \& Holm 1984). Due to the differences in design these ratings are not really comparable. The 6months postoperative rating in the current study was on the average 7.5 , which did not really differ from the average rating of the seventeen subjects in Penckofer and Holm's study who were interviewed between 6 and 8 months atter CAB-surgery: their mean rating at that time was 8.0. The changes in well-being over the first six months in the current study were found to be related to the changes in self-care over this period. Nevertheless, it is not possible to statistically examine whether in this case the effect of health state on state of well-being is direct or indirect. The increase in levels of well-being after surgery might be completely or partly due to 
improvement of self-care, or to the change in health state itself, or can be ascribed to another factor, for example "having survived major surgery". Whether the effect of recurrence of chest discomfort after CAB-surgery on state of well-being, could be explained by the effect of recurrence of chest discomfort on the achievement of self-care requisites however was examined. It was found that the relationship between recurrence and state of well-being can be interpreted as being of an indirect nature. The experience of chest discomfort led to lesser achievement of self-care in the area of rest and activity, as well as in the area of intake of nutrients and eliminative processes, which affected the state of well-being in a negative way.

In summary, it seems that in most instances the effect of the basic conditioning factors on state of well-being is indirect. The effect of recurrence of chest discomfort, posthospital professional help, and socio-economic status can be explained by their effect on the achievement of self-care requisites. Only, with the immediate threat of CAB-surgery prevalent, a direct negative effect of socioeconomic status on state of well-being can be found; whereas postoperatively, under more 'normal' circumstances, a combined effect of age and self-care has been detected. The finding that the influence of the basic conditioning factors on state of well-being works mainly through their effect on achievement of self-care requisites can be seen as a step towards the further development of Orem's theory. No indications were found in the theoretical work on the existence of direct relationships between state of well-being and the basic conditioning factors. The outcome of this study supports the suggestion that indirect relationships exist between the two concepts. New studies should be conducted to validate and refine such an extension of the theory.

\subsection{THE EFFECT OF SELF-CARE AGENCY AND BASIC CONDTIONING FACTORS ON THE RELATIONSHIP SELF-CARE - STATE OF WELL-BEING}

A hypothesis was formulated to test the notion that it is the fulfilment of self-care needs rather than the abilities for engaging in action to meet these needs that contributes to an individual's state of well-being. This notion was derived from Orem's statements about the relationship between self-care and well-being, and between self-care and self-care agency. The finding that no significant correlations remained between self-care agency and state of well-being, after controlling for achievement of self-care requisites, lends support to the idea that it is the fulfilment of self-care needs which promotes well-being. Abilities for self-care only contribute indirectly to state of well-being.

Thus, the empirical data were found to be supportive of the theoretical notions. The definitions of both self-care and self-care agency as put forth by Orem are highly theoretical. Orem speculates that individuals develop something which she calls a capability for self-care, and that persons use this capability or power to engage in 
self-care action. Besides, she theorizes that when persons apply this power adequately, they will meet so-called self-care needs, which in turn will enhance their sense of well-being. The results of this study support this line of thinking. It has been possible to identify empirical referents to measure the theoretical concepts, and it has been demonstrated empirically that relationships between them can be found which are in accordance with the theorist's speculative notions.

Finally, a last research question has been formulated which focused on the possible influence of the basic conditioning factors on the relationship between selfcare and well-being. In most instances, no significant effect was found. Having a relatively better or less good cardiac health does not affect how much fulfilment of self-care requisites contributes to the state of well-being. Neither is the achievernent of self-care requisites more or less important for achieving well-being for people who have received sufficient professional help after discharge versus persons who have not. The effect of age and socio-economic status has already been discussed. It seems that in the period after CAB-surgery, older people are somewhat less dependent on the achievement of self-care requisites for reaching a certain level of well-being than younger people. Whereas before CAB-surgery, the achievement of self-care requisites does not seem as important in relation to their state of well-being, for people with the highest socio-economic status, as it does to persons with a lower occupational status. The threat of the coming surgery may weigh heavier or may be perceived as a much greater disturbance of their life for persons with the higher status. This may also be the case for men, since a significant difference between men and women was found in the measurement before CAB-surgery. While after surgery, the achievement of self-care requisites is as important for men as for women in achieving well-being, before surgery the selfcare performance seems much more predictable of the state of well-being of the women than of the men.

\subsection{A SUMMARY OF THE FINDINGS}

The results of the study can be summarized in a new picture of the research model (figure 5.2.). The significant relationships, including their directions as observed in this study are represented by the arrows in the model. The relationships that were only found pre-operatively are marked with a ' $\square$ '; the ones that were only found for the postoperative measurements are marked with '- $\mathbf{}$ '. In interpreting the model it should be remembered that the relationship between basic conditioning factors and self-care agency has not been investigated in this study.

Achievement of self-care requisites has been found to be positively related to state of well-being. Pre-operatively, socio-economic status is negatively correlated with state of well-being; whereas postoperatively, age is positively related to well-being. 


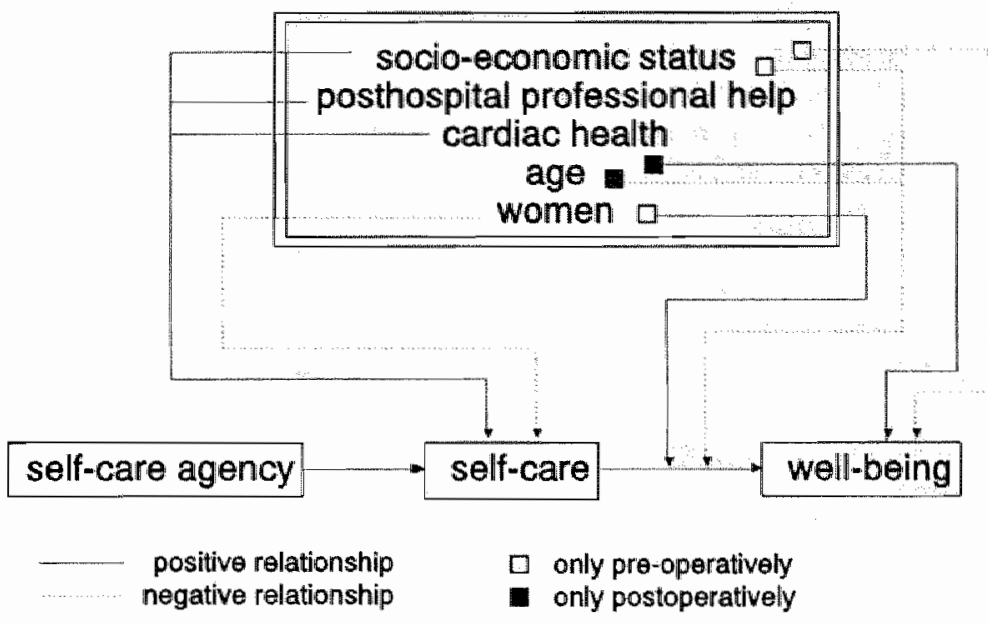

figure 5.2

Research madel including direction of significant relationships

The relationship between self-care and state of well-being is pre-operatively stronger for women than for men, as well as stronger for persons with a lower socio-economic status; while postoperatively, it is stronger for middle-aged than for older people. Achievement of self-care requisites is positively influenced by selfcare agency. A relatively good cardiac health state, being a male, and sufficient posthospital professional help also contribute to better fulfilment of self-care needs. Lastly, having a higher socio-economic status seems to contribute indirectly to better self-care performance.

\subsection{METHODOLOGICAL ISSUES}

Before the final conclusions can be drawn from this study, some methodological issues need to be discussed. These concern the design, the operationalizations of the concepts, as well as the generalizability of the results.

In the final chapter of her study on Thai cancer patients, Hanucharurnkul recommends that future studies on the relationships between self-care, social support and quality of life of cancer patients should be of a longitudinal nature, so that relationships can be studied at various phases of the disease process. Moreover, such a design would allow for investigating the direction of causality. In this study among coronary artery bypass patients a longitudinal design has been used to study the relationships between basic conditioning factors, self-care and state of well-being. The major variables have been measured at four moments 
during a time period of three years. This indeed has the advantage that the relationships can be studied during different stages of the disease and recovery process. Besides, the stability of the relationships can be examined. To repeatingly detect significant relationships between variables adds more evidence to the existence of 'true' empirical relationships, than a single detection in a crosssectional study. Moreover, in this study the longitudinal design was used in the examination of the effect of a change in the basic conditioning factor health state on self-care and state of well-being. Since changes occurred in both self-care and well-being after CAB-surgery, these findings lend support to the notion that health state can be interpreted as a causal factor. As there was a time period of half a year between the pre-operative and the first postoperative measurement, it is not very likely that these outcomes can be ascribed to the so-called 'test-effect'.

However, caution should be taken with the interpretation of the direction of causality in many of the other relationships that were observed in this study. Correlation does not prove causality. Although changes in self-care over time correlate with changes in well-being over the same period, although self-care at one moment correlates with the state of well-being at a later moment in time, there is no evidence that an individual's state of well-being depends on his/her self-care, and not the other way around. Thus, empirical support for Orem's theory in this study, means that the findings are congruent with the formulated expectations that were derived from the theory. It does not mean 'proof' in the literal sense. The finding that self-care continues to be significantly related to well-being does not prove that self-care promotes well-being, but the finding supports the theoretical thought. Still, with a population of persons who have recently undergone CABsurgery, it is more likely that these persons feel happy because their mobility is good, than that their mobility is good because they are happy. In this case, correlational studies are about the best researchers can do, since it is not possible to assign persons randomly to groups with high or low self-care, and subsequently examine their state of well-being. When more insight has been gained through these type of descriptive studies, in a next step, more advanced experimental designs are conceivable. In such studies, the effect of (nursing) interventions which are proven successful in improving the fulfilment of specific self-care requisites on person's state of well-being, can be compared with the effect of 'interventions' which do not bring about an improvement in the achievement of self-care requisites. Extra control-groups will be needed to manage the Hawthorne-effect.

In this study self-care has been operationalized as achievement of universal and health-deviated self-care requisites. Since the measurement of health-deviated selfcare has been limited to only one aspect of it, the main focus of the study has been on the universal self-care. The fact that the achievement of requisites has been measured, and not the self-care requisites or the self-care actions, restricts the interpretation of the results with respect to the effect of the basic conditioning factors. The basic conditioning factors are predicted by Orem to affect the self-care needs, the self-care abilities, the self-care action, as well as the fulfiment of the selfcare needs. It has been part of the focus of this study to examine the effect of the 
factors on the fulfilment of the self-care requisites. This means that based on this study nothing can be concluded on the effect of the basic conditioning factors on the self-care needs or the self-care actions. It was observed that men and women differ in their achievement of self-care requisites, but it is not clear from this study whether they have different needs, or whether they take different self-care actions to meet these needs. As far as the effect of the basic conditioning factors on selfcare agency is concerned, the study revealed some openings for further investigation.

Both the concepts self-care and state of well-being have been operationalized in this study with measures that rely on self-reports. Besides, the two instruments use similar methods of scaling. These similarities between the two measures may have artificially increased the values of their intercorrelations. Thus, the actual relation between performance of effective universal self-care and state of well-being may be somewhat smaller than was found here. As far as the issue of 'self-reports' is concerned, with the concept of state of well-being this seemed the best approach. State of well-being is by definition a subjective experience. However, the achievement of self-care requisites may be studied with other methods as well, such as asking a 'significant other' (or nurse), or by observation.

Another important methodological issue concerns the external validity of the study. To what degree can the results be generalized to settings or samples other than coronary artery bypass patients in Limburg, the Netherlands. It has been the intention of this study to test certain propositions from Orem's theory, with particular focus on the relationship between self-care and state of well-being. To study such a relationship in CAB-patients may not be the most obvious approach. as it certainly limits the generalizability of the results. The sample is rather homogeneous with respect to age and especially with respect to health state. Besides, due to the particular health state men are overrepresented.

However, there are also valuable advantages in studying this particular group of patients. Firstly, they represent a group of patients which receives nursing care for a considerable period of time, which makes insight into the factors affecting their state of well-being relevant nursing knowledge. Secondly, the use of a longitudinal design with this group of patients provides two more extra possibilities. Firstly, the effect of a change in one of the major basic conditioning factors (health state) can be studied. And secondly, the relationships of interest can be studied at different stages of the disease and recovery process. The longitudinal design captured a moment in which the health state was very unfavorable (subjects needed to have CAB-surgery the next day). a moment in which the health state was such that the majority had resumed their 'normal life" (three years after CAB-surgery). as well as moments early and later in the recovery process. Since most of the investigated relationships 'hold' in the different situations, these results may be generalized to groups of cardiac patients who receive other treatments, or are in another stage of the disease process. The relationships that were found between socio-economic status, self-care agency, the total score of achievement of universal self-care requisites, and state of well-being are probably also valid for populations with other 
(severe) chronic diseases. Particularly, since the findings of this study are congruent with the findings of the study among Thall cancer patients. However, the central role for the achievement of self-care requisites with relation to activity and rest; which was observed in this population is not necessarily true for people with other health problems. The finding that this particular requisite explained relatively the most of the variance in state of well-being is probably characteristic for a sample of cardiac patients. New studies with healthy samples, or samples with subjects diagnosed with other chronic or acute health problems are needed to investigate the role of health state factors, the different universal and healthdeviated self-care requisites as well as professional health care after discharge in more detail. The impact of the basic conditioning factors age and gender is better examined in a more heterogeneous population. Whether the results are specific for subjects from the south of the Netherlands, will be examined in the near future, as this study is currently being replicated in the north of the country.

\subsection{CONCLUSION}

The conclusions that can be drawn from this study can be grouped under three categories. Firstly of course, conclusions are presented in relation to the validity of Orem's General Theory of Nursing. Secondly, some implications for nursing practice are derived with respect to the self-care and well-being of CABS-patients. Finally, recommendations for further study are given.

\subsubsection{Orem's General Theory of Nursing}

It has been stated as the purpose of this study to test and further explore relationships as proposed in Orem's theory. The testing leads to validation or rejection, the exploration to refinement and possible extension of the theoretical statements. To a certain degree both purposes have been realized. Despite the methodological limitations which do not allow for drawing conclusions on causality, this study shows strong support for Orem's theoretical notion that self-care promotes well-being. Subjects with low achievement of self-care requisites report low levels of well-being. whereas subjects with high achievement of self-care requisites report high levels of well-being. Moreover, changes over time in self-care are accompanied by changes over time in state of well-being, and self-care continues to be a significant predictor of state of well-being after contralling for the level of well-being of some time before. Besides, when basic conditioning factors are included achievement of self-care requisites remains the major predictor of state of well-being, both in situations of favorable and unfavarable health state. Twenty to forty-five percent of the variance in well-being could be expllained for by performance of self-care. These findings are strongly supportive of Orem's 
proposition in which it is stated that self-care is necessary for general well-being.

With respect to the relationship between self-care and well-being additional hypotheses have been formulated for the purpose of refining the theory. From Orem's statements it was inferred that it was the needfulfilment and not the abilities for self-care which contributes to state of well-being, and this was supported by the results. Besides, it was observed that at least in times in which the disease is very prominent, the fulfilment of both universal and health-deviated self-care requisites contributes most to the state of well-being. Thus when health problems exist, the achievement of requisites in both categories are necessary for well-being. Another indication for the importance of health state as a basic conditioning factor is the finding that in this sample of CABS-patients, the achievement of the self-care requisite in relation to activity and rest patterns was the greatest predictors of state of well-being. This outcome was found to fit Orem's speculations, that under unfavorable conditions the achievement of certain self-care requisites becomes more important than that of others. Lastly, the results of the regression analyses indicate that the impact of the basic conditioning factors gender, socio-economic status, posthospital professional health care, and health state factors on state of well-being is mainly indirect. Having a relatively good health state, receiving sufficient professional help, being a male and having a high occupational status contributes to better achievement of self-care requisites, which leads to higher levels of well-being.

Orem's notion that persons who engage in self-care possess a so-called 'self-care agency' has also been validated in this study. Obviously, abilities for self-care and achievement of self-care can be distinguished empirically, and are found to be interrelated. In this study, the capacity for self-care accounts for about $10 \%$ of the variance in self-care achievement.

Lastly, the role of several basic conditioning factors has been examined. Orem predicts that these factors can have an active influence at points in time on selfcare and on self-care agency. However, she does not specify the nature of the relationships. Thus, the results of this study add both to the validation and to the refinement of the theory. Health state, gender, socio-economic status, and posthospital professional health care were observed to relate to achievement of self-care requisites. The influence of age could not be determined. Although the findings as described in this study have contributed to better understanding of the influence of the basic conditioning factors, further study into the triad basic conditioning factors, self-care agency and self-care is needed to gain more detalied insights.

Thus, a beginning to the further refinement of Orem's theory has been made with respect to (1) needfulfilment rather than abilities contribute to state of well-being; (2) the role of the different types of self-care requisites in the promotion of state of well-being; (3) the role of health state in the determination of which aspects of selfcare contribute most to state of well-being: (4) the nature of the relationships 
between basic conditioning factors and state of well-being; and (5) the nature of the relationships between basic conditioning factors and self-care. These findings were all found to be in accordance with Orem's speculations in other parts of her work than the official theoretical propositions. The fact that in this study a significant relation has been demonstrated between self-care and state of well-being, is important both for the internal as well as for the external validity of Orem's theory. Internally, because this relationship represents a major tenet of the theory. Orem states that the primary concern of nurses is the enabling of individuals to engage in effective self-care over time. Nurses' actions are directed at either increasing the individual's self-care agency, or at the fulfilment of his/her self-care needs. As the ultimate goal of nursing services is to contribute to the well-being of their clients, it is significant that the identified primary focus of nurses indeed leads to higher levels of well-being. This is at the same time a sign of the external validity or social relevance of Orem's theory. If nurses claim that their contribution to society is in the area of the quality of life of its members, self-care as described by Orem seems a valid focus of their actions. The outcome of this study challenges the doubts expressed by some critics of Orem's model (Melnyk 1983; Meleis 1985), that the theory does not seem very useful in the promotion of the health and well-being of nursing clients.

\subsubsection{The self-care and well-being of coronary artery bypass patients - implications for nursing practice -}

The focus of this thesis has been on theory testing. As such it is meant to contribute in the first place to the further development of the knowledge component of the nursing discipline. However, studying the self-care and wellbeing of particularly the group of coronary artery bypass patients, has been identified as an advantage of the design, for it concerns a category of patients which receives nursing care for a considerable period of time. Thus, although the aim has not been to respond to immediate needs of nurse practitioners who care for coronary bypass patients, the study does offer some insights that are relevant for the practical component of the nursing discipline. Some of these insights are identified here.

- Firstly, it is relevant knowledge for nurses to learn that it is especially the self-care in relation to the rest and activity balance which contributes to the wellbeing of persons having coronary artery bypass surgery. The finding that this particular requisite continues to play a major role in the well-being of this category of patients for at least several years after their surgery, is important information with respect to the (planning of) their after-care.

Secondly, the outcomes of this study emphasize the significance of the health state factor in nursing. It thas been demonstrated that health state not onlly influences the effectiveness of the individual's self-care, but also plays a role in the determination of which requisites contribute the most to the individual's state of well-being. For example, the change in health state induced by CAB-surgery was found to result in an improvement in the self-care with respect to the rest and 
activity balance. Next, the experience of chest discomfort after surgery, which is a sign of a lesser gain in health state, was found to lead to lesser achievement of self-care requisites in the areas of activity and rest, as well as in relation to appetite, digestion and bowel movement. Subsequently, the results of the study indicate that in times of acute health problems, the achievement of health-deviated self-care requisites are important for the level of well-being of the patients, whereas at times in which the health problems are of a less acute nature only the achievement of universal self-care requisites plays a major role in reaching certain levels of wellbeing. These different ways in which the health state affects important patient variables imply that the accurate and continuous assessment of the health state of the patient is vital for a good understanding of the patient's self-care needs.

Thirdly, the role of nonsmoking in relation to the state of well-being. may well be interpreted as pointing at a potential task for nurses. If nurses can be successful during especially the acute phases of coronary artery disease in helping patients to quit smoking they not only assist in the secondary prevention of the pathology, but at the same time contribute to the patient's well-being. If this finding can be generalized to other health-deviated self-care requisites which were not included in the design of this study, it signifies the role of the nurse in assisting patients with meeting (new) self-care needs which arise from their health state.

In the fourth place, the findings on the relationship between self-care agency and achievement of self-care requisites indicate that for the understanding of an individual's self-care it is important for nurses to examine the individual's selfcare capabilities. In combination with the finding that effective self-care leads to higher levels of well-being, this information suggests that nurses can contribute in two ways to the individual's well-being. They can do so indirectly by enhancing the individual's self-care agency, and directly by fulfilling the individual's self-care needs.

Next, it is also apparent from the results of this study that investigation into the individual's values on the basic conditioning factors reveals relevant knowledge as well with respect to the understanding of the person's self-care. Information on the person's age, gender, sociocultural background and so forth becomes almost as important for nurses as knowledge on the health state. The finding that men and women differ in their achievement of self-care requisites, and that women under 60 report relatively low levels of well-being, may indicate that women with a diagnosis of cardiac disease require additional or at least different nursing care than men. The relatively low levels of well-being reported by the group of persons with a higher socio-economic status prior to surgery can also be interpreted as relevant practical information. This finding implies that the general bellef among health care professionals that persons with a higher socio-economic status tend to do better with respect to such factors as self-care and well-being does not necessarily hold in times of acute health problems.

- Lastly, the outcome of this study suggests that assistance from professional health care personnel after discharge from the hospital is advantageous for the effective performance of self-care and thus for the promotion of the well-being of the CABS-patients, provided that the professional care is in balance with the perceived need for it. In light of their responsibility in the clischarge 
planning of patients, nurses could have a role in the assessment of the patients" needs for follow-up care. It follows from the results of this study that the patient's own perception of his/her need forms an essential part of such an assessment.

\subsubsection{Need for further study}

From the discussion of the results, the methodology and the scope of this study several recommendations for further study can be inferred. In generall, the finding that the variable self-care explains a considerable amount of the variance in the variable state of well-being, seems to indicate that new studies with a focus on the well being or quality of life of (CABS-)patients could gain in significance by including a measure of self-care, next to indicators of cardiac health state. As for the testing of Orem's General Theory of Nursing, the following suggestions are presented:

The relationships between the basic conditioning factors, self-care, and well-being need to be examined in other samples. Studying these relationships in populations with other chronic or acute health problems will enhance the insight into the effect of health state on self-care, state of well-being, as well as on the relationship between. them. Although the achievement of self-care requisites will probably continue to contribute to the state of well-being, the role of each requisite may differ with the health state of the population under examination. In healthy persons the achievement of universal self-care requisites is likely to be the major predictor of well-being. It is not so clear though which aspects of it would contribute most to well-being. On the other hand, when samples with chronic health problems such as cancer patients or persons with rheumatoild arthritis are being studied the role of the health-deviated self-care requisites may play a greater role than was found in the sample of coronary bypass patients. It is also likely that the achievement of the needs in relation to nutrition and the eliminative process will be found to be the major predictor for the state of well-being of for examplle cancer patients receiving chemotherapy. Another interesting group for studying the relationship between self-care and well-being would consist of patients with a more acute health problem at the moment of their first admission to the hospital. As these patients will be receivers of nursing care, it becomes relevant knowledge for nurse practitioners as to which needs are important in reaching certain levels of well-being. The results of the current study indicate that these needs may vary with the sociocultural orientation of the patients.

- The influence of the basic conditioning factors age and gender as such is probably best studied in populations with no particular health problem. Moreover, it would be interesting to examine whether in so-called healthy samples the relationships between the basic conditioning factors and well-being can also be explained as being of an indirect nature, as was the case for most of these factors in this study. The role of the developmental self-care requisites can also be studied in these populations, as long as there is enough variation in developmental state. Replicating this study in other samples could both validate and refine the findings in relation to the effect of the basic conditioning factors on self-care and well-being. 
How the different relationships will hold in populations with a psychiatric diagnosis is yet another question which needs further study,

A limitation of the current study has been the lack of a baseline moment of measurement. Subjects who were entered in the study had been diagnosed with cardiac disease at different moments in the past. Therefore, cohort-studies are recommended which take subjects in the sample at the moment of their diagnosis, and follow them for a number of years. Although such designs are time-consuming and therefore expensive, in the long run they will answer the type of questions on time-order and causality which were left unanswered in the current study.

Since health state has been identified as a central factor in the field of nursing knowledge, future studies should preferably include more precise and complete measurements of the different componients of health. This may lead to a more detailed insight into how health state affects the important patient variables of self-care and self-care agency. For this purpose an interdisciplinary approach is recommended.

To advance the knowledge with respect to the effect of health-deviated selfcare on state of well-being, new studies should include more complete measures of health-deviated self-care. From a practical point of view it is important to know what the effect is on the individual's state of well-being of, for example, specific medically prescribed measures, or the requirement for changing one's self-image. Studies including more health-deviated requisites would also present the opportunity to study the relationship between universal and health-deviated self-care requisites.

New studies can be designed in which the relationship between basic conditioning factors and self-care agency, as well as between self-care requisites and self-care action is examined. These studies should preferably include measures of self-care and self-care agency which do not rely completely on selfreports. Some questions with respect to the relationship between the basic conditioning factor gender, self-care agency and self-care have already been raised in this study.

The outcomes of studies as recommended here, can be used to refine and extend the General Theory of Nursing as proposed by Dorothea Orem. Next, based on the knowledge derived from these studies nursing interventions can be developed and tested, which aim at promoting the well-being of persons with different health problems and different backgrounds. Further study is needed for the further validation and refinement of Orem's General Theory for Nursing. Lack of clarity about what constitutes theory testing in nursing (Silva 1986) is no longer a valid reason for nurse researchers to refrain from putting research effort in testing the underlying validity of nursing theories. As was argued in the first chapter, in the end only theories that are empirically validated will be meaningful for nursing practice. 


\section{SUMMARY}

The use of theories in the scientific component of the nursing discipline has long been debated. Currently, their existence is generally accepted and valued. Theories are perceived as providing the discipline with a relevant and specific perspective on its phenomena of interest. They are considered as guides in identifying what nurses need to know, guides in deriving relevant research questions, and guides for setting goals in nursing practice. Moreover, they give structure to the body of nursing knowledge. Nursing theories have been developed over the last three to four decades and have mainly been used for educational purposes. There is a trend showing that they are applied more often in the generation of research questions, and in relation to that in giving structure to the accumulation of research findings. Recently efforts are being made to use the nursing theories in nursing practice, but lack of empirical validation has inhibited this process. Thus, at the moment there is a need for studies that aim at the testing of the underlying assumptions and propositions of the different theories.

The purpose of this study is to examine the underlying validity of certain propositions from Orem's General Theory of Nursing. Since Orem's statements on the relationships between some of the major concepts of her theory are not very specific, rigid testing of the theory is not possible. However, it makes the further exploration of the relationships a worthwhile focus of nursing research, as exploration leads to more precise knowledge on the nature of the relationships. In this way, the research can contribute to the further development of the theory. The central focus of this study is on the proposed relationship between self-care and state of well-being. For the purpose of further investigation into this relationship, the related concepts of basic conditioning factors and self-care agency are included in the research model. Three sets of research questions were formulated, which deal respectively with the relationship between self-care and state of well-being, with the relationships between self-care agency, self-care and state of well-being; and with the influence of the basic conditioning factors on self-care, on state of well-being, and on the relationship between them.

Aspects of the following propositions from Orem's theory were being tested in this study. Firstly, the 2nd presupposition of the theory of self-care deficit: 'Self-care as a form of self-regulation is necessary for life itself, for health, for human development, and for general well-being'. Next, with respect to the relation between self-care agency and self-care, from the theory of self-care deficit proposition 1 : 'Persons who take action to provide their own self-care or care for dependents have specialized capabilities for action'. Lastly, the influence of the basic conditioning factors is defined in proposition 5 of theory of self-care: 'Universal self- 
care requisites and ways of meeting them may be modified by the age, sex, or developmental or health state of individuals' and in presupposition 2 of theory of self-care: 'Ways of meeting self-care needs are cultural elements and vary with individuals and larger social groups.'

On the basis of Orem's theories of self-care and self-care deficit in combination with findings in the literature twenty-five hypotheses were derived for the purpose of the testing and the further exploration of the theoretically proposed relationships. It was predicted that the achievement of both universal and health-deviated selfcare requisites contribute positively to state of well-being. Besides, it was expected that changes in the achievement of self-care requisites over time would be accompanied by changes in the same direction and over the same period in state of well-being. The achievement of different aspects of self-care requisites were predicted to contribute equially to state of well-being. It was anticipated that it is the fulfilment of self-care requisites rather than the ability to engage in self-care action which promotes well-being. It was hypothesized that self-care agency and the achievement of self-care requisites were positively correlated. The basic conditioning factors health state, age, gender, socio-economic status and received professional care after discharge from the hospital were predicted to show a direct relationship with achievement of self-care requisites. The influence of these same 5 factors on state of well-being was expected to be more of an indirect nature. A last hypothesis was formulated which predicted that the basic conditioning factors would not affect the relationship between self-care and state of well-being.

These trypotheses were tested in a sample of Dutch patients undergoing coronary artery bypass surgery (CABS). A longitudinal research diesign was used, including one pre-operative and three predesignated postoperative measurements. Subjects were interviewed one day before surgery in the hospital. Next, they were interviewed in their homes six months and twelve months after surgery. Three years after CAB-surgery they received a mailed questionnaire. All data were collected through the use of structured questionnaires. The method of timebound sampling was used. Eighty-six of the 107 subjects who initially entered the study completed all phases. They were 66 men and 20 women, all Dutch, with a mean age of 60.1 years at the time of their surgery. Five subjects died within the 3-year period, whereas 16 did not participate in one or more of the follow-up phases.

State of well-being was measured with Cantril's Self Anchoring Life Satisfaction Ladder. The achievement of universal self-care requisites was measured with the Self-Care Inventory. Principal component factor analysis revealed three subscales. within this instrument, which correspanded with different types of Orem's universal self-care requisites: the subscale NUB consists of 4 items which describe the achievement of needs related to intakes of water and food, as well as those related to eliminative processes. The subscale SIB consists of 2 items which measure the fulfilment of needs for social interaction; the third subscale RAB contains 5 items which can be grouped as reporting on the achievement of rest and activity needs. The achievement of specific health devilated self-care requisites was operationalized 
in questions on smoking and exercise. The Appraisal of Self-care Agency Scale was used to measure self-care agency. As indicators of the basic conditioning factor cardiac health state, history of myocardial infarction, duration of cardiac cisease and chest discomfort were selected. Moreover, the change in health state which is effected by the CAB-surgery, is expected to affect the achievement of selfcare requisites as well. The other basic conditioning factors are operationalized by measures of age, gender, socio-economic status and posthospital use of professional health care.

At all four moments of measurement, achievement of self-care requisites was found to be positively correlated with perception of well-being. This correlation showed stability over time. Persons who did not smoke and persons who exercised sufficiently tended to perceive their state of well-being at a higher level than persons who did smoke and persons who did not exercise sufficiently. Thus, achievement of both universal and health-deviated self-care requisites contributed to higher levels of well-being. Moreover, changes in achievement of self-care requisites were parallelled by changes in the same direction in state of well-being. Hierarchical multiple regression analyses showed that achievement of self-care requisites continued to be a significant predictor of state of well-being after controlling for the level of well-being of some time before. These findings support Orem's proposition on the existence of a positive relationship between self-care and well-being.

To further examine the role of the different aspects of self-care, stepwise multiple regressions were conducted. It was found that the individual's state of well-being prior to and 6 months after surgery was predicted by the achievement of the universal self-care requisites in the area of maintaining a balance between activity and rest, together with the health-deviated self-care requisite nonsmoking. Whereas the achievement of the universal self-care requisites in the area of maintaining a balance between activity and rest and in the area of maintaining a balance between solitude and social interaction were the greatest predictors of state of well-being one and three years after CAB-surgery. It was concluded that in times of health problems, both the achievement of universal and health-deviated self-care requisites are necessary to promote well-being. In times of less acute health problems the responses of the CABS-patients seemed more in line with the views of 'healthy' populations, as to what aspects are important in achieving a certain level of well-being. The major role of the self-care requisite in relation to activity and rest was found to be congruent with findings in the literature on the quality of life of CABS-patients, and could also be explained from Orem's theorizing.

Orem's notion that persons who engage in self-care action have specialized capabilities for action (= self-care agency) was supported by the results. At all four moments of measurement, a significant and positive correlation was found between the variables achievement of self-care requisites and self-care agency. The relationship showed stability over time. Partial correlations supported the hypothesis that self-care agency is related to state of well-being through 
achievement of self-care needs. Thus the derivation from Orem's statements that it is the needfulfilment rather than the capability to engage in self-care action which promotes well-being was supported by the empirical data.

After CAB-surgery subjects continued to repont higher levels of self-care achievement than before surgery. This indicates a positive effect of the improvement in the basic conditioning factor thealth state on performance of selfcare. Except for age, all other identified basic conditioning factors were found to relate to the achievement of self-care requisites. The health state indicators related mainly to the achievement of self-care requisites in the area of maintaining a balance between activity and rest. This could be explained by the fact that only cardiac health state indicators were selected in this study, as cardiac disease is known to hinder people in their physical activities, to decrease their endurance and to disturb their sleep. Men consistently reported higher levels of achievement of self-care requisites in relation to the intake of nutrients and the eliminative processes than women. Persons with a relatively high socio-economic status continued to have greater achievement of self-care requisites in the area of maintaining a balance between activity and rest. Not receiving sufficient professional help after discharge from the hospital was rellated to significantly lower levels of self-care in the areas of maintaining a balance between activity and rest, and between solitude and social interaction. The lack of observed relationship between age and achievement of self-care requilsites may be caused by the health state of the sample. It is not unlikely that in a population which is not healthy, health state is a greater predictor of performance of self-care than age.

When both self-care agency and the basic conditioning factors were entered as predictors in stepwise multiple regression analyses with achievement of self-care requisites as dependent variable, self-care agency was consistently selected as the first or second explaining variable. This can be interpreted as a validation of Orem's theorizing, where she states that it is important for the understanding of a person's self-care to examine his/her self-care abilities.

As far as the influence of the different basic conditioning factors on state of wellbeing was concerned, most of the relationships could be considered indirect. When both the achievement of self-care requisites and the basic conditioning factors were included in the stepwise multiple regressions with state of well-being as the dependent variable, by far the greatest proportion of variance was explained by the self-care variables. Together, the universal and health-deviated self-care requisites explained twenty to forty-five percent of the variance in the ratings of state of well-being.

It was concluded that the findings in this study were supportive of Orem's theory with respect to the proposed relationships between self-care and well-being, and between self-care agency and self-care, as well as with respect to the influence of the basic conditioning factors health state, gender, socio-economic status, and health care system elements. Besides, a beginning to the further refinement of Orem's theory has been made with respect to certain relationships. It was found 
that it is the self-care needfulfilment rather than the self-care abilities which contributes to state of well-being. Insight was gained in the role of the different types of self-care requisites in the promotion of state of well-being, as well as in the role of health state in the determination of which aspects of self-care contribute most to state of well-being. Next, indications have been found that the relationships between basic conditioning factors and state of well-being are indirect. Lastly, further understanding of the nature of the relationships between basic conditioning factors and self-care could be inferred.

The important role that can be ascribed to the achievement of self-care requisites in the promotion of well-being does not only validate a major underlying assumption of Orem's General Theory of Nursing, but is also considered to support the social relevance of the model. In Orem's perspective the self-care of individuals and groups is the major focus of attention for nurses. Nurses claim that the ultimate goal of their actions is in the promotion of the well-being of their clients. If indeed the contribution of nursing to society is in the area of the quality of life of its members, self-care as described by Orem seems a valid focus of their actions. 


\section{SAMENVATTING}

Het gebruik van theorieen in de verplegingswetenschap heeft lang ter discussie gestaan. Tegenwoordig is het bestaan van de zogenaamde verplegingswetenschappelijke theorieën algemeen aanvaard. De theorieën voorzien de discipline van een eigen perspectief op de essentiële verschijnselen van de verpleegkunde. Ze worden geacht richting te geven aan hetgeen verpleegkundigen dienen te weten (opleiding), aan het formuleren van relevante onderzoeksvragen, alsmede aan het stellen van doelstellingen in de verpleegkundigen praktijk. Bovendien leveren ze structuur en samenhang aan het geheel van verpleegkundige kennis. De laatste 30-40 jaar zijn diverse verplegingswetenschappelijke theorieën ontwikkeld, die tot nu toe vooral gebruikt zijn voor onderwijsdoeleinden. $\mathrm{Er}$ is nu een trend zichtbaar waarin de theorieën gebruikt worden bij het genereren van onderzoeksvragen, en als gevolg daarvan een rol gaan spelen bij het geven van samenhang aan de accumulatie van onderzoeksresultaten. Sinds kort worden er bovendien pogingen ondernomen om de theorieën in de verpleegkundige praktijk toe te passen, maar het huidige gebrek aan empirische validering remt dit proces. Het wordt dus noodzakelijk dat verplegingswetenschappelijke onderzoekers zich gaan bezig houden met het toetsen van de diverse theorieën aan de werkelijkheid.

Het doel van het onderhavige onderzoek is het toetsen van een aantal van de vooronderstellingen van Orem's Algemene Theorie van Verplegen. In haar huidige vorm leent de theorie van Orem zich niet voor rigide toetsing, aangezien de relaties tussen de concepten niet bijzonder gepreciseerd zijn. Dit maakt het echter wel mogelijk en bovendien zinvol om met behulp van onderzoek de aard van de relaties verder te exploreren, zodat de onderzoeksresultaten kunnen leiden tot meer specifieke kennis omtrent de aard van de relaties. Op deze wijze levert het wetenschappelijk onderzoek een bijdrage aan de verdere ontwikkeling van de theorie. De studie waar hier verslag van wordt gedaan richt zich met name op de veronderstelde relatie tussen de concepten 'zelfzorg' en 'welbevinden'. Om deze relatie nauwkeuriger te bestuderen, en om meer uitspraken over de aard van deze relatie te kunnen doen zijn de concepten 'zelfzorgvermogen' en 'conditionerende factoren' opgenomen in het onderzoeksmodel. Er zijn drie sets van onderzoeksvragen geformuleerd, gericht op ten eerste de relatie zelfzorgwelbevinden, ten tweede de relatie zelfzorgvermogen-zelfzorg-welbevinden, en tenslotte op de invloed van de zogenaamde conditionerende factoren op zelfzorg. op welbevinden en op de relatie tussen zelfzorg en welbevinden.

Aspecten van de volgende proposities uit de Algemene Theorie van Orem worden in dit onderzoek getoetst. Ten eerste, de tweede presuppositie van de theorie van zelfzorgtekort: "Zelfzorg als een vorm van zelf-regulatie is noodzakelijk voor het 
leven zelf, voor gezondheid, voor de ontwikkeling van de mens, en voor algemeen welbevinden". Vervolgens met betrekking tot de relatie tussen zelfzorgvermogen en zelfzorg, de tweede propositie van de theorie van zelfzorgtekort: "Personen die acties ondernemen om in de eigen zelfzorg te voorzien beschikken over gespecialiseerde capaciteiten". Tenslotte is de invloed van de conditionerende factoren gedefinieerd in propositie 5 van de theorie van zelfzorg: "Universele zelfzorgbehoeften en het voorzien daarin kunnen verschillem naar gelang leeftijd, geslacht, ontwikkelingsstadium en gezondheidstoestand" en in presuppositie 2 van de theorie van zelfzorg: "De wijze waarop in de zelfzorgbehoeften wordt voorzien is cultureel bepaald en varieert tussen individuen en grotere sociale groepen".

Op basis van Orem's theorieën van zelfzorg en zelfzorgtekort en op basis van de literatuurstudie zijn 25 hypotheses geformuleerd die dienen om de proposities te toetsen en meer inzicht te krijgen in de aard van de relaties. Zo werd voorspeld dat het voorzien in zowel de universele als in de gezondheidgerelateerde zelfzorgbehoeften positief zou bijdragen aan het individuele welbevinden. Bovendien werd verwacht dat veranderingen in het voorzien in zelfzorgbehoeften in de tijd zouden samengaan met soortgelijke veranderingen in welbevinden in dezelfde periode. Het voorzien in de verschillende aspecten van zelfzorg werd voorspeld in gelijke mate aan het welbevinden bij te dragen. Er werd verwacht dat de feitelijke bevrediging van de zelfzorgbehoeften meer dan het vermogen om in de behoeften te voorzien zou bijdragen aan het welbevinden. Een andere hypothese stelde dat het zelfzorgvermogen positief gerelateerd is aan de mate waarin wordt voorzien in de zelfzorgbehoeften. Van de conditionerende factoren gezondheid, leeftijd, geslacht, sociaal-economische status en de ontvangen professionele hulp na ontslag uit het ziekenhuis, werd verwacht dat zij een directe relatie met het voorzien in zelfzorgbehoeften zouden hebben. Van deze zelfde vijf factoren werd voorspeld dat zij een indirecte invloed zouden hebben op de mate van welbevinden. In de laatste hypothese werd voorspeld dat de conditionerende factoren niet van invloed zouden zijn op de relatie tussen zelfzorg en welbevinden.

Deze hypothesen zijn getoetst in een populatie van Nederlandse patiënten die een coronaire bypass-operatie (CABG) ondergingen. $\mathrm{Er}$ is gebruikt gemaakt van een longitudinale onderzoeksopzet met één pre-operatief en drie van te voren vastgestelde postoperatieve meetmomenten. De personen werden één dag voor operatie in het ziekenhuis geînterviewd. De daarop volgende interviews vonden plaats zes en twaalf maanden na operatie bij de respondenten thuis. Drie jaar na operatie ontvingen de respondenten een met de post gestuurde vragenlijst. Alle gegevens werden verzameld door middel van voorgestructureerde vragenlijsten. De onderzoekspopulatie was samengesteld met behulp van de methode van tijdgebonden steekproeftrekking. Zesentachtig van de 107 personen die oorspronkelijk aan de studie begonnen hebben aan alle fasen deelgenomen. Zij waren 66 Nederlandse mannen en 22 vrouwen met een gemiddelde leeftijd van 60,1 jaar ten tijde van hun operatie. Vijf van de respondenten stierven binnen drie jaar na operatie, terwijl de overige 16 personen niet participeerden in tenminste één van de drie follow-up fasen. 
De toestand van welbevinden is gemeten met behulp van Gantril's Self Anchoring Life Satisfaction Ladder. De mate waarin in de universele zelfzorgbehoeften werd voorzien is gemeten door middel van de Zelfzorgvragenlijst. Na toepassing van principale componenten factor-analyse konden in dit instrument drie subschalen worden onderscheiden die correspondeerden met verschillende aspecten van de door Orem gedefinieerde universele zelfzorgbehoeften: De subschaal NUB bestaat uit 4 items en beschrijft het voorzien in universele zelfzorgbehoeften in relatie tot de inname van voldoende voedsel, lucht en vocht, alsmede in relatie tot de uitscheiding. De subschaal SIB bevat 2 items die de behoefte aan sociale interactie beschrijven; de derde subschaal tenslotte RAB heeft 5 items die kunnen worden gegroepeerd onder de zelfzorgbehoefte met betrekking tot rust-activiteitbalans. Het voorzien in de gezondheidgerelateerde zelfzorgbehoeften is geoperationaliseerd met behulp van vragen over roken en lichaamsbeweging. De Beoordeling ZelfzorgVermogen ASA Schaal is gebruikt om het zelfzorgvermogen te meten. Als operationaliseringen van de conditionerende factoren cardiale gezondheidstoestand zijn geselecteerd: pre-operatief myocard-infarct, duur van de hartkwaal en pijn op de borst. Bovendien wordt verwacht dat de verandering in gezondheidstoestand zoals door de CABG-operatie wordt bewerkstelligd ook van invloed is op de mate waarin in de zelfzorgbehoeften wordt voorzien. De andere conditionerende factoren zijn geoperationaliseerd als kalenderleeftijd, geslacht, sociaal-economische status en de perceptie van de patiënt op de ontvangen professionele hulp na ontslag uit het ziekenhuis.

Op alle vier de meetmomenten is er een positieve correlatie tussen de mate waarin men in de universele zelfzorgbehoeften voorziet en het welbevinden. De mate van samenhang is redelijk stabiel in de tijd. Personen die niet roken en personen die voldoende aan lichaamsbeweging menen te doen, schatten hun welbevinden hoger in dan personen die roken en personen die niet voldoende lichaamsbeweging hebben. Dus het voorzien in zowel de universele als de gezondheidgerelateerde zelfzorgbehoeften draagt bij aan een hoger niveau van welbevinden. Bovendien gaan veranderingen in de tijd in het voorzien in universele zelfzorgbehoeften samen met gelijkgerichte veranderingen in de mate van welbevinden. Hiërarchische multiple regressie analyses laten zien dat de mate waarin in de universele zelfzorgbehoeften wordt voorzien een significante voorspeller van welbevinden blijtt, nadat gecontroleerd wordt voor het niveau van welbevinden van enige tijd daarvoor. Deze bevindingem ondersteunen Orem's propositie waarin een positieve relatie tussen zelfzorg en welbevinden wordt verondersteld.

Om de rol van de diverse aspecten van zelfzorg verder te bestuderen zijn stapsgewijze multiple regressie analyses uitgevoerd. Er is gevonden dat het individuele welbevinden voor CABG-operatie en 6 maanden na CABG-operatie mede wordt bepaald door het voorzien in universele zelfzorgbehoeften met betrekking tot de rust-activiteitenbalans samen met de aan gezondheid gerelateerde zelfzorgbehoefte 'niet roken'. Eén en drie jaar na operatie wordt het welbevinden met name bepaald door twee categorieen van universele 
zelfzorgbehoeften: die in relatie tot de rust-activiteitenbalans en die in relatie tot sociale interactie. Het ziet er naar uit dat in tijden waarin er (acute) problemen met de gezondheid zijh zowel de universele als de gezondheidgerelateerde zelfzorgbehoeften een rol spelen ten aanzien van het individuele welbevinden. In tijden waarin de gezondheidsproblemen minder acuut zijn en minder op de voorgrond treden, lijkt het antwoordpatroon van de CABG-patiënten in relatie tot wat belangrijk is voor het welbevinden meer op dat van 'gezonde' populaties. De dominerende rol van de universele zelfzorgbehoefte in relatie tot de rustactiviteitenbalans kan verklaard worden met Orem's theorie en is bovendien in overeenstemming met bevindingen in de literatuur met betrekking tot de kwaliteit van leven van CABG-patiënten.

Orem's propositie met betrekking tot het bestaan van een relatie tussen zelfzorgvermogen en zelfzorgactiviteiten wordt onderschreven door de resultaten. Op alle vier de meetmomenten is er een positieve correlatie gevonden tussen de mate waarin men in de zelfzorgbehoeften voorziet en het zelfzorgvermogen. De mate van samenhang is stabiel in de tijd. Partiële correlaties ondersteunen de hypothese waarin gesteld wordt dat de relatie tussen zelfzorgvermogen en welbevinden indirect is. De tussenliggende variabele is het voorzien in zelfzorgbehoeften. Dus de empirische data komen overeen met de theoretische veronderstelling dat het niet het vermogen tot zelfzorg is welke bijdraagt aan het welbevinden, maar het feitelijke voorzien in de zelfzorgbehoeften.

$\mathrm{Na}$ bypass-operatie rapporteren de respondenten steeds een grotere mate van bevrediging van de zelfzorgbehoeften dan voor operatie. Dit duidt op een positief effect van de conditionerende factor gezondheidstoestand op de zelfzorg. Behalve de variabele leeftijd, vertonen ook de andere conditionerende factoren samenhang met de mate waarin in de zelfzorg wordt voorzien. De gezondheidsindicatoren zijn vooral gerelateerd aan de zelfzorg in relatie tot de rust-activiteitenbalans. Dit kan worden verklaard door het gegeven dat in deze studie alleen gezondheidsindicatoren in relatie tot de hartkwaal zijn gebruikt als operationalisering. Het is bekend dat coronaire lijden met name gevolgen heeft voor de fysieke activiteiten van patiënten, het vermindert het uithoudingsvermogen en beïnvloedt de nachtrust. Mannen rapporteren zowell voor als na operatie een grotere mate van bevrediging van de universele zelfzorgbehoeften in relatie tot de inname van voldoende voedsel, lucht en vocht, alsmede in relatie tot de uitscheiding, dan de vrouwen. Personen met een relatief hogere sociaaleconomische status hebben voortdurend een hogere mate van bevrediging in zelfzorgbehoeften in relatie tot de rust-activiteitenbalans, dan mensen met een lagere status. Respondenten die een tekort aan professionele hulp na ontslag uit het ziekenhuis hebben ervaren, hebben significant lagere scores met betrekking tot het voorzien in zelfzorgbehoeften in relatie tot zowel de rust-activiteitenbalans als de sociale interactie. Het gegeven dat er geen significante relatie tussen leeftijd en zelfzorg is gevonden, heeft mogelijk te maken met de gezondheidstoestand van de populatie. Het is niet onwaarschijnlijk dat in een 'ongezonde' populatie, de invloed van de conditionerende factor gezondheid de rol van leeftijd overschaduwt. Als 
zowel het zelfzorgvermogen als de conditionerende factoren als onathankelijke variabelen in de regressie-analyses worden opgenomen, wordt zelfzorgvermogen steeds als eerste of tweede predictor van het voorzien in universele zelfzorgbehoeften geselecteerd. Dit kan worden geinterpreteerd als een validering van het theoretische werk van Orem, waar zij stelt dat voor het begrijpen van de zelfzorg van cliënten, het essentieel is dat men inzicht heeft in hun zelfzorgvermogen.

Wat de invloed van de diverse conditionerende factoren op het welbevinden van de respondenten betreft, kunnen de meeste relaties als indirect worden aangemerkt. Tezamen verklaren in deze studie de universele en de gezondheidgerelateerde zelfzorgbehoeften twintig tot vijfenveertig procent van de variantie in de mate van welbevinden.

Er kan worden geconcludeerd dat de resultaten van deze studie Orem's theorie ondersteunen wat de door haar veronderstelde relaties betreft tussen zelfzorg en welbevinden, tussen zelfzorgvermogen en zelfzorg, alsmede met betrekking tot de invloed van de conditionerende factoren gezondheid, geslacht, sociaaleconomische status en elementen van gezondheidszorg-systemen. Bovendien is er met dit onderzoek een bijdrage geleverd aan de verdere verfijning van de aard van een aantal van deze relaties. $\mathrm{Er}$ is gevonden dat het niet het vermogen tot zelfzorg is maar het feitelijke voorzien in de zelfzorgbehoeften welke bijdraagt aan het welbevinden. Het onderzoek levert extra inzicht in de rol van de diverse typen van zelfzorgbehoeften in relatie tot welbevinden, alsmede in de rol van de conditionerende factor gezondheid in de relatie tussen zelfzorg en welbevinden. Vervolgens zijn aanwijzingen gevonden die duiden op een indirecte relatie tussen de conditionerende factoren en welbevinden. Tenslotte is er meer duidelijkheid ontstaan over de aard en richting van de invloed van de conditionerende factoren op zelfzorg.

De belangrijke rol die het voorzien in zelfzorgbehoeften speelt bij het bereiken van een bepaalde mate van welbevinden is niet enkel een validering van een van de belangrijkste onderliggende vooronderstellingen van Orem's Algemene Theorie van verplegen. Deze bevinding onderschrijft bovendien de sociale relevantie van de theorie. Volgens Orem is de zelfzorg van de cliënt het belangrijkste aandachtspunt van de verpleegkundige. In het algemeen pretenderen verpleegkundigen als uiteindelijke doel van hun activiteiten het welbevinden van hun cliënten voor ogen te hebben. Als de maatschappelijke bijdrage van de verpleegkunde inderdaad op het terrein van de kwaliteit van leven van de leden ligt, dan lijkt zelfzorg zoals beschreven door Orem bijzonder relevant als centraal aandachtsgebied van verpleegkundige activiteit. 


\section{REFERENCES}

Abdellah, F. (1960). Patient-Centered Approaches to Nursing; MacMillan, New York. Abdellah, F.G. (1969). The Nature of Nursing Science; Nursing Research 18(5), 390-393.

Achterberg. Th. van (1988). Sexe en Zelfzorgvermogen; Unpublished Master's Thesis, Rijksuniversiteit Limburg, the Netherlands.

American Nurses' Association (1980). Nursing: A Social Policy Statement; ANA, Kansas City.

Anderson, A.J.; J.J. Barboriak; R.G. Hoffman et al. (1980). Retention or Resumption of Employment After Aortacoronary Bypass Operations; JAMA 243, 543-545.

Andreoli, K.G. \& C.E. Thompson (1977). The Nature of Science in Nursing; Image 9(2). 32-37.

Bach, C.A. (1989). The Relationship Among Perceived Control of Activities of Daily Living, Depression and Life Satisfaction in Quadriplegic Adults; Dissertation Abstracts International 49(7), 2563b.

Barnes, G.K.; M.J. Ray; A. Oberman et al. (1977). Changes in Working Status of Patients Following Coronary Artery Bypass Surgery; JAMA 238, 1259-1262.

Bradburn, N.M. (1969). The Structure of Psychological Well-being; Aldine Publ. Company, Chicago.

Braun, J.W. (1987). Self-care Agency and Adult Health Promotion; Doctoral Dissertation, WSU, Detroit (University Microfilms no. 87-18331).

Brown, J.S. \& M.E. Rawlinson (1979). Psychosocial Status of Patients Randomly Assigned to Medical or Surgical Therapy for Chronic Unstable Angina; American Journal of Cardiology 44, 546-554.

Brugge, P. (1981). The Relationship Between Family as a Social Support System, Health Status, and Exercise of Self-care Agency in the Adult With a Chronic Illness; Doctoral Dissertation, WSU, Detroit (University Microfilms no. 82-09277).

Burns, M.A. (1986). The Use of Self-care Agency to Meet the Need for Solitude and Social Interaction by Chronically III Individuals; Doctoral Dissertation, WSU, Detroit (University Microfilms no. 86-03277).

Campeau, L.; L. Philippe; J. Herman et al. (1981). Recurrence of Angina After

Coronary Bypass Surgery; Journal of Cardiovascular Medicine 6, 69-71.

Cantril, H. (1963). A Study of Aspirations; Scientific American 208(2), 41-45.

Cantril, H. (1965). The Pattern of Human Concerns; Rutgers University Press, New Brunswick, New Jersey.

CASS Principal Investigators and their Associates, Coronary Artery Surgery Study: A Randomized Trial of CABS (1983). Quality of Life in Patients Randomly 
Assigned to Treatment Groups; Circulation 68, $951-960$.

Chamberlain, K. (1988). On the Structure of Subjective Well-being; Social Indicators Research 20, $581-604$.

Cohen, C. (1982). On the Quality of Life: Some Philosophical Reflections; Circulation 66(Supp|.|ll), 29-33.

Conway, M. (1985). Toward a Greater Specificity in Defining Nursing's Metaparadigm; Advances in Nursing Science 7(4), 73-81.

Davidson, J.D.U. (1989). Health Embodiment: The Relationship between Self-care Agency and Health Promoting Behaviors; Dissertation Abstracts International 49(8), 3102b.

Denyes, M.J. (1988). Orem's Model Used for Health Promotion: Directions from Research; Advances in Nursing Science 11(1), 13-21.

Dodd, J. (1984). Measuring Informational Intervention for Chemotherapy Knowledge and Self-Care Behavior; Research in Nursing and Health 7, 43-50.

Donaldson, S.K. \& D.M. Crowley (1978). The Discipline of Nursing; Nursing Outlook 26(2), 113-120.

Duffey, M. \& A.F. Muhlenkamp (1974). A Framework for Theory Anallysis: Nursing Outlook 22(9), 570-574.

Eisler, J.; J.A. Wolfer \& D. Diers (1972). Relationship Between Need for Social Approval and Postoperative Recovery and Welfare; Nursing Research 22, 394-401.

Ellis, R. (1968). Characteristics of Significant Theories; Nursing Research 17(3), $217-222$.

Ellis, R. (1982). Conceptual Issues in Nursing; Nursing Outlook 32(4), 406-410.

Erdman, R.A.M. (1982). Een Medisch Psychologische Vragenlijst ter Bepaling van het Welbevinden bij Hartpatiënten; Hart Bulletin 13(2), 143-147.

Erdiman R.A.M. (1975). Welbevinden bij Hartpatiënten: Samenstelling van een Medische Psychologische Vragenliist (de MPVH) ter Bepaling van het Welzilin Bii Hartpatiënten; Swets \& Zeitlinger "Lisse.

Evers, G.C.M. (1989). Appraisal of Self-Care Agency A.S.A.-Scale; Van Gorcum, Assen/Maastricht.

Fawcett, J. (1978). The Relationship between Theory and Research: A Double Helix; Advances in Nursing Science 1(1), 49-62.

Fawcett, J. (1984). Analysis and Evaluation of Conceptual Models of Nursing; F.A. Davis, Philadelphia.

Flynn, M.K. \& M. Frantz (1987). Coronary Artery Bypass Surgery: Quality of Life during Early Convalescence; Heart \& Lung 16(2), 159-167.

Folks, D.G. \& D.J. Blake et al. (1986). Quality of Life Six Months After Coronary Artery Bypass Surgery: A Preliminary Report: Southern Medical Journal 79. 397-399.

Frank, K.A. \& S.S. Heller (1972). A Survey of Adjustment to Cardiac Surgery: Archives of linternall Medicine 130, 735-738.

Frey. M.A. \& M.J. Denyes (1989). Health and lliness Self-care in Adolescents With IDDM: A Test of Orem's Theory; Advances in Nursing Science 12(1), 67-75.

Gazda, K. (1986). Coronary Revascularization: The Early Impact on Quality of Life: Unpublished Master's Thesis, Wayne State University, Detroit, U.S.A. 
Gortner, S.R.; C.L. Gilliss; J.A. Shinn; et al. (1988). Improving Recovery Following Cardiac Surgery: A Randomized Clinical Trial; Journal of Advanced Nursing $13,649-661$.

Grypdonck, M. (1990). Theory Development in Nursing: Have the Promises been Fulfilled? A Case Study of Orem's Theory; Proceedings 5th Biennial Conference of the W.E.N.R., Budapest, Vol. 1;209-235.

Gundle, M.J.; B.R. Reeves et al. (1980). Psychosocial Outcome After Coronary Artery Surgery: American Joumal of Psychiatry 137(12), 1591-1594.

Hanucharurnkul, S. (1988). Social Support, Self-Care, and Quality of Life in Cancer Patients Receiving Radiotherapy in Thailand; Doctoral Dissertation WSU, Detroit (University Microfilms no. 89-03228).

Hardy, M.E. (1978). Perspectives on Nursing Theory; Advances in Nursing Science $1(1), 37-48$.

Harper, D.C. (1984). Application of Orem's Theoretical Constructs to Self-Care Medication Behaviors in the Elderly; Advances in Nursing Science 6(2). 29-46.

Hartweg, D.L. (1990). Health Promotion Self-care Within Orem's General Theory of Nursing; Journal of Advanced Nursing 15, 35-41.

Heller, S.S.; K.A. Frank; D.S. Kornfeld et al. (1974). Psychosocial Outcome Following Open-Heart Surgery; Archives of Internal Medicine 134, 908-914.

Henderson, V. \& B. Harmer (1955). Textbook of the Principles and Practice of Nursing; MacMillan, New York.

Isenberg, M.A. \& M.C.M. Senten (1991). Testing Orem's Self-Care Deficit Theory With Patients Having Coronary Artery Bypass Surgery; International Journal of Nursing Studies, (accepted for publication).

Jacobs, M.K. \& S.E. Huether (1978). Nursing Science: The Theory-Practice Linkage; Advances in Nursing Science 1(1),63-73.

Jenkins, C.D.; B.A. Stanton et al. (1983). Coronary Artery Bypass Surgery Physical, Psychological, Social and Economic Outcomes Six Months Later $\therefore$ JAMA 250(6), 782-788.

Johnson, D.E. (1959). The Nature of a Science of Nursing; Nursing Outlook 7(5). 291-294.

Johnson, D. (1959). A philosophy of Niursing; Nursing Outlook 7(4), 198-200.

Kearney, B.Y. \& B.J. Fleischer (1979). Development of an Instrument to Measure Exercise of Self-Care Agency; Research in Nursing and Health 2(1), 25-34.

Kilpatrick, F.P. \& H. Cantril (1960). Self-Anchoring Scaling: A Measure of Individuals" Unique Reality Worlds; Journal of Individual Psychology 16, 158-173.

King, K.B. \& K.A. Parrinello (1988). Patient Perceptions of Recovery from Coronary Artery Bypass Grafting after Discharge from the Hospital; Heart \& Lung 17(6pt1), 708-715.

King. I.M. (1968). A Conceptual Frame of Reference for Nursing; Nursing Research $17(1), 27-31$.

Kornfeld, D.S. \& S.S. Heller (1982). Psychological and Behavioral Responses After Coronary Artery Bypass Surgery; Circulation 66 (Suppl.III), 24-28.

LaMendola, W.F. \& R.V. Pellegrini (1979). Quality of Life and Coronary Artery 
Bypass Surgery Patients; Social Science \& Medicine 13a, 457-461.

Levine, M. (1969). Introduction to Clinical Nursing; F.A. Davis, Philadelphia.

Meleis, A.l. (1985). Theoretical Nursing: Development and Progress; Lippincott, Philadelphia.

Meleis, A.l. (1987). Theoretical Nursing: Today's Challenges, Tomorrow's Bridges; Nursing Papers/Perspectives en Nursing 19(1), 45-57.

Melnyk, K.A.M. (1983). The Process of Theory Analysis: An Examination of the Nursing Theory of Dorothea E. Orem; Nursing Research 32(3), 170-174.

Menke, E.M. (1990). Rhetoric and Reality in the Development of Nursing Knowledge. In N.L. Chaska:; The Nursing Profession - Turning Points C.V. Mosby, St. Louis.

Nightingale, F. (1859). Notes on Nursing: What it is, and What it is not; Harrisons and Sons, London.

Notter, L.E. (1975). The Case for Nursing Research; Nursing Outlook 23(12), $760-763$.

Nursing Development Conference Group (1979). Concept Formalization in Nursing: Process and Product; Little, Brown and Company, Boston; 2nd ed..

O'Connor, A.M. (1983). Factors Related to the Early Phase of Rehabilitation Following Aortacoronary Bypass Surgery; Research in Nursing and Health 6. $107-116$.

Orem, D.E. (1988). The Form of Nursing Science; Nursing Science Quarterly 1(2), 75-79.

Orem, D.E. (1971). Nursing - Concepts of Practice -; McGraw-Hill, New York.

Orem, D.E. (1980). Nursing - Concepts of Practice -; 2nd ed. McGraw-Hill, New York.

Orem, D.E. (1985). Nursing - Concepts of Practice -; 3rd ed. McGraw-Hill, New York.

Orem, D.E. (1991). Nursing - Concepts of Practice -; 4th ed. Mosby, St. Louis.

Paterson, J.G. \& L.T. Zderad (1976). Humanistic Nursing; John Wiley \& Sons, New York.

Peet, R. van der (1990). Verpleegkunde, Vol, I-IV; De Tijdstroom, Lochem.

Penckofer, S.H. \& K. Holm (1984). Early Appraisal of Coronary Revascularization on Quality of Life; Nursing Research 33(2), 60-63.

Peplau, H. (1952). Interpersonal Relations in Nursing; G.P Putnam's Sons, New York.

Peplau, H.E. (1988). The Art and Science of Nursing: Similarities, Differences, and Relations; Nursing Science Quarterly 1(1), 8-15.

Polit, D.F. \& B.P. Hungler (1987). Nursing Research - Principles and Methods -; 3rd ed., J.B. Lippincott Company, Philadelphia.

Ramshaw, J.E. \& G. Stanley (1981). Individual Differences in Lifestyle to Coronary Artery Bypass Surgery; British Journal of Medical Psychology 54, 83-89.

Rogers, M. (1970). An Introdluction to the Theoretical Basis of Nursing; F.A. Davis, Philadelphia.

Rombouts, R.; G. Jambroes; I. Vromans \& J.F. Hitchcock (1984). Verbetering. Welzijn en Hulpvraag na Coronaire Bypass-Chirurgie: Hart Bulletin 15(2). $28-32$. 
Roy, C. (1970). Adaptation: A Conceptual Framework for Nursing; Nursing Outlook 18(3), 42-45.

Russell, B. (1945). A History of Western Philosophy and its Connection with Political and Social Circumstances from the Earliest Times to the Present Day; Simon and Schuster, New York.

Schlotfeldt, R.M. (1988). Structuring Nursing Knowledge: A Priority for Creating Nursing's Future; Nursing Science Quarterly 1(1), 35-38.

Schuessler, K.F, \& G.A. Fisher (1985). Quality of Life Research and Sociology; Annual Review of Sociology 11, 129-149.

Senten, M.C.M.; G.C.M. Evers; M.A. Isenberg \& H. Philipsen (1990). Veranderingen in Zelfzorg na Coronaire Bypass-Operatie: Eem Prospectieve Studie; Verpleegkunde - Nederlands Vlaams Wetenschappelijk Tijdschrift voor Verpleegkundigen 5(1), 34-43.

Silva, M.C. (1986). Research Testing Nursing Theory: State of the Art; Advances in Nursing Science 9(1), 1-11.

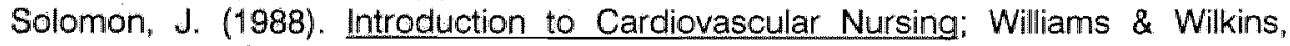
Baltimore.

Tatarkiewicz, W. (1976). Analysis of Happiness; Martinus Nijhoff, Den Haag.

Veenhoven, R. (1984). Conditions of Happiness; Erasmus University, Rotterdam.

Walker L.O. \& K.C. Avant (1988). Strategies for Theory Construction in Nursing; 2nd ed., Appleton \& Lange, Norwalk.

Zyzanski, S.J. \& B.A. Stanton (1981). Medical and Psychosocial outcomes in Survivors of Major Heart Surgery; Journal of Psychosomatic Research 23(3), 213-221. 


\section{APPENDIX I}

\section{ANALYSIS OF NON-RESPONSE AND DROPOUT}
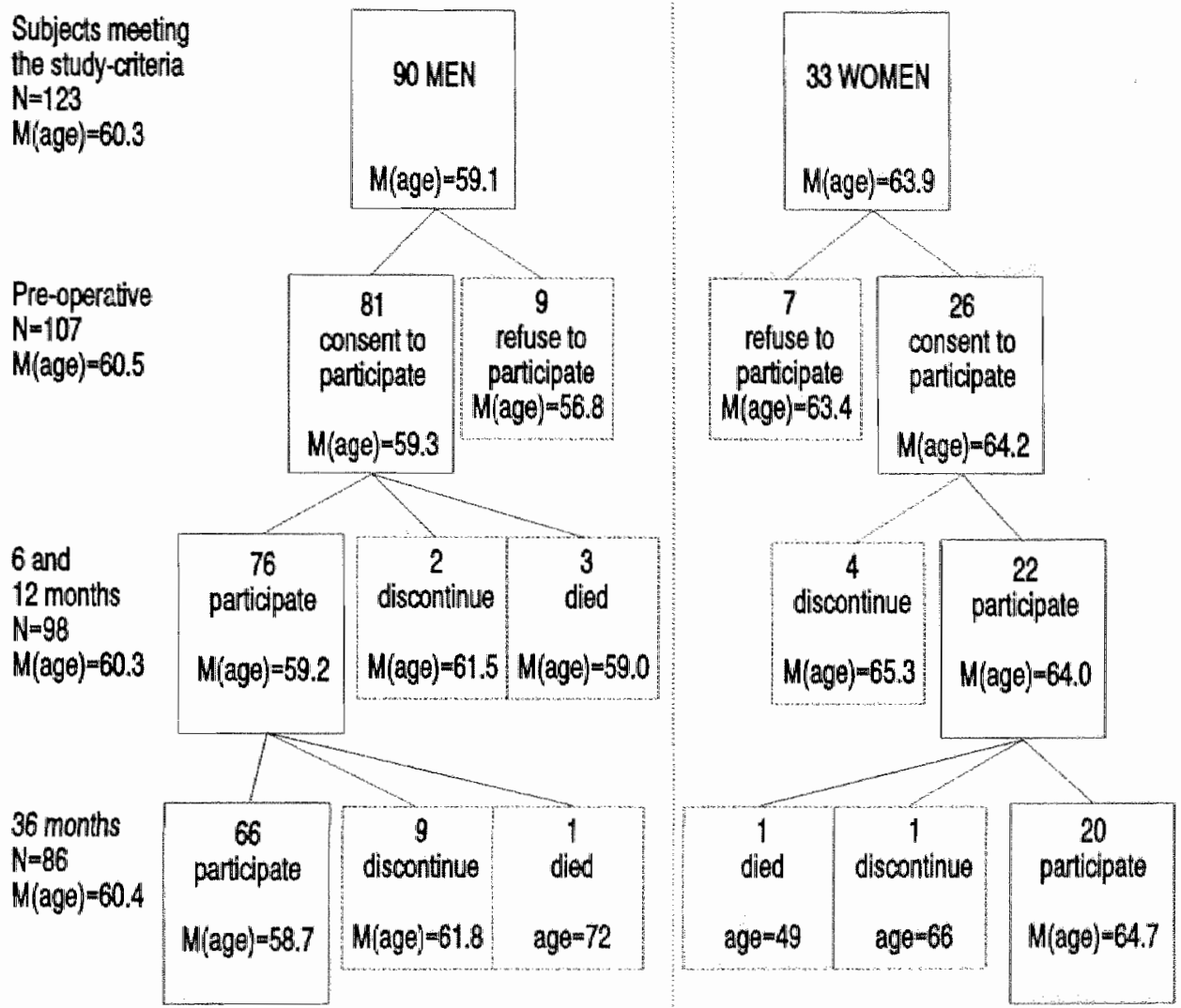

Do the proportions off women significantly differ between the final sample and the 123 eligible persons?

$Z$-Test for differences in 2 proportions, with $Z$ following a normal distribution if $Z>1.96$, than the two proportions are significantly different.

$z=$ $\mathrm{B} 1 / \mathrm{n} 1-\mathrm{B} 2 / \mathrm{n} 2$

$[((B 1+B 2) /(n 1+n 2)) \times(1-(B 1+B 2) /(n 1+n 2)) \times(1 / n 1+1 / n 2)]^{1 / 2}$

Here:

$\mathrm{B} 1 / \mathrm{n} 1=33 / 123$

Thus:

$\mathrm{B} 2 / \mathrm{n} 2=20 / 86$

$Z=.571859$, the proportions of women are not significaantly different. 


\section{APPENDIX II}

Factor Analysis over pre-operative items Self-Care Inventory

rotated factor matrix

\section{Factor Loadings}

FACTOR 1

urination

bowel

stomach

appetite

movement

energy

self

sex

sleep

social

surroundings

Eigenvalue

cum. \% variance

.76470
.72703
.67805
.58097

$-.00139$

$-.07096$

.35078

.25266

.46570

$-00073$

.32443

3.80058

$34.6 \%$
FACTOR 2

$-.00709$

.16086

.10962

.11937

.81795

.74550

.64350

.52893

.52198

.10295

.19712

.86356

.73264

1.49126

1. 15365

$48.1 \%$

$58.6 \%$ 


\section{APPENDIX III}

\section{Verbal explanation of the Study}

I am interested in talking with people who are scheduled to be admitted to the academic hospital for coronary artery bypass surgery. We expect the information from this study to be helpful in the planning of patient care during and after the period of hospitalization. I would like to describe the study to you and you can decide if you would like to participate.

In this study we are trying to identify the care needs and abilities of persons having coronary artery bypass surgery. We will also determine how these needs change over the course of the recovery period. The project is divided into two phases: A hospital phase and a follow-up phase after discharge from the hospital.

During the hospital phase you will be asked a few questions on the day before surgery. In the follow-up phase of the project, you will be contacted at 2 intervals: 6 months and 12 months after surgery. If you decide to participate in this study, you will be asked some questions about your personal activities as eating, sleeping. and activity patterns. You will also be asked about your general state of health and well-being. In addition you will be asked about any discomfort that you may be experiencing. Finally, you will be asked some general questions about yourself and your hospital experiences. We would also like to review you hospital record for information about your surgical procedure and medications.

The decision to participate in this study is up to you, and will in no way affect your health care. If you decide to participate in this study, you are free to change your mind at any time and withdraw from the study. Also, you can refuse to participate in any part of the study that you wish.

Because I realize that participation in this study will take up some of your time and that there are no direct benefits to you from participating in the study, I will be sending to participants a gratuity of a VVV-gift-certificate upon completion of the data collection.

The information that you provide is confidential and will only be available to the research staff. Your name or identity will not be revealed in any report or discussion of this study.

Do you have any questions?

Would you agree to participate?

If yes: Would you sign the consent form?

Thank you. I appreciate your taking time to let me talk to you about this study. 


\section{Informed Consent Form}

\section{WRITTEN CONSENT FORM}

The research study, entitled "Changes in Self-care in relation to Coronary Artery Bypass Surgery" has been explained to me and \| understand that the purpose of the study is to provide information about the recovery process that people experience after coronary artery bypass surgery. I understand that if I agree to participate I will be asked to answer questions about the following: (1) my personal activities, such as sleeping, eating, and physical activity; (2) my general state of health and well-being; (3) discomfort that may be experienced. I understand that I will be asked to answer these questions during my hospital stay and afterwards at two intervals - 6 and 12 months after surgery during a visit of the research staff at my home.

I further understand that:

All information is confidential and my identity will not be revealed.

My participation is voluntary.

My decision to participate will not affect the care or services | receive.

I am free to withdraw my consent and to discontinue my participation in the project at any time without explanation.

Any questions I have about the project will be answered.

I will receive a copy of this signed consent form.

On the basis of the above statements, I agree to participate in this project. 


\section{APPENDIX IV}

table N-1. Results stepwise multiple regression predicting the pre-operative SCH-score

\begin{tabular}{lccc}
\hline variables & step & beta & RSQ \\
\hline socio-economic status & 1 & .22 & .05 \\
history of MI & 2 & .16 & .07 \\
gender & 3 & -.16 & .10 \\
age & 4 & n.s. & \\
duration of cardiac disease & 5 & n.s. & \\
\hline
\end{tabular}

table N-2. Results stepwise multiple regression predicting the 6months SCH-score

\begin{tabular}{lccc}
\hline variables & step & beta & ASQ \\
\hline professional help & 1 & $n .24$ & . \\
socio-economic status & 2 & 17 & .09 \\
history of MI & 3 & n.s. & \\
chest discomfort & 4 & n.s. \\
gender & 5 & n.s. \\
duration of cardiac disease & 6 & n.s. & \\
age & 7 & n.s. & \\
\hline
\end{tabular}

table N-3. Results stepwise multiple regression predicting the 12-months SCl-score

\begin{tabular}{lccc}
\hline variables & step & beta & RSQ \\
\hline chest discomfort & 1 & .33 & .11 \\
socio-economic status & 2 & .16 & .14 \\
age & 3 & $n . s$. & \\
history of MI & 4 & n.s. & \\
gender & 5 & n.s. & \\
duration of cardiac disease & 6 & n.s. & \\
\hline
\end{tabular}

table $N-4$ Results stepwise multiple regression predicting the 36-months SCl-score

\begin{tabular}{lccc}
\hline variables & step & beta & ASQ \\
\hline gender & 1 & -.29 & .08 \\
chest discomfort & 2 & .21 & .12 \\
socio-economic status & 3 & .17 & .15 \\
duration of cardiac disease & 4 & n.s. & \\
age & 5 & $n . s$. & \\
history of MI & 6 & n.s. & \\
\hline
\end{tabular}


table N-5. Results stepwise multiple regression predicting the pre-operative SCl-score fincl. ASA-score as predictor)

\begin{tabular}{lccc}
\hline variables & step & beta & RSQ \\
\hline ASA-score & 1 & .25 & .06 \\
gender & 2 & -.23 & .11 \\
duration of cardiac disease & 3 & -15 & .14 \\
socio economic status & 4 & n.s. & \\
history of MI & 5 & n.s. & \\
age & 6 & n.S. & \\
\hline
\end{tabular}

table N-6. Results stepwise multiple regression predicting the 6-months SCl-score fincl. ASA-score as predictor)

\begin{tabular}{lccc}
\hline varlables & step & beta & RSO \\
\hline ASA-score & 1 & .28 & .08 \\
professional help & 2 & -.18 & .11 \\
chest discomfort & 3 & n.s. & \\
history of MI & 4 & n.s. \\
age & 5 & n.s. \\
socio-economic status & 6 & n.s. \\
duration of cardiac disease & 7 & n.s. \\
gender & 8 & n.s. \\
\hline
\end{tabular}

table N-7. Results stepwise multiple regression predicting the 12-months SCH-score (incl. ASA-score as predictor)

\begin{tabular}{lccc}
\hline variables & step & beta & RSQ \\
\hline chest discomfort & 1 & .33 & .11 \\
ASA-score & 2 & .19 & .15 \\
gender & 3 & -.17 & .17 \\
history of MI & 4 & n.s. & \\
age & 5 & n.s. & \\
socio-economic status & 6 & n.s. & \\
duration ol cardiac disease & 7 & n.s. & \\
\hline
\end{tabular}

table $\mathrm{N}-\mathrm{B} . \quad$ Results stepwise multiple regression predicting the 36months SC/-score (incl. ASA-score as predictor)

\begin{tabular}{lccc}
\hline Variables & step & beta & RSQ \\
\hline gender & 1 & -.29 & .08 \\
ASA.score & 2 & .30 & .17 \\
chest dlscomfort & 3 & .19 & .21 \\
duration of cardiac disease & 4 & n.s. & \\
socio-economic status & 5 & n.s. & \\
age & 6 & n.s. & \\
history of MI & 7 & n.s. & \\
\hline
\end{tabular}


table N9. Results stepwise multiple regression predicting the pre-operative NUB-score (incl. ASA-score as predictor)

\begin{tabular}{lccc}
\hline variables & step & beta & ASQ \\
\hline gender & 1 & .34 & 11 \\
ASA-score & 2 & .25 & 18 \\
history of MI & 3 & .19 & 21 \\
age & 4 & -.18 & 24 \\
socio-economic status & 5 & n.s. & \\
duration of cardiac disease & 6 & n.s. & \\
\hline
\end{tabular}

table N-10. Results stepwise multiple regression predicting the 6-months NUB-Scone (incl. ASA-score as predictor)

\begin{tabular}{|c|c|c|c|}
\hline variables & step & beta & BSQ \\
\hline professional help & 1 & n.s. & \\
\hline duration of cardiac disease & 2 & n.s. & \\
\hline chest discomfort & 3 & n.s. & \\
\hline sociomeconomic status & 4 & n.s. & \\
\hline gender & 5 & $\mathrm{n} . \mathrm{s}$. & \\
\hline history of MI & 6 & n.s. & \\
\hline ASA-score & 7 & n.s. & \\
\hline age & 8 & n.s. & \\
\hline
\end{tabular}

table N-11. Results stepwise multiple regression predicting the 12-months NLB-score (incl. ASA-score as predictor)

\begin{tabular}{lccc}
\hline variables & step & beta & ASQ \\
\hline chest discomfort & 1 & .33 & .11 \\
gender & 2 & -.22 & .16 \\
ASA-score & 3 & .18 & .19 \\
history of MI & 4 & $n . s$. & \\
age & 5 & n.s. & \\
socio-economic status & 6 & n.s. & \\
duration of cardiac disease & 7 & n.s. & \\
\hline
\end{tabular}

table N-12. Results stepwise multiple regression predicting the 36-months NUB-score (incl. ASA-score as predictor)

\begin{tabular}{|c|c|c|c|}
\hline variables & step & beta & RSO \\
\hline gender & 1 & .42 & .17 \\
\hline ASA-score & 2 & .15 & .20 \\
\hline duration of cardiac disease & 3 & n.s. & \\
\hline socio-economic status & 4 & n.s. & \\
\hline chest discomfort & 5 & n.s. & \\
\hline age & 6 & n.s. & \\
\hline history of MI & 7 & n.s. & \\
\hline
\end{tabular}


table N-13. Results stepwise multiple regression predicting the pre-operative SfB-score finct. ASA-score as predictor)

\begin{tabular}{lccc}
\hline variables & step & beta & RSQ \\
\hline ASA-score & 1 & .29 & .09 \\
history of MI & 2 & n.s. & \\
gender & 3 & n.s. \\
socio-economic status & 4 & n.s. \\
age & 5 & n.s. \\
duration of cardiac disease & 6 & n.s. \\
\hline
\end{tabular}

table N-14. Results stepwise multiple regression predicting the 6-months SiB-score (incl. ASA-score as predictor)

\begin{tabular}{lccc}
\hline variables & step & beta & RSQ \\
\hline professional help & 1 & -.24 & .06 \\
ASA-score & 2 & .17 & .09 \\
chest discomfort & 3 & n.s. & \\
history of MI & 4 & n.s. \\
age & 5 & n.s. \\
socio-economic status & 6 & n.s. \\
duration of cardiac disease & 7 & n.s. & \\
gender & 8 & n.s. & \\
\hline
\end{tabular}

table $N$-15. Results stepwise multiple regression predicting the 12-months SIB-score (incl. ASA-score as predictor)

\begin{tabular}{lccc}
\hline variables & step & beta & RSQ \\
\hline ASA-score & 1 & .31 & .10 \\
history of MI & 2 & n.s. & \\
age & 3 & n.s. \\
chest discomiont & 4 & n.s. \\
socio-economic status & 5 & n.s. \\
duration of cardiac disease & 6 & n.s. \\
gender & 7 & n.s. & \\
\hline
\end{tabular}

table N-16. Results stepwise multiple regression predicting the 36-months SIB-score (incl. ASA-score as predictor)

\begin{tabular}{lccc}
\hline variables & step & beta. & RSQ \\
\hline ASA-score & 1 & .29 & .09 \\
chest discomfort & 2 & .17 & .11 \\
duration of cardiac disease & 3 & n.s. & \\
age & 4 & n.s. \\
socio economic status & 5 & n.s. \\
history of MI & 6 & n.s. \\
gender & 7 & n.s. & \\
\hline
\end{tabular}


table $N$-17. Results stepwise multiple regression predicting the pre-operative AAB-score (incl. ASA-score as predictor)

\begin{tabular}{lccc}
\hline variables & step & beta & RSQ \\
\hline socio-economic status & 1 & .25 & .06 \\
duration of cardiac disease & 2 & -.21 & .11 \\
age & 3 & n.s. & \\
ASA-score & 4 & n.s. & \\
gender & 5 & n.s. & \\
history of MI & 6 & n.s. & \\
\hline
\end{tabular}

table N-18. Results stepwise multiple regression predicting the 6-months RAB-score (incl. ASA-score as predictor)

\begin{tabular}{lccc}
\hline variables & step & beta & RSQ \\
\hline ASA-score & 1 & .32 & .10 \\
professional help & 2 & -.21 & .14 \\
socio-economic status & 3 & .16 & .16 \\
history of MI & 4 & n.s. & \\
chest discomfort & 5 & n.s. & \\
age & 6 & n.s. & \\
duration of cardiac disease & 7 & n.s. & \\
gender & 8 & n.s. & \\
\hline
\end{tabular}

table N-19. Results stepwise multiple regressian predicting the 12.months AAB-score (incl. ASA-score as predictor)

\begin{tabular}{lccc}
\hline variables & step & beta & RSQ \\
\hline chest discomfort & 1 & .30 & .09 \\
sacio-economic status & 2 & .18 & .12 \\
age & 3 & n.s. & \\
history of MI & 4 & n.s. \\
ASA-score & 5 & n.s. \\
duration of cardiac disease & 6 & n.s. \\
gender & 7 & n.s. & \\
\hline
\end{tabular}

table N-20. Results stepwise mutiple regression predicting the 36-months RAB-scone (incl. A.SA-score as predictor)

\begin{tabular}{lccc}
\hline variables & step & bela & RSQ \\
\hline chest discomfort & 1 & .33 & .11 \\
ASA-score & 2 & .32 & .21 \\
gender & 3 & -.22 & .26 \\
socio-economic status & 4 & .18 & .29 \\
age & 5 & n.s. & \\
duration of cardiac disease & 6 & n.s. & \\
history of Mll & 7 & n.s. & \\
\hline
\end{tabular}


table N-21. Results stepwise multiple regression predicting the pre-operative WELL-BENG rating

\begin{tabular}{lccc}
\hline yariables & step & beta & RSQ \\
\hline RAB-score & 1 & .35 & .12 \\
NUB-score & 2 & .22 & .16 \\
Non Smoking & 3 & .19 & .20 \\
socio-economic status & 4 & -.18 & .23 \\
history of Ml & 5 & n.s. & \\
gender & 6 & n.s. \\
duration of cardiac disease & 7 & n.s. \\
age & 8 & n.s. \\
SIB-score & 9 & n.s. \\
\hline
\end{tabular}

table N-22.

Fesults stepwise multiple regression predicting the 6-months WELL-BEING rating

\begin{tabular}{lccc}
\hline variables: & step & beta & RSQ \\
\hline RAB-score & 1 & .62 & .40 \\
Non Smoking & 2 & .26 & .46 \\
gender & 3 & -.20 & .48 \\
age & 4 & .17 & .50 \\
socio-economic status & 5 & n.s. & \\
history of MI & 6 & n.s. \\
chest discomfort & 7 & n.s. \\
professional help & 8 & n.s. \\
duration of cardiac disease & 9 & n.s. \\
sufficient exercise & 10 & n.s. \\
SIB-score & 11 & n.s. \\
NUB-score & 12 & n.s. & \\
\hline
\end{tabular}

table N-23. Results stepwise multiple regression predicting the 12-months WELL-BEING rating

\begin{tabular}{lccc}
\hline variables & step & beta & RSQ \\
\hline SIB-score & 1 & .62 & .38 \\
RAB-score & 2 & .25 & .43 \\
duration of cardiac disease & 3 & n.s. & \\
gender & 4 & n.s. \\
sufficient exercise & 5 & n.s. \\
Non Smoking & 6 & n.s. \\
socio-economic status & 7 & n.s. \\
history of Ml & 8 & n.s. \\
chest discomfort & 9 & n.s. \\
age & 10 & n.s. \\
NuB-score & 11 & n.s. \\
\hline
\end{tabular}


table N-24. Results stepwise multiple regression predicting the 36-months WELL-BEING rating

\begin{tabular}{lccc}
\hline variables & step & beta & IASQ \\
\hline RAB-score & 1 & .59 & .34 \\
SIB-score & 2 & .27 & .39 \\
age & 3 & .16 & .41 \\
duration of cardiac disease & 4 & n.s. & \\
chest discomfort & 5 & n.s. \\
Non Smoking & 6 & n.s. \\
socio-economic status & 7 & n.s. \\
sufficient exercise & 8 & n.s. \\
gender & 9 & n.s. \\
history of MI & 10 & n.s. \\
NuB-score & 11 & n.s. \\
\hline
\end{tabular}




\section{CURRICULUM VITAE}

Marina Senten was born in October 1962 in Hilversum, the Netherlands. After completion of the highschool she started studying Health Sciences at the University of Limburg in Maastricht. As part of her specialization in nursing science, she studied the wintersemester of 1986 at the College of Nursing at Wayne State University in Detroit, U.S.A. After her graduation from the Health Sciences program in september 1986, she was hired as a research associate at the department of nursing science of the University of Limburg. In this position she worked as the researcher on two consecutive projects financed by the Netherlands Heart Foundation. From January 1, 1987 until April 30, 1989, on the research project "Changes in Self-Care After Coronary Artery Bypass Surgery: A Longitudinal Study"; and since October 1, 1989, on the project "Changes in Self-Care After Percutaneous Transluminal Coronary Angioplasty and Coronary Artery Bypass Surgery: A Comparative Study".

\section{CURRICULUM VITAE}

Marina Senten is geboren op 30 oktober 1962 in Hilversum. Na het behalen van haar VWO-diploma in 1981 begon zij aan de studie Gezondheidswetenschappen (Sociale Gezondheidkunde) aan de Rijksuniversiteit Limburg in Maastricht. Als onderdeel van de afstudeerrichting Verplegingswetenschap studeerde zij het wintersemester van 1986 aan het College of Nursing. Wayne State University, U.S.A. In september 1986 studeerde zij af. Vanaf 1 oktober 1986 werkt zij bij de vakgroep Verplegingswetenschap van de Rijksuniversiteit Limburg. De eerste drie jaar als assistent in opleiding op het door de Nederlandse Hartstichting gefinancierde project "Changes in Self-Care After Coronary Artery Bypass Surgery: A Longitudinal Study". Vervolgens als toegevoegd onderzoeker op het eveneens door de Hartstichting gesubsieerde vervolgonderzoek "Changes in Self-Care After Percutaneous Transluminal Coronary Angioplasty and Coronary Artery Bypass Surgery: A Comparative Study". 